\title{
Estimating Terrain Parameters With a Rigid Wheeled Rover Using Neural Networks
}

\author{
by \\ Matthew D.G. Cross, M.Eng

\begin{abstract}
A Thesis submitted to
the Faculty of Graduate Studies and Research

in partial fulfillment of

the requirements for the degree of

Master of Applied Science

in

Aerospace Engineering Carleton University

Ottawa, Ontario, Canada
\end{abstract} \\ Department of Mechanical and Aerospace Engineering
}

August 2012

Copyright (C)

2012 - Matthew D.G. Cross, M.Eng 
Library and Archives

Canada

Published Heritage

Branch

395 Wellington Street

Ottawa ON K1A ON4

Canada
Bibliothèque et

Archives Canada

Direction du

Patrimoine de l'édition

395 , rue Wellington

Ottawa ON K1A ON4

Canada
Your file Votre référence

ISBN: 978-0-494-93487-6

Our file Notre référence

ISBN: 978-0-494-93487-6
NOTICE:

The author has granted a nonexclusive license allowing Library and Archives Canada to reproduce, publish, archive, preserve, conserve, communicate to the public by telecommunication or on the Internet, loan, distrbute and sell theses worldwide, for commercial or noncommercial purposes, in microform, paper, electronic and/or any other formats.

The author retains copyright ownership and moral rights in this thesis. Neither the thesis nor substantial extracts from it may be printed or otherwise reproduced without the author's permission.
AVIS:

L'auteur a accordé une licence non exclusive permettant à la Bibliothèque et Archives Canada de reproduire, publier, archiver, sauvegarder, conserver, transmettre au public par télécommunication ou par l'Internet, prêter, distribuer et vendre des thèses partout dans le monde, à des fins commerciales ou autres, sur support microforme, papier, électronique et/ou autres formats.

L'auteur conserve la propriété du droit d'auteur et des droits moraux qui protege cette thèse. $\mathrm{Ni}$ la thèse ni des extraits substantiels de celle-ci ne doivent être imprimés ou autrement reproduits sans son autorisation.
In compliance with the Canadian Privacy Act some supporting forms may have been removed from this thesis.

While these forms may be included in the document page count, their removal does not represent any loss of content from the thesis.
Conformément à la loi canadienne sur la protection de la vie privée, quelques formulaires secondaires ont été enlevés de cette thèse.

Bien que ces formulaires aient inclus dans la pagination, il n'y aura aucun contenu manquant. 


\section{Abstract}

This thesis presents a method for extracting data on regolith online with a planetary exploration micro-rover. The method uses a trained neural network to map engineering data from an instrumented chassis to estimates of regolith parameters. The target application for this method is a low-cost micro-rover scout to Mars that will autonomously traverse the surface and detect changes in the regolith cohesion and shearing resistance without the need for dedicated visual sinkage estimation on each wheel. This method has been applied to Kapvik, a $30 \mathrm{~kg}$ micro-rover analogue designed and built for the Canadian Space Agency. Data was collected using a motor controller interface designed for Kapvik using off-the-shelf components. The neural network was trained from parameters derived by classical terramechanics theory using Matlab's Neural Network Toolbox. The results demonstrate a proof of concept that the neural networks can estimate the terrain parameters, which were found to be consistent with the terrain on which Kapvik was tested. 


\section{Acknowledgments}

I would first like to thank my supervisor Prof. Alex Ellery. Alex took a chance on an unproven graduate student to work on the Kapvik project. Despite a rocky start, he continued to poke and prod me without giving up.

My work on Kapvik and this thesis would not be possible without the collaboration of my SEEG partners. I would to thank Dr. Ala' Qadi who took on the challenge of "herding cats" and saving us from death-by-documentation. Ala' managed the Kapvik project and his interactions from the point-of-view of a recent graduate and post-doc. He provided guidance, encouragement, and support throughout the Kapvik project, my studies, and my thesis. He also provided a glimpse at post-doctoral life and, surprisingly, didn't discourage the continuation into academia.

I would like to thank Tim Setterfield, Marc Gallant and Rob Hewitt for blazing

the Masters trail ahead of me and showing what was needed to make it through. Furthermore, my collaborations with Tim form the basis of my thesis work and Rob stayed around just long enough to help get me through most of the writing process. In addition I'd like to thank Cameron Frazier, Jesse Hiemstra, Helia Sharif, Brian Lynch, and Adam Mack for their contributions to Kapvik and "extra-Kapvik" activities. I would like to extend my gratitude to close friend and colleague Chris Nicol. Our time together, be it in the lab, at a conference, on a road trip, in the pub, or in the classroom, had an incredibly positive influence on my life over these two years.

I would like to acknowledge the encouragement and support of several faculty 
and staff at Carleton: my former M.Eng supervisor Professor Moyra McDill for her recommendation that allowed me to come back to Carleton; Professor Mojtaba Ahmadi, whose mechatronics course fuelled my interest in robotics and control systems; and Nagui Mikhail for allowing me access to his electronics equipment at all hours of day and night.

A huge thank you goes to my roommate and friend Andrew Bene for meticulously proofreading my thesis. \#sixchaptersandanappendix

And finally, I'd like to thank my family for their love and support through yet another degree program. 


\section{Table of Contents}

Abstract $\quad$ ii

Acknowledgments $\quad$ iii

Table of Contents $\quad$ v

List of Tables viii

List of Figures $\quad$ ix

List of Definitions $\quad$ xiii

List of Symbols $\quad$ xvii

1 Introduction 1

1.1 Research Question ..................... 1

1.2 Motivation and Problem Statement . . . . . . . . . . . . 2

1.3 Kapvik Micro-Rover . . . . . . . . . . . . . . . 4

1.4 Terrain Parameter Estimation . . . . . . . . . . . . . . . 7

1.5 Outline . . . . . . . . . . . . . . . . . 9

2 Application of Terramechanics for Estimating Terrain Parameters 11

2.1 Planetary Terramechanics . . . . . . . . . . . . . 12

2.2 Terrain Modelling . . . . . . . . . . . . . . . . 12 
2.3 Rigid Wheel Systems . . . . . . . . . . . . . . . 14

2.3.1 Vertical Loading on Wheel . . . . . . . . . . . . . . 16

2.3.2 Torque About Wheel Axis . . . . . . . . . . . . . . . . 19

2.3 .3 Slippage . . . . . . . . . . . . . . . . 20

2.3.4 Terrain Contact Angle and Wheel Sinkage . . . . . . . 23

2.3.5 Wheel Sinkage and Wheel Loading . . . . . . . . . . . 24

2.4 Traction Analysis of the Rigid Wheel . . . . . . . . . . . . . . 29

2.4 .1 Tractive Force . . . . . . . . . . . . . . . . . . . . . 29

2.4.2 Land Locomotion Resistance . . . . . . . . . . . . . . . 31

2.5 Mars Regolith Parameters . . . . . . . . . . . . . . 32

2.5.1 Lunar Regolith Parameters . . . . . . . . . . . . . . . 36

2.6 Non-Geometric Obstacles . . . . . . . . . . . . . . . . . . . . . . . . 38

3 Multilayer Perceptron with Backpropogation $\quad 39$

3.1 Artificial Neural Networks . . . . . . . . . . . . . . . . . . 40

3.1 .1 Simple Neuron . . . . . . . . . . . . . . . . 40

3.1 .2 Activation Functions $\ldots \ldots \ldots \ldots$

3.1.3 The Simple Perceptron . . . . . . . . . . . . . . . . . . 42

3.1.4 Multilayer Perceptron . . . . . . . . . . . . . . . 44

3.1.5 Network Architecture and Construction . . . . . . . . 46

3.2 Backpropagation Learning $\ldots \ldots \ldots \ldots \ldots \ldots$

4 Method 49

4.1 Kapvik's Motor Controller Interface . . . . . . . . . . . . 49

4.1.1 Motor and Wheel Assembly . . . . . . . . . . . . 50

4.1.2 Maxon Motors EPOS 24/1 Motor Controller . . . . . . . 51

4.1 .3 Communication Network . . . . . . . . . . . . . . . 52

4.1 .4 Implementation $\ldots \ldots \ldots \ldots \ldots \ldots \ldots \ldots$ 
4.2 Parameter Estimation with a Neural Network . . . . . . . . . . 54

4.2 .1 Hidden Layer Sizing . . . . . . . . . . . . . . 55

4.2 .2 Neural Network Training Set . . . . . . . . . . . . . 56

4.3 Field Tests at Petrie Island . . . . . . . . . . . . . . . . 59

5 Results $\quad 61$

5.1 Estimating Petrie Island Terrain Parameters with Kapvik . . . . . . 61

6 Conclusions and Recommendations $\quad 72$

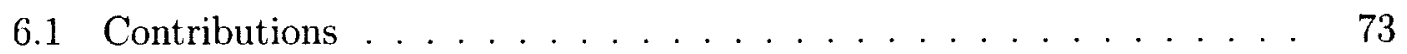

6.2 Future Work . . . . . . . . . . . . . . . . 74

6.3 Recommendations . . . . . . . . . . . . . . . . . . . 74

$\begin{array}{ll}\text { List of References } & 76\end{array}$

Appendix A Terrain Estimation Results $\quad 82$

A.1 Prepared Terrain Results . . . . . . . . . . . . . . . . 82

A.2 Unprepared Terrain Results . . . . . . . . . . . . . . . . 89

Appendix B Motor and Controller Temperature Testing 96

$\begin{array}{ll}\text { Appendix C Hardware Specifications } & 102\end{array}$

C.1 RE25 Motor and Gearing . . . . . . . . . . . . . . . . 102

C. 2 EPOS 24/1 Motor Controller . . . . . . . . . . . . . . . 103

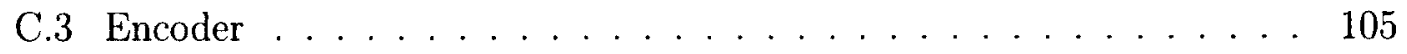

C.4 Load Sensor . . . . . . . . . . . . . . . . 105 


\section{List of Tables}

1 Mars regolith parameters estimated by the Sojourner rover team . . .

2 Mars regolith parameters estimated in-situ by the Spirit and Opportunity. The test labels correspond to which rover conducted the test (labelled as 'A' for Spirit and 'B' for Opportunity) and on which sol . . . . . . . . . . . . . . . . .

3 Mars regolith parameters estimated in-situ by the Viking and Phoenix

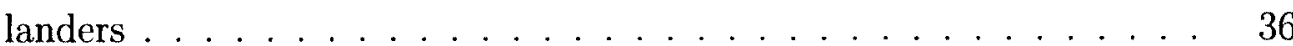

4 Recommended cohesion and friction angle for lunar regolith based on

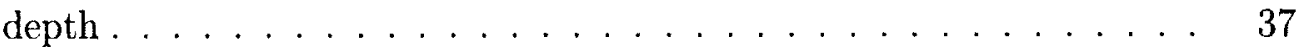

5 Soil parameters derived from tests on lunar soil simulants . . . . . . . 37

6 Terrestrial soil parameters used in initial neural network training . . . 58

7 Reported parameters of various terrains . . . . . . . . . . . 63

8 Terrain parameter estimates for prepared terrain . . . . . . . . . 65

$9 \quad$ Relative standard deviation (RSD) for sensor data collected on prepared terrain .......................... 66

10 Terrain parameter estimates for unprepared terrain . . . . . . . . 69

11 Relative standard deviation (RSD) for sensor data collected on unprepared terrain .................... 69

12 Operating and Storage Temperatures $\left({ }^{\circ} \mathrm{C}\right)$ for Selected Components . $\quad 97$ 


\section{List of Figures}

1 The Mars Exploration Rover Spirit became a stationary research base after becoming immobilized by a non-geometric obstacle: loose terrain. Image courtesy of NASA/JPL-Caltech . . . . . . . . . . . 3

2 Opportunity's hazard identification camera image of embedded left-front wheel. Image courtesy of NASA/JPL-Caltech . . . . . . . . . . . 4

3 Kapvik in its final configuration during final testing at CSA's Mars Yard 5

4 Diagram of rigid wheel in contact with terrain. $W$ is the weight on the wheels; $T$ is the torque driving the wheels as determined by the motor current draw; $\omega$ is the rotational speed of the wheel as determined by the encoder; and $\theta_{C}$ is the wheel-terrain contact angle . . . . . . .

5 Diagram of rigid wheel in contact with terrain. $W$ is the weight on the wheels; $T$ is the torque driving the wheel; $\omega$ is the rotational velocity of the wheel; and $\theta_{C}$ is the wheel-terrain contact angle $\ldots \ldots 15$

6 The vertical forces acting on the rigid wheel: the weight on the wheel $W$; shear stress $\tau$ and normal stress $\sigma$ act over a contact area defined by the wheel radius, wheel width, and the contact angle $\theta \ldots \ldots 17$

7 Diagram showing the two regions of normal stress, $\sigma_{1}$ and $\sigma_{2}$, on either side of the maximum stress $\sigma_{m} \ldots \ldots \ldots \ldots$

8 Shear stresses at the wheel-terrain interface . . . . . . . . . 20

9 The slip velocity occurs along the wheel-terrain interface . . . . . . 21 
10 Relationship between the wheel sinkage $z$ and the contact angle $\theta_{C} \quad . \quad 24$

11 Relationship between the wheel sinkage $z$ and the wheel load $W \ldots 25$

12 Diagram of the forces acting on a micro-rover accelerating up an incline 30

13 A simple artificial neuron, $q$. $n$ inputs are each connected by synaptic weight to a summing junction. The output of the summing junction is sent through an activation function ............. 41

14 A simple perceptron with neuron $q$. The weights are updated until the output $y_{q}$ approximates the desired output $d_{q} \ldots \ldots . \ldots 43$

15 A multilayer perceptron with input $\mathbf{x} \in \Re^{n \times 1}$ : the first hidden layer contains $i$ neurons; the $k$ th hidden layer contains $j$ neurons; and the output layer contains $m$ neurons. The weights are updated until the output $\mathbf{y} \in \Re^{m \times 1}$ approximates the desired output vector $\mathbf{d} \in \Re^{m \times 1} .45$

16 A Maxon Motor brushed DC motor drives a $15 \mathrm{~cm}$ diameter wheel . . 50

17 The Maxon Motor EPOS 24/1 motor controller. Each controller has power, data and communications connections. An LED indicates the function state of the controller .............. . . 53

18 Testing Kapvik's mobility system at Petrie Island . . . . . . . . . . . 59

19 Wheel numbering for rover showing forward direction of motion . . 62

20 Terrain cohesion estimate for Wheel 3 on prepared terrain . . . . . 64

21 Terrain shearing resistance angle estimate for Wheel 3 on prepared terrain 65

22 Terrain cohesion estimate from Wheel 3 on unprepared terrain . . . . 67

23 Terrain shearing resistance angle estimate from Wheel 3 on unprepared terrain .......................... 68

24 Terrain cohesion estimate with changing slip ratio for Wheel $3 \ldots$. . 70

25 Terrain cohesion estimate for Wheel 1 on prepared terrain . . . . . 82

26 Terrain shearing resistance angle estimate for Wheel 1 on prepared terrain 83

27 Terrain cohesion estimate for Wheel 3 on prepared terrain . . . . . 83 
28 Terrain shearing resistance angle estimate for Wheel 2 on prepared terrain 84

29 Terrain cohesion estimate for Wheel 3 on prepared terrain . . . . . . 84

30 Terrain shearing resistance angle estimate for Wheel 3 on prepared terrain 85

31 Terrain cohesion estimate for Wheel 4 on prepared terrain . . . . . 85

32 Terrain shearing resistance angle estimate for Wheel 4 on prepared terrain 86

33 Terrain cohesion estimate for Wheel 5 on prepared terrain . . . . . 86

34 Terrain shearing resistance angle estimate for Wheel 5 on prepared terrain 87

35 Terrain cohesion estimate for Wheel 6 on prepared terrain . . . . . 87

36 Terrain shearing resistance angle estimate for Wheel 6 on prepared terrain 88

37 Terrain cohesion estimate for Wheel 1 on unprepared terrain . . . . . 89

38 Terrain shearing resistance angle estimate for Wheel 1 on unprepared terrain . . . . . . . . . . . . . . . . . 90

39 Terrain cohesion estimate for Wheel 3 on unprepared terrain . . . . 90

40 Terrain shearing resistance angle estimate for Wheel 2 on unprepared terrain ................................ 91

41 Terrain cohesion estimate for Wheel 3 on unprepared terrain . . . . . 91

42 Terrain shearing resistance angle estimate for Wheel 3 on unprepared terrain . . . . . . . . . . . . . . . . . . . 92

43 Terrain shearing resistance angle estimate for Wheel 4 on unprepared terrain ................................ 92

44 Terrain shearing resistance angle estimate for Wheel 4 on unprepared

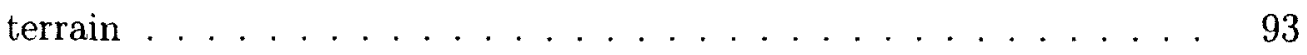

45 Terrain cohesion estimate for Wheel 5 on unprepared terrain . . . . 93

46 Terrain shearing resistance angle estimate for Wheel 5 on unprepared terrain .............................. 94

47 Terrain cohesion estimate for Wheel 6 on unprepared terrain . . . . . 94 
48 Terrain shearing resistance angle estimate for Wheel 6 on unprepared

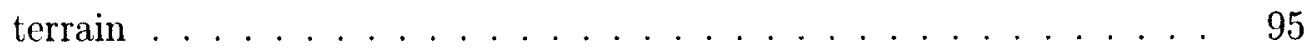




\section{List of Definitions}

\begin{tabular}{ll}
\hline Acronyms & Definition \\
\hline ANN & Artificial Neural Network \\
CAN & Controller Area Network \\
COTS & Commercially Available Off the Shelf \\
CSA & Canadian Space Agency \\
ESA & European Space Agency \\
ESM & Exploration Surface Mobility \\
IMU & Inertial Measurement Unit \\
JPL & Jet Propulsion Laboratory \\
LRV & MacDonald Dettwiler and Associates \\
MIT & Massachusetts Institute for Technology \\
MLP & Multilayer Perceptron \\
ME & Mars
\end{tabular}


MSE

NASA

QC

RSD

SEEG

UTIAS

VSE
Mean Square Error

National Aeronautics and Space Administration

Quadrature Counts

Relative Standard Deviation

Space Exploration Engineering Group

University of Toronto Institute for Aerospace Studies

Visual Sinkage Estimation

xiv 
Activation Function Limits the strength of the neuron output

Artificial Neuron The data processing unit of the artificial neural network

Axon The output of the neuron

Bevameter An instrument used to measure terrain cohesion and shearing resistance angle

Bias or Threshold Determines whether or not, or to what extent, the neuron will fire

Clay A type of soil made up of fine particles with principle size up to $5 \mu \mathrm{m}[1]$

Coarse Sand A type of soil made up of fine particles with principle size between 0.42 and $2 \mathrm{~mm}[1]$

Drawbar Pull The net force available after the tractive force has overcome resisting forces. Drawbar pull is the potential force to push or pull an external load, or the potential for slope climbing or acceleration

Epoch A single network training cycle; the network is presented with a training pair and the weights are updated

Fine Sand A type of soil made up of fine particles with principle size between $74 \mu \mathrm{m}$. and $0.42 \mathrm{~mm}[1]$

Geometric Obstacles Obstacles characterized by their geometry

Learning or Training The process by which the synapses are adjusted so that the output converges to the expected output

Non-Geometric Obstacles Obstacles characterized by their mechanical properties 
Off-Road Vehicle A terrestrial vehicle intended to be driven over terrain as opposed to paved roads

Regolith Regolith refers to the top layer of terrain found on top of solid rock. In this thesis, regolith refers to terrain found on extraterrestrial surfaces. Mars regolith is similar to moderately dense Earth soils. Loose drift material, such as sand, is layered on top of denser material [2]

Rover An unmanned planctary off-road vehicle. This vehicle is intended to be driven remotely or autonomously. In this thesis, a micro-rover refers to a rover with a mass of approximately $30 \mathrm{~kg}$

Silt A type of soil made up of fine particles with principle size between 5 and $74 \mu \mathrm{m}$ [1]

Soil In this thesis, soil refers to terrestrial terrain. An idealized three-phase soil will include soil particles, water, and air. Soil particles are either fine particles such as clay or sand, or coarse particles such as gravel [3]

Synapse The connections between inputs, outputs, and neurons. Synapses are the free parameters of the network that are adjusted during training

Terrain Terrain refers to the natural, physical surface over which the micro-rover will drive

Tractive Force The force that must be developed by the motors to overcome resisting forces in order to develop sufficient drawbar pull 


\section{List of Symbols}

\begin{tabular}{|c|c|c|}
\hline Variable & Variable Meaning & Unit \\
\hline$a$ & Acceleration & {$\left[\mathrm{m} / \mathrm{s}^{2}\right]$} \\
\hline$c$ & Terrain cohesion & {$[\mathrm{kPa}]$} \\
\hline$d$ & Desired response of neural network & - \\
\hline$D_{W}$ & Wheel diameter & {$[\mathrm{m}]$} \\
\hline$D P$ & Drawbar pull & {$[\mathrm{N}]$} \\
\hline$e$ & $\begin{array}{l}\text { Error signal between neural network output } \\
\text { and desired response }\end{array}$ & - \\
\hline$f(\cdot)$ & Generic function & - \\
\hline$F$ & Tractive force, or thrust & {$[N]$} \\
\hline$F_{N}, F_{S}$ & $\begin{array}{l}\text { Normal force, shear force along wheel-terrain } \\
\text { contact area }\end{array}$ & {$[N]$} \\
\hline$g(\cdot), g_{b s}$ & Activation function, binary sigmoid function & - \\
\hline$i$ & Slip ratio & - \\
\hline$I$ & Motor current & {$[\mathrm{A}]$} \\
\hline
\end{tabular}




\begin{tabular}{|c|c|c|}
\hline$j$ & Slippage / shear displacement & {$[\mathrm{m}]$} \\
\hline$K$ & Shear deformation parameter & {$[\mathrm{m}]$} \\
\hline$k_{c}$ & $\begin{array}{l}\text { Pressure-Sinkage parameter in Bekker's } \\
\text { equation }\end{array}$ & {$\left[\mathrm{kPa} / \mathrm{m}^{n-1}\right]$} \\
\hline$k_{S S}$ & Non-dimensional slip sinkage parameter & - \\
\hline$k_{\phi}$ & $\begin{array}{l}\text { Pressure-Sinkage parameter in Bekker's } \\
\text { equation }\end{array}$ & {$\left[\mathrm{kPa} / \mathrm{m}^{n}\right]$} \\
\hline$m$ & Mass & {$[\mathrm{kg}]$} \\
\hline$n$ & $\begin{array}{l}\text { Non-dimensional exponent of sinkage in } \\
\text { Bekker's equation }\end{array}$ & - \\
\hline$N_{T}$ & Number of neurons in hidden layer & - \\
\hline$r_{W}$ & Wheel radius & {$[\mathrm{m}]$} \\
\hline$R, R_{a}, R_{t}$ & $\begin{array}{l}\text { Resistance force, aerodynamic resistance, and } \\
\text { terrain resistance }\end{array}$ & {$[\mathrm{N}]$} \\
\hline$t$ & Time & {$[s]$} \\
\hline$T$ & Torque & {$[\mathrm{Nm}]$} \\
\hline$u$ & Output of activation function, neuron output & - \\
\hline$v$ & Output of summation junction & - \\
\hline$V$ & Rover velocity & {$[\mathrm{m} / \mathrm{s}]$} \\
\hline$V_{j}$ & Slip velocity & {$[\mathrm{m} / \mathrm{s}]$} \\
\hline
\end{tabular}




\begin{tabular}{|c|c|c|}
\hline$V_{M O T}$ & Motor voltage & {$[\mathrm{V}]$} \\
\hline$w$ & Synaptic weight & - \\
\hline$w_{W}$ & Wheel width & {$[\mathrm{m}]$} \\
\hline$W$ & Vertical load & {$[\mathrm{N}]$} \\
\hline$W_{E M}$ & Electromechanical work & {$[\mathrm{J}]$} \\
\hline$W_{N E T}$ & Net work & {$[\mathrm{J}]$} \\
\hline$W_{N L}$ & No Load work & {$[\mathrm{J}]$} \\
\hline$x$ & Neural network input & - \\
\hline$y$ & Neural network output & - \\
\hline$z, z_{S S}, z_{r}$ & $\begin{array}{l}\text { Wheel sinkage, wheel sinkage including slip } \\
\text { sinkage, and wheel sinkage at location } r\end{array}$ & {$[\mathrm{~m}]$} \\
\hline$\alpha$ & Adjustable slope parameter & - \\
\hline$\delta$ & Local error in backpropagation algorithm & - \\
\hline$\zeta_{P G}, \zeta_{H D}$ & Gear ratio, planetary gear and harmonic drive & - \\
\hline$\eta_{P G}, \eta_{H D}$ & $\begin{array}{l}\text { Transmission efficiency, planetary gear and } \\
\text { harmonic drive }\end{array}$ & - \\
\hline$\theta_{1}, \theta_{2}, \theta_{m}, \theta$ & $\begin{array}{l}\text { Wheel-terrain contact entrance angle, exit } \\
\text { angle, angle of maximum stress, all with re- } \\
\text { spect to vertical axis }\end{array}$ & [degrees] \\
\hline$\theta_{C}$ & Angle of wheel-terrain contact & [degrees] \\
\hline
\end{tabular}




\begin{tabular}{|c|c|c|}
\hline$\kappa$ & Torque constant & {$[\mathrm{Nm} / \mathrm{A}]$} \\
\hline$\mu$ & Backpropagation learning rate & - \\
\hline$\sigma, \sigma_{1}, \sigma_{2}, \sigma_{m}$ & $\begin{array}{l}\text { Normal stress at the wheel-terrain interface, } \\
\text { normal stress in Region } 1 \text { and Region 2, } \\
\text { maximum normal stress }\end{array}$ & {$\left[\mathrm{N} / \mathrm{m}^{2}\right]$} \\
\hline$\tau, \tau_{1}, \tau_{2}, \tau_{m}$ & $\begin{array}{l}\text { Shear stress at the wheel-terrain interface, } \\
\text { shear stress in Region } 1 \text { and Region 2, } \\
\text { maximum shear stress }\end{array}$ & {$\left[\mathrm{N} / \mathrm{m}^{2}\right]$} \\
\hline$\phi$ & Shearing resistance angle & [degrees] \\
\hline$\Psi$ & Soil angle of repose & [degrees] \\
\hline$\Omega$ & Commanded angle of motor rotation & [degrees] \\
\hline$\omega$ & Motor shaft angular speed & {$[\mathrm{rad} / \mathrm{s}]$} \\
\hline
\end{tabular}




\section{Chapter 1}

\section{Introduction}

This thesis presents a method to estimate, and detect changes in, planetary terrain parameters with a micro-rover using a supervisor-trained artificial neural network. The use of a trained artificial neural network is novel to planetary terrain parameter estimation. Two parameters, cohesion $c$ and shearing resistance angle $\phi$, are estimated from sensor data on an instrumented micro-rover chassis. A micro-rover may benefit from knowledge of such terrain parameters; loose terrain is characterized by low cohesion. Such conditions represent non-geometric obstacles that may cause a loss of traction.

\subsection{Research Question}

This thesis provides evidence to support the following research question:

Can a planetary micro-rover estimate terrain parameters online during its traverse phase without measuring the wheel contact angle $\theta_{C}$ or wheel sinkage $z$ ?

The results of research show it is possible to estimate, without measuring the wheel contact angle $\theta_{C}$ or wheel sinkage $z$, the terrain cohesion $c$ and shearing resistance 
angle $\phi$ using a trained neural network. Application of this research will allow future planetary exploration micro-rovers to estimate terrain parameters without the need for dedicated visual sinkage estimates. Online terrain parameter estimation has applications in non-geometric obstacle detection and online traction control. The following section provides the motivation for answering this question.

\subsection{Motivation and Problem Statement}

The Mars Exploration Rover (MER) Spirit, shown in Figure 1, landed on the plains of Gusev Crater on 4 January 2004. Its original mission life was 90 Martian solar days, otherwise known as sols. Spirit continued to operate until sol 2210 when communication with Earth ended. Its right front wheel drive actuator failed during its extended mission. This failure caused the front right wheel to be pushed through the terrain instead of being driven. Spirit continued its extended exploration mission with five active whecls until it became cmbedded in loose terrain on sol 1871. Several attempts were made to extract Spirit from the loose soil. However, on sol 2104 the right rear wheel also failed which furthered impeded Spirit's mobility. With only four

functioning wheels, Spirit was unable to overcome the terrain resistance and continued to function merely as a stationary research base [4].

Spirit wasn't the only MER to be impeded by loose terrain. Opportunity encountered $30 \mathrm{~cm}$ of loose aeolian deposits at Meridiani Plains in which all six wheels became embedded. The rover required 23 Sols and $150 \mathrm{~m}$ of commanded wheel movements to move $26 \mathrm{~cm}$ and free itself from the "Purgatory Ripple" [5].

Spirit and Opportunity became immobilized due to the presence of a non-geometric obstacle: loose terrain. The loose terrain that trapped Spirit was believed to be a weakly cohesive mixture of sulfate and basaltic sands that caused the rover to experience greater wheel slip and wheel sinkage. The tractive force generated by the 


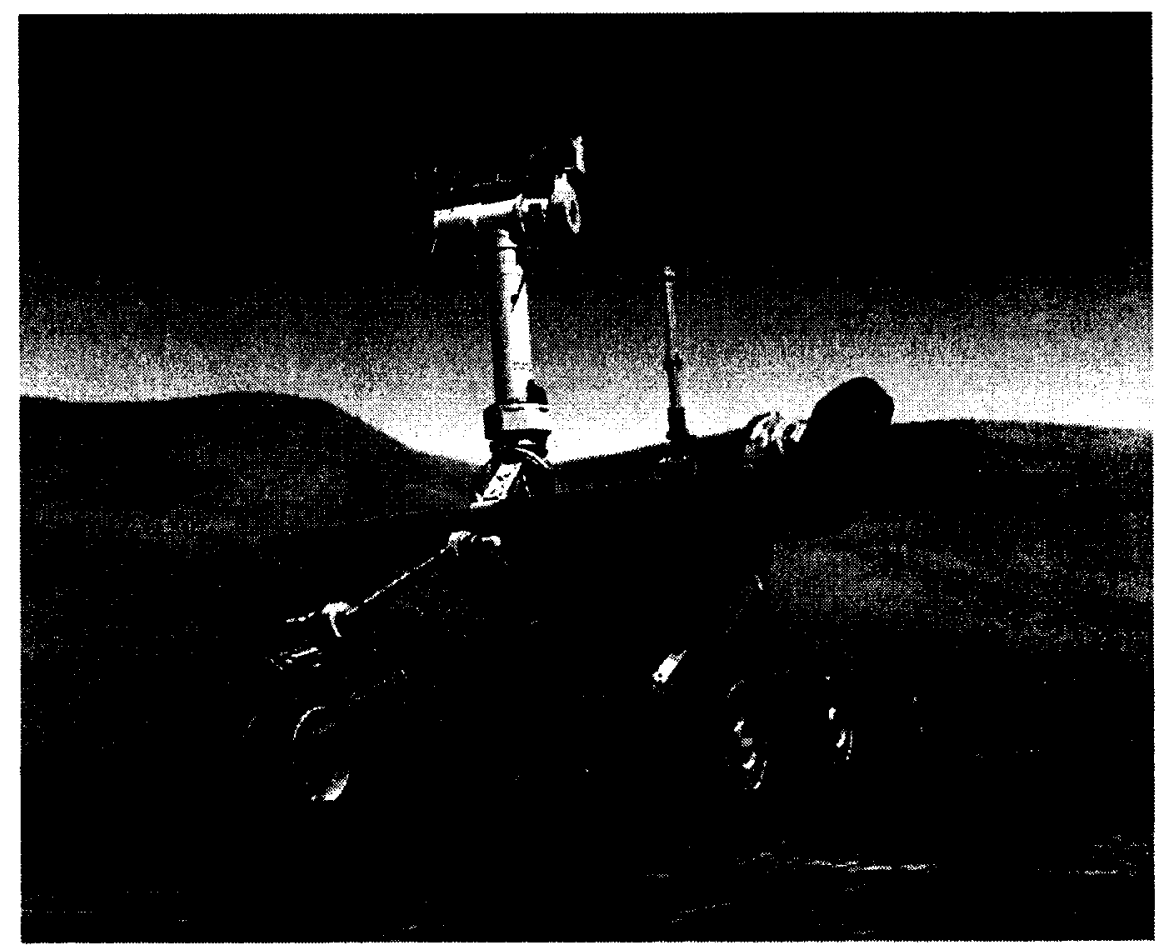

Figure 1: The Mars Exploration Rover Spirit became a stationary research base after becoming immobilized by a non-geometric obstacle: loose terrain. Image courtesy of NASA/JPL-Caltech

wheel-terrain interaction was not enough to overcome the terrain resistance. Classical terramechanics theory, with previously estimated terrain parameters, validated this conclusion [4].

The purpose of this thesis is to provide a proof of concept of estimating Mars terrain parameters online during a micro-rover's traverse phase using trained neural networks. Mars soil is otherwise known as regolith. Micro-rovers are intended to be low-cost ${ }^{1}$ scouts for a larger class of rover, such as Curiosity and ExoMars. The research includes the development of motor controller interface software that provides the sensor inputs to the neural network. The research presented is an extension of the motor controller interface software developed for the Kapvik micro-rover.

\footnotetext{
${ }^{1}$ The rationale for a low-cost micro-rover is that it could serve as Canada's contribution to an international exploration program; a micro-rover scout would benefit an entire Mars exploration mission and could fit within the limited budget of the Canadian Space Agency.
} 


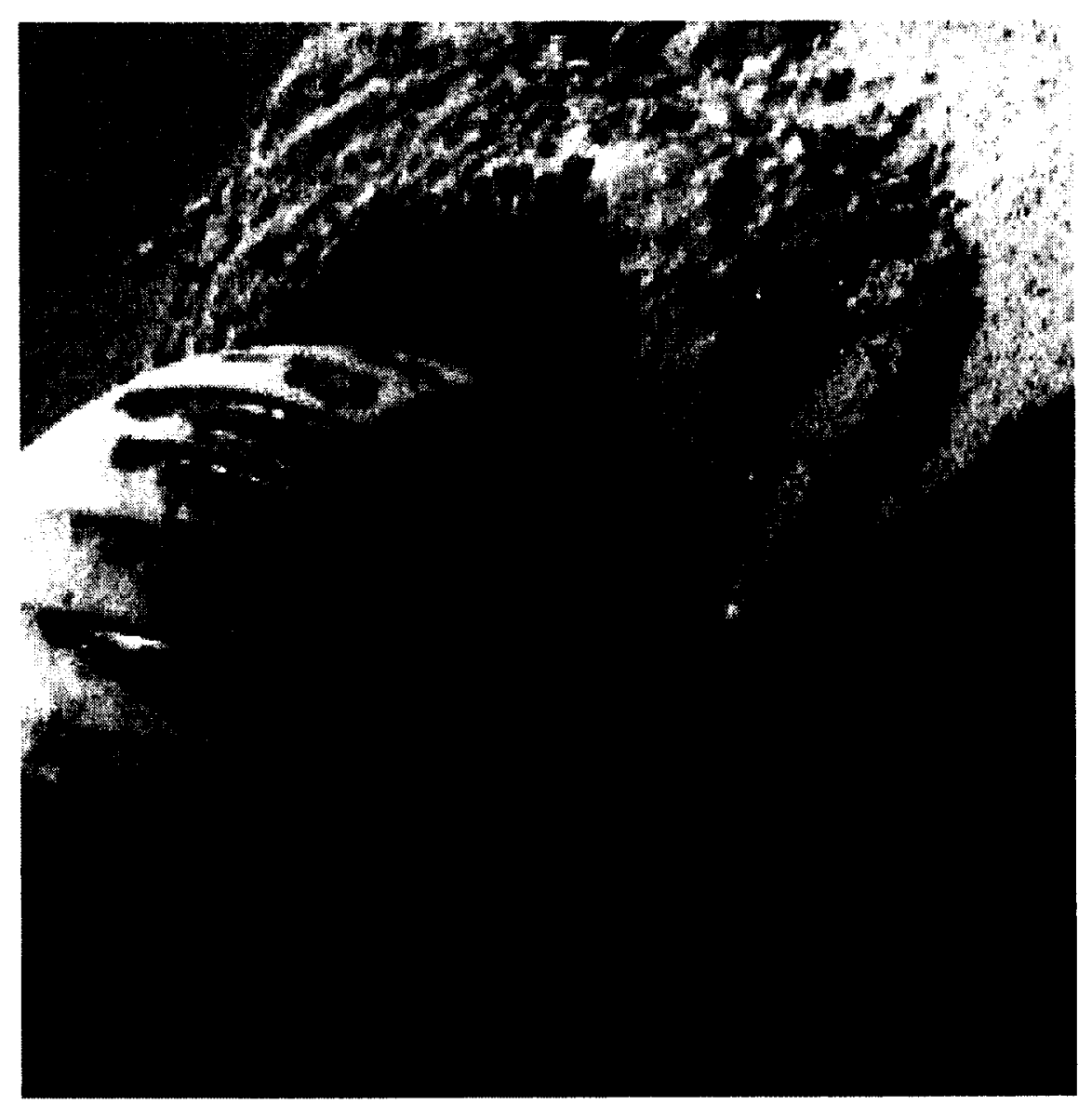

Figure 2: Opportunity's hazard identification camera image of embedded left-front wheel. Image courtesy of NASA/JPL-Caltech

\subsection{Kapvik Micro-Rover}

The thesis question resulted from development work on the Kapvik micro-rover project $[6,7]$. Kapvik, as shown in Figure 3, is a micro-rover analogue designed as a tool for further developing Canada's planetary exploration capabilities. It was funded by the Canadian Space Agency (CSA) through their Exploration Surface Mobility (ESM) project and administered by MPB Communications Incorporated. Ryerson University, the University of Toronto Institute for Aerospace Studies (UTIAS), and MacDonald Dettwiler and Associates (MDA), and Xiphos Technologies Inc. also contributed to Kapvik's development. This prototype was designed with a view to 
achieving flight qualification and to help assess potential exploration missions to which Canada may contribute. Its trial operations will be in an unknown environment analogous to the Martian equatorial surface, such as the Canadian Arctic.

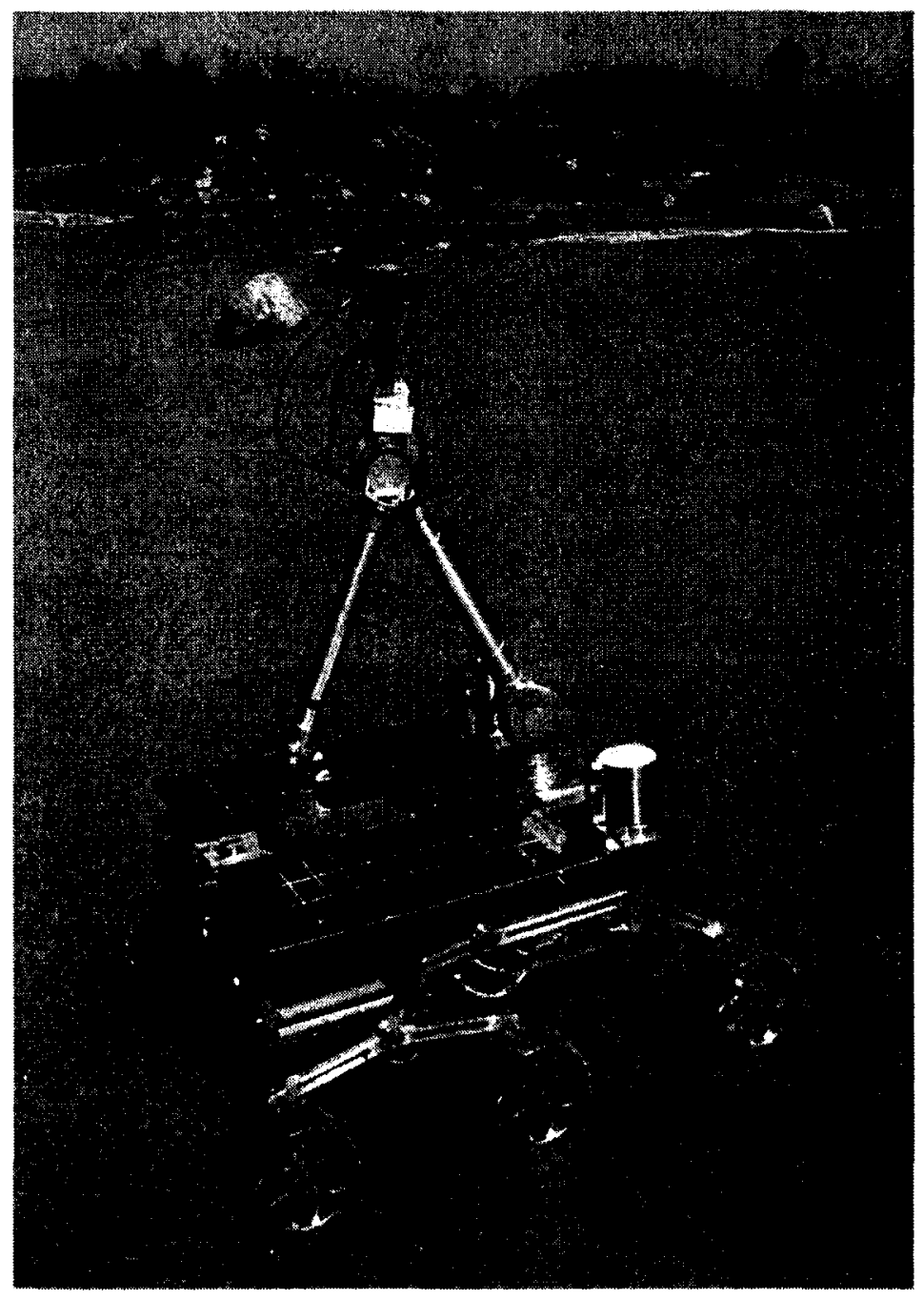

Figure 3: Kapvik in its final configuration during final testing at CSA's Mars Yard

Kapvik is a micro-rover with a mass of approximately $30 \mathrm{~kg}$. It has an instrumented six-wheeled rocker-bogie system with differential drive [6] similar to NASA's fleet of exploration rovers: Sojourner [8], Spirit [4], Opportunity [5] and Curiosity [9]. The rocker-bogie allows all six wheels to maintain ground contact to enhance mobility 
while allowing the rover to climb over rocks $[10,11]$. Each of the six rigid wheels have 24 grousers. The grousers extend $5 \mathrm{~mm}$ from the base of the $145 \mathrm{~mm}$ diameter wheel giving the wheel an average diameter of $150 \mathrm{~mm}$ [6]. Kapvik contains a suite of instruments for localization:

- A laser range finder;

- A stereo vision camera;

- An inertial measurement unit (IMU); and

- A sun sensor.

A robotic arm comes equipped with a scoop for collecting soil samples. Solar panels are mounted on top of the cab to provide unregulated power at $24 \mathrm{~V}$. Inside the cab, the avionics system includes the motor controllers, on-board computing and power electronics. When fully operational, Kapvik is capable of semi-autonomous navigation using localization and path planning.

An instrumented chassis with individually throttleable wheel motors was an early design objective for Kapvik's mobility system. The instrumented chassis allows for the mobility system to adapt to changing terrain conditions. Each motor can be individually throttled to provide traction control on Mars micro-rovers. Each of the six wheels is driven by a Maxon Motor RE25 motor with planetary gearing and harmonic drive. The wheel motor assemblies include planetary gearing and a harmonic drive for a gear ratio of 1400:1, and are contained at the wheel base inside an enclosure to protect against weathering and dust. Each of the motor assemblies is powered and driven by a Maxon Motor EPOS 24/1 motor controller. Wheel odometry is provided by incremental encoders attached to each motor. Single axis load cells are mounted on top of each wheel to measure the vertical force. Potentiometers provide the rotational angles of the differential drive and the rockers. When calibrated, the potentiometers 
provide an orientation of each of the wheels relative to the body frame of the rover. The potentiometers, load cells and incremental encoders all connect to the motor controller; all of the motor controllers are connected via a controller area network (CAN) bus to a central computer on a Xiphos Q6 card, which is located within an avionics enclosure on the rover.

Each of Kapvik's nine motor controllers is connected by a communication bus to a central computer: six operate the wheels; two operate the camera pan \& tilt mechanism; and one operates the laser range finder tilt mechanism. The six wheel motor controllers provide sensor data required by the navigation system as follows:

- Encoder data; the controller provides position and rotational speed, $\omega$;

- Current drawn by the motor, $I$;

- Analogue response from load cells. The interface converts this response to weight-on-wheels data, $W$; and

- Analogue response from potentiometers; the interface converts this response to rocker-bogie angles data.

\subsection{Terrain Parameter Estimation}

Kleiner [12] successfully classified terrain based on vision and wheel vibrations; however, the terrain greatly varied (grass versus asphalt versus gravel) and there was no indication this classification method could detect changes in the properties of a single terrain type. Brooks $[13,14]$ also used wheel vibrations to classify between more similar terrain types but not to estimate terrain parameters. The terrain cohesion $c$ and shearing resistance angle $\phi$ are estimated from Bekker's [15] and Wong's [16] terramechanics theory. The shear stress distribution equation, $\tau=$ $(c+\sigma \tan \phi)\left(1-e^{-j / K}\right)$ where $j=r_{w}\left(\theta_{C}-\sin \theta_{C}+i \sin \theta_{C}\right)$, describes the shear stress 
distribution along the wheel-terrain interface. The shear stress can be related to the following variables shown in Figure 4:

- The shear deformation parameter $K$ is experimentally derived for a particular terrain;

- The wheel radius $r_{W}$ and width $w_{W}$ are known values. The wheel contact area $A=r_{W} w_{W} \theta_{C}$

- The amount of slippage $j=f\left(i, \theta_{C}\right)$ is determined by the slip ratio $i=1-V / r_{W} \omega$ from the measurable rover velocity $V$ and the motor shaft rotational speed $\omega$;

- The normal stress $\sigma=f\left(W, \theta_{C}\right)$ is determined by the measurable wheel load $W$ acting over the contact area $A$; and

- The shear stress $\tau=f\left(I, \theta_{C}\right)$ over the contact area $A$ is determined from the torque $T$ applied by the motor, which draws a measurable current $I$.

The shear stress $\tau$ over the wheel contact area $A$ determines the maximum allowable thrust $F=f(\tau)$. Therefore, the terrain cohesion $c$ and shearing resistance angle $\phi$ influence the mobility of a rigid-wheeled vehicle on terrestrial and planetary terrain. Knowledge of these terrain parameters is required for autonomous traction control [17, $18]$.

The final unknown variable, wheel-terrain contact angle $\theta_{C}$ shown in Figure 4 , is needed to estimate terrain cohesion $c$ and shearing resistance angle $\phi$ using classical terramechanics theory. The wheel-terrain contact angle $\theta_{C}$ can be calculated using estimates of the wheel sinkage $z$ where $\theta_{C}=\cos ^{-1}\left(1-z / r_{W}\right)$. Dedicated vision measurements can provide estimates of the wheel sinkage $z$ and contact angle $\theta$. However, the size, mass, and power consumption required to support dedicated vision measurements are beyond the scope of a low-cost micro-rover. 


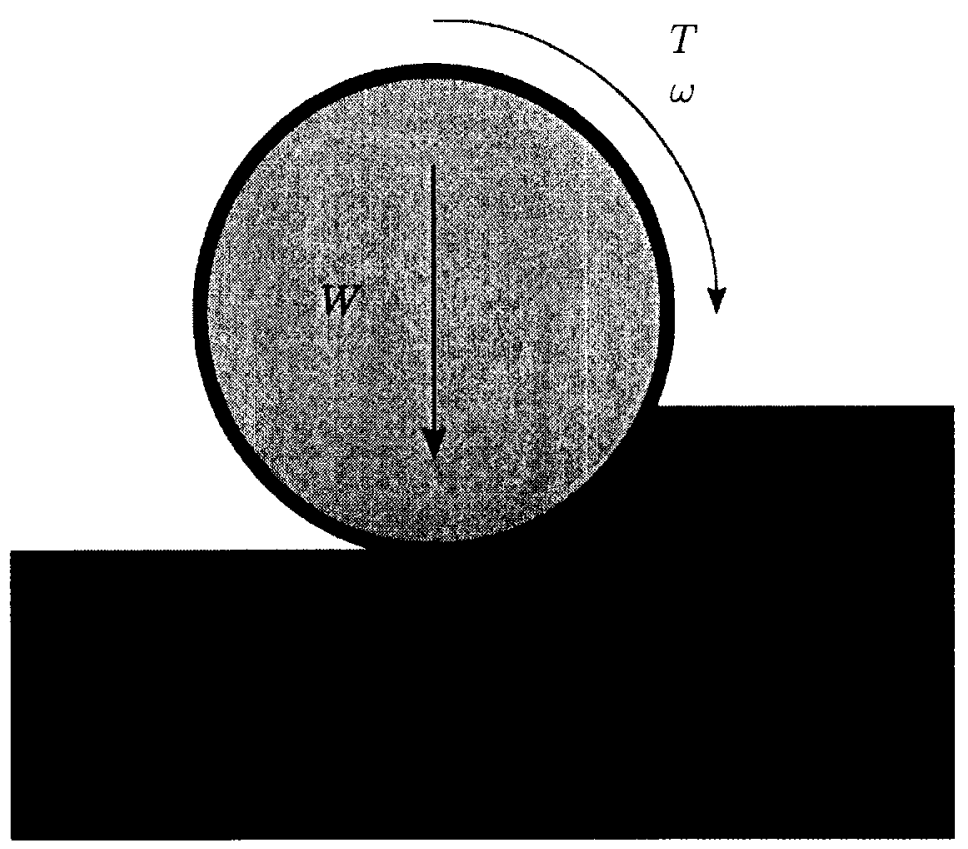

Figure 4: Diagram of rigid wheel in contact with terrain. $W$ is the weight on the wheels; $T$ is the torque driving the wheels as determined by the motor current draw; $\omega$ is the rotational speed of the wheel as determined by the encoder; and $\theta_{C}$ is the wheel-terrain contact angle

A simplified wheel-terrain interaction model [19-21] allows the terrain parameters to be a multivariable function of the sensor measurements $[c, \phi]=f\left(V, \omega, \theta_{C}, W, I\right)$. That mapping exists as an approximate function even if one or more of the values is unknown. Trained neural networks have been shown to be universal function approximators $[22]$ and map $[W, i, I]$ to $[c, \tan \phi]$.

\subsection{Outline}

This thesis is presented in an additional five chapters. Chapter 2 provides a review of classical terramechanics theory and its relevance to planetary exploration rovers. 
Related work in terrain parameter estimation and non-geometric obstacle detection is also included in Chapter 2. Chapter 3 provides a review of artificial neural networks and how they are used for function approximation. Chapter 4 presents the method used for estimating terrain properties using a trained neural network. Chapter 5 presents the results of field testing and a discussion of how they can be applied to a low-cost exploration rover. Chapter 6 presents the conclusions and recommendations for future work. 


\section{Chapter 2}

\section{Application of Terramechanics for Estimating Terrain Parameters}

This chapter provides a review of classical terramechanics theory and its application to Mars regolith parameter estimation. Terramechanics is the study of vehicle-terrain interaction mechanics; it is to off-road vehicle engineering as aerodynamics is to aircraft engineering. The study breaks down into two primary areas: improving vehicle characteristics to perform on any given terrain; and improving knowledge of how the terrain reacts to vehicle loading. Vehicle-terrain interaction models developed by Bekker [15] and Wong [16,23] use parameters specific to particular soils. The objective of these models is to predict with reasonable certainty how the vehicle will perform on a given terrain.

Previous work by Bekker and Wong studied vehicle-terrain interaction using a variety of terrains: mineral terrains, organic terrains and snow. Mineral terrains include sand, sandy loam, clayey loam, and loam. Organic terrain and snow exhibit greater compressibility and do not conform to the plastic material model presented later. Bekker and Wong also studied vehicle-terrain interaction using a variety of vehicle running gears: rigid wheels, flexible wheels, rigid tracks and flexible tracks, amongst others. 
Rigid wheels have been used on past, current and planned Mars exploration rovers (Sojourner, Spirit, Opportunity and Curiosity); rigid wheels were included on the Kapvik micro rover. Mars regolith is characterized to be a mineral terrain similar to clayey silt [2]. Therefore, the discussion of terramechanics in this thesis is limited to rigid wheels interacting with mineral terrains.

\subsection{Planetary Terramechanics}

Classical terramechanics theory developed by Bekker [15] has been applied to planetary vehicles since the Apollo program [24,25]. Much of the recent research on applying terramechanics to planetary rovers has been led by the Massachusetts Institute for Technology (MIT) Field and Space Robotics Laboratory and MIT Robotic Mobility Group. Therefore, the simplified wheel-terrain interaction model in this thesis is based upon their research [19-21].

Many other research groups have been researching terramechanics for planetary rovers. The Space Robotics University at Tohoku University has been developing autonomous traction control for planetary rovers $[17,18]$. The terramechanics of wheel grousers for planetary rovers has been researched at Dalhousie University [26, 27]. Current planetary rover research in Europe is studying flexible wheels [28, 29].

\subsection{Terrain Modelling}

Vehicle-terrain interaction models require knowledge of how the terrain responds to forces applied by the vehicle. Terrain can be modelled as either an elastic or plastic material; both models have their advantages and disadvantages.

Modelling terrain as an elastic material allows for classical elasticity theory to be applied to analysis: the strain, or deformation, of the material is proportional to 
the stress applied. The wheel weight is modelled to be a point mass acting on the terrain. The stresses within the terrain are a function of the distance from the point mass. The elastic model estimates the stress distribution pattern that radiates from the point load through the terrain. Usage of the elastic model is limited to vehicle loads within the elastic behaviour region of dense terrain.

When the vehicle load reaches the limit of elastic behaviour, the terrain is at the critical state between elastic and plastic behaviour; the terrain is in plastic equilibrium. The terrain material transitions from plastic equilibrium to a plastic flow state when the load continues to increase. Wong states that the terrain has failed at this point. The Mohr-Coulomb failure criterion is widely used to define the failure of soil:

$$
\tau=c+\sigma \tan \phi
$$

where $\tau$ and $\sigma$ are the shear stress and radial stress, respectively, at the wheel-terrain interface; the terrain cohesion $c$ and shearing resistance angle $\phi$ are the two terrain parameters to be estimated. The Mohr-Coulomb criterion is limited to static loads on terrain as it does not take into account the shear deformation at the wheel-terrain interface. The plastic terrain model can only be accurately applied to dense terrains, such as sand, subjected to high vehicle loads. The model does not apply well to highly compressible terrains such as snow and organic terrain.

In addition to the elastic and plastic terrain models, other terrain models exist. These include the critical state soil mechanics model, the finite element model, and the discrete element models. The critical state soil mechanics model requires the terrain to be modelled as an idealized homogeneous and isotropic material. The latter two models require pre-existing detailed terrain conditions and intensive computational resources.

These additional models are not practical for a Mars exploration rover. Mars 
regolith is a heterogeneous and anisotropic material; the critical state soil mechanics model has limited applications to off-road vehicle-terrain interaction and will not be considered. Mars regolith is not sufficiently characterized to have a detailed finite or discrete element model created. A crude model could be used; however, the computational resources required are not available on a micro-rover.

The terrain behaviour in response to vehicle loads can be characterized by several parameters. The soil compacts in response to a vertical load and shears in response to a rotating wheel. The following section details the rigid wheel interaction with terrain.

\section{$2.3 \quad$ Rigid Wheel Systems}

The mechanics of the wheel-terrain interaction can be determined with knowledge of the terrain. Bekker [15] and Wong [16,23] developed rigid wheel-terrain interaction models for wheels that are stationary, driven, towed, pushed, and breaking. The wheels on the Kapvik were individually powered and controllable to allow for throttling and enhanced traction control. Therefore, the research in this thesis is limited to the interaction between powered rigid wheels and the terrain.

The mechanics of a rigid wheel in motion can be studied by examining the free body diagram in Figure 5 and the following equation for the shear stress distribution along the wheel-terrain interface [16]:

$$
\tau=(c+\sigma \tan \phi)\left(1-e^{\frac{-j}{K}}\right)
$$

where

- The shear deformation parameter $K$ is experimentally derived for a particular terrain;

- $c$ is the terrain cohesion and one of the parameters to be estimated; 


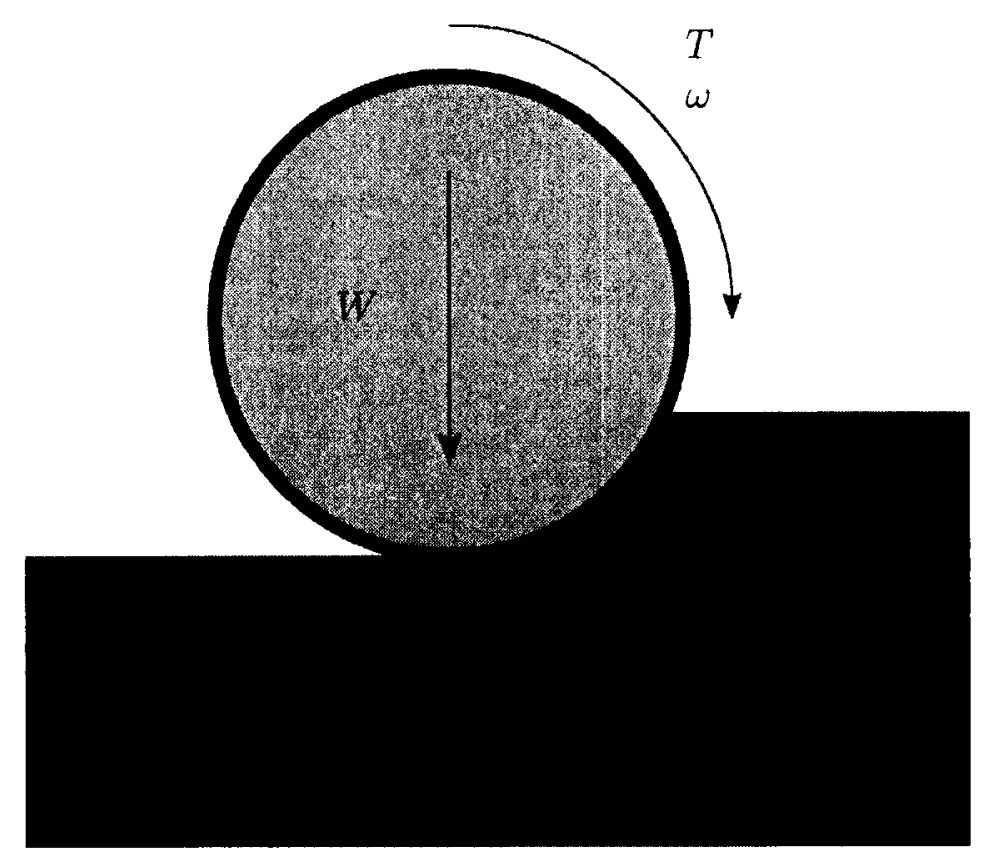

Figure 5: Diagram of rigid wheel in contact with terrain. $W$ is the weight on the wheels; $T$ is the torque driving the wheel; $\omega$ is the rotational velocity of the wheel; and $\theta_{C}$ is the wheel-terrain contact angle

- $\phi$ is angle of shearing resistance and is the other parameter to be estimated;

- The amount of slippage $j=f\left(i, \theta_{C}\right)$ is determined by the slip ratio $i=1-V / r_{W} \omega$ from the measurable rover velocity $V$ and the motor shaft rotational speed $\omega$;

- The shear stress $\tau=f\left(I, \theta_{C}\right)$ over the contact area $A=r_{W} w_{W} \theta_{C}$ is determined from the torque $T$ applied by the motor, which draws a measurable current $I$;

- The normal stress $\sigma=f\left(W, \theta_{C}\right)$ is determined by the measurable wheel load $W$ acting over the contact area $A=r_{W} w_{W} \theta_{C} ;$ and

- The wheel radius $r_{W}$ and width $w_{W}$ are known values.

The shear stress $\tau$ in Equation 2 determines the maximum allowable thrust available 
to propel the wheel. The terrain cohesion and shearing resistance angle therefore influence a rover's thrust $F=f(\tau)$. A decrease in either cohesion or shearing resistance angle will result in a decrease in the maximum thrust available at the wheel. When the thrust available is less than the resisting force of the terrain, the wheel becomes immobilized.

To estimate the terrain parameters $c$ and $\phi$, the remaining terms in Equation 2 must be known. Tan [30] and Yousefi Moghaddam [31] each proposed a method for estimating terrain parameters online; however their application was for excavation and not based on wheel-terrain interaction. Iagnemma used a simplified wheel-terrain interaction model [19-21] for estimating the two terrain parameters online for an exploration rover. He solved for $c$ and $\phi$ using linear least squares with a set of sensor data $(V, \omega, z, I)$ and assumed values $(K)$. His laboratory experiments, using an instrumented testbed, showed that the least squares estimates for the $c$ and $\phi$ values of the sand were within range of the bevameter measurements. An a priori value for the shear deformation parameter was needed to solve the least squares estimate. He also estimated the terrain parameters for a six-wheeled rover in a Matlab simulation using simulated noisy sensor data. His simulation results showed that the least squares estimates of sand were within error. Iagnemma's simulation did not describe how the wheel sinkage, or wheel-terrain contact area, was measured; only a simulated value was used for the estimation of the terrain parameters. The following sections of this chapter describe how each of the four rover wheel parameters can be measured, and how those measurements are used with terramechanics theory to estimate the terrain parameters.

\subsubsection{Vertical Loading on Wheel}

The vertical load, or weight $W$, on the wheel can be estimated by quasi-static analysis for a slow-moving rover [19-21]. However, Kapvik's instrumented chassis contains 
a vertical load sensor to measure $W[6]$. This measured weight is used to solve the vertical forces as shown in the rigid wheel free body diagram (Figure 6). The force balance is given in Equation 3:

$$
W=r_{W} w_{W}\left(\int_{\theta_{2}}^{\theta_{1}} \sigma(\theta) \cos \theta \mathrm{d} \theta+\int_{\theta_{2}}^{\theta_{1}} \tau(\theta) \sin \theta \mathrm{d} \theta\right)
$$

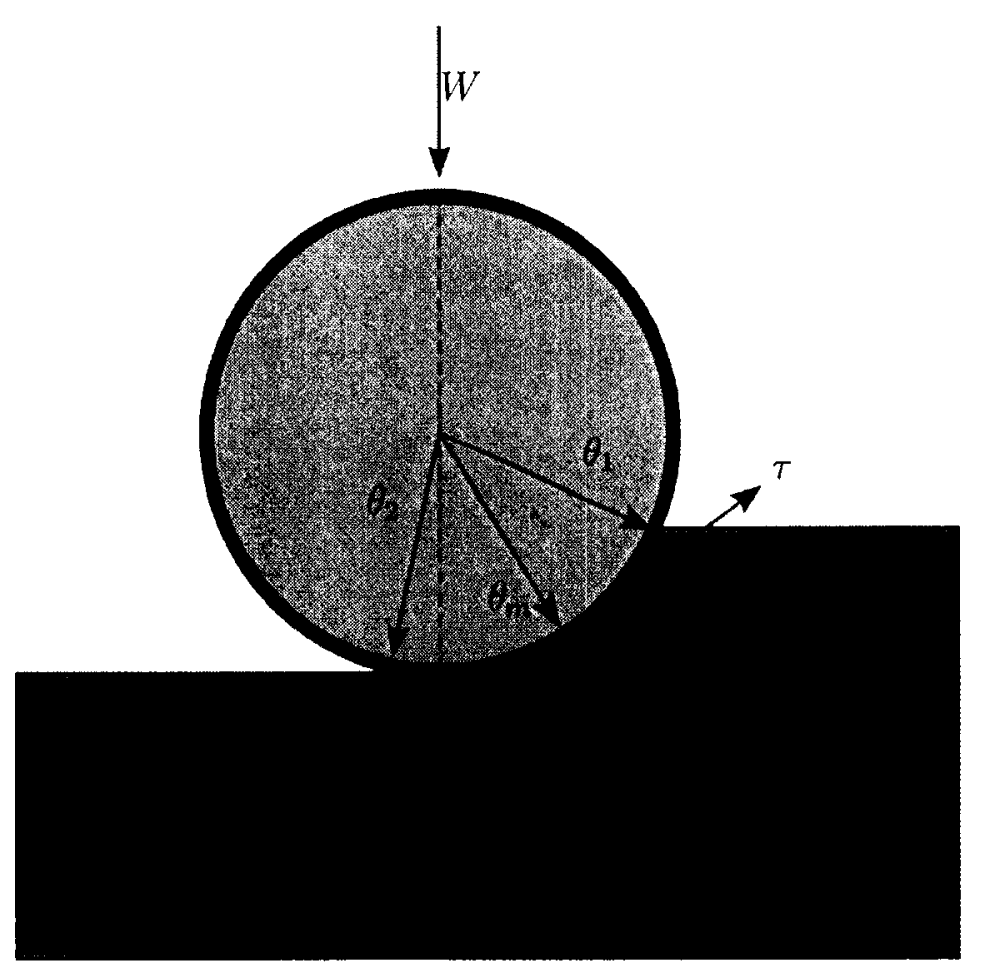

Figure 6: The vertical forces acting on the rigid wheel: the weight on the wheel $W$; shear stress $\tau$ and normal stress $\sigma$ act over a contact area defined by the wheel radius, wheel width, and the contact angle $\theta$

The normal stress $\sigma(\theta)$ is divided into two regions on either side of the maximum normal stress $\sigma_{m}$. The normal stress in Region $1, \sigma_{1}$, occurs in the region between the wheel-terrain interface entry point $\theta_{1}$ and the maximum stress point $\theta_{m}$; The normal stress in Region 2, $\sigma_{2}$, occurs in the region between $\theta_{m}$ and the interface exit point $\theta_{2}$. These regions of normal stress are shown in Figure 7. Iagnemma $[20,21]$ 
states that the maximum normal stress and maximum shear stress can be assumed to be co-located at the same angle $\theta_{m}$ "for a wide range of soil values". He further states that the maximum stresses occur approximately midway along the contact angle $\theta_{m}=\frac{1}{2}\left(\theta_{1}+\theta_{2}\right)$, and this is "reasonable for a wide range of soils". With these assumptions, the simplified stress distribution along the wheel-terrain interface can be shown:

$$
\begin{gathered}
\sigma(\theta)= \begin{cases}\sigma_{1}(\theta)=\frac{\theta_{1}-\theta}{\theta_{1}-\theta_{m}} \sigma_{m} & \text { for } \theta=\theta_{1} \rightarrow \theta_{m} \\
\sigma_{2}(\theta)=\frac{\theta-\theta_{2}}{\theta_{m}-\theta_{2}} \sigma_{m} & \text { for } \theta=\theta_{m} \rightarrow \theta_{2}\end{cases} \\
\tau(\theta)= \begin{cases}\tau_{1}(\theta)=\frac{\theta_{1}-\theta}{\theta_{1}-\theta_{m}} \tau_{m} & \text { for } \theta=\theta_{1} \rightarrow \theta_{m} \\
\tau_{2}(\theta)=c+\frac{\theta-\theta_{2}}{\theta_{m}-\theta_{2}}\left(\tau_{m}-c\right) & \text { for } \theta=\theta_{m} \rightarrow \theta_{2}\end{cases}
\end{gathered}
$$

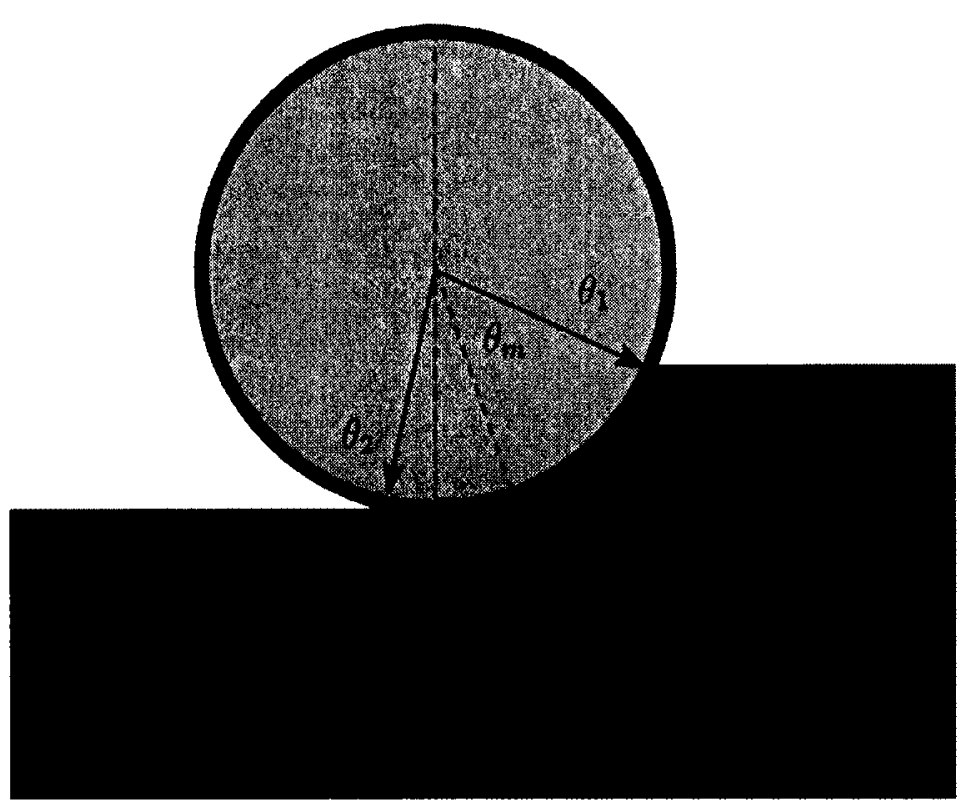

Figure 7: Diagram showing the two regions of normal stress, $\sigma_{1}$ and $\sigma_{2}$, on either side of the maximum stress $\sigma_{m}$

The exit angle $\theta_{2}$ is taken to be approximately 0 (in line with the vertical axis) [20, 21]. Equation 3 then reduces to Equation 6 after this assumption and, as shown in 
Equation 7, the weight remains a function of the normal stress, shear stress and the contact angle:

$$
\begin{gathered}
W=r_{W} w_{W}\left(\int_{0}^{\theta_{1}} \sigma(\theta) \cos \theta d \theta+\int_{0}^{\theta_{1}} \tau(\theta) \sin \theta d \theta\right) \\
W=r_{W} w_{W}\left(\int_{0}^{\theta_{m}} \sigma_{2}(\theta) \cos \theta \mathrm{d} \theta+\int_{\theta_{m}}^{\theta_{1}} \sigma_{1}(\theta) \cos \theta \mathrm{d} \theta\right)+ \\
r_{W} w_{W}\left(\int_{0}^{\theta_{m}} \tau_{2}(\theta) \sin \theta \mathrm{d} \theta+\int_{\theta_{m}}^{\theta_{1}} \tau_{1}(\theta) \sin \theta \mathrm{d} \theta\right)
\end{gathered}
$$

\subsubsection{Torque About Wheel Axis}

The previous section provides the relation between shear and normal stresses, contact angle and loading in the vertical axis. This section presents the relationship about the axis of wheel rotation as shown in Figure 8. The motor output torque about the wheel axis, $T$, is required to overcome the shear stress $\tau$ acting over the contact area as given in Equation 8:

$$
\begin{aligned}
& T=r_{W}^{2} w_{W} \int_{\theta_{2}}^{\theta_{1}} \tau(\theta) \mathrm{d} \theta \\
& T=r_{W}^{2} w_{W}\left(\int_{0}^{\theta_{m}} \tau_{2}(\theta) \mathrm{d} \theta+\int_{\theta_{m}}^{\theta_{1}} \tau_{1}(\theta) \mathrm{d} \theta\right)
\end{aligned}
$$

where the contact area is determined by the wheel radius $r_{W}$, contact angle $\theta_{C}$ and wheel width $w_{W}$. The simplifying assumptions regarding the exit angle $\theta_{2}$ and the stresses allow Equation 8 to become Equation 9. The output torque $T=f(I)$ is determined by the current draw that is measured by the motor controllers; current draw provides another measurable quantity to solve for the terrain parameters. 


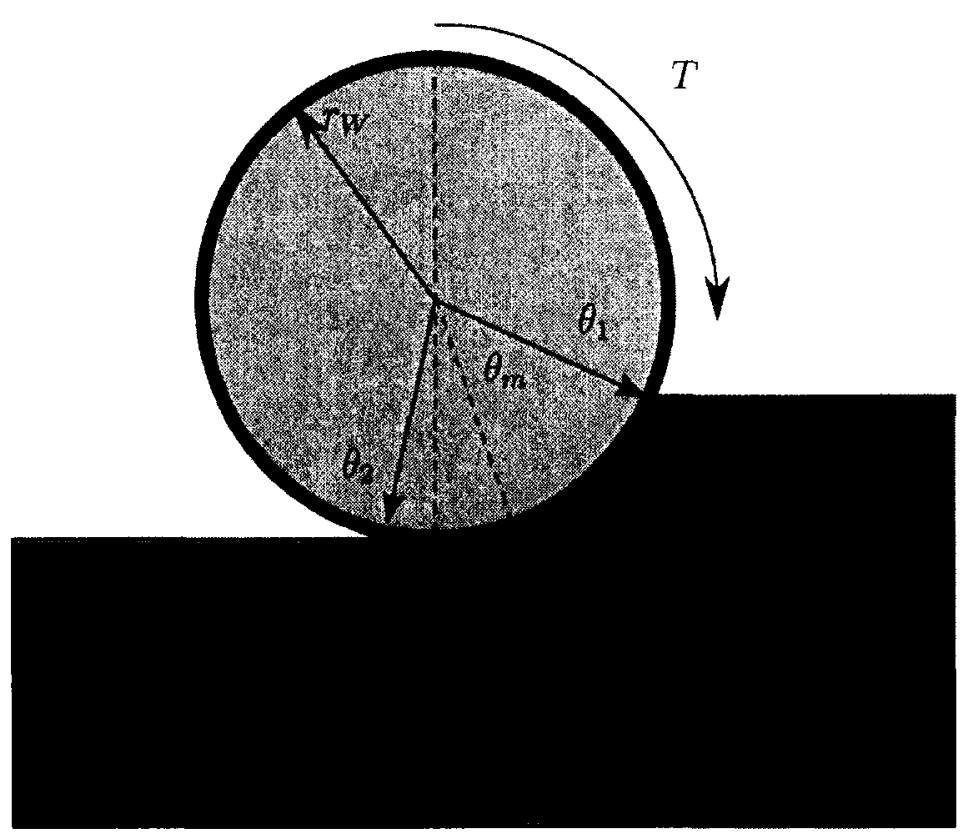

Figure 8: Shear stresses at the wheel-terrain interface

\subsubsection{Slippage}

For this thesis, slippage $j$ refers to the shear displacement caused by wheel slip. Wheel slip is the difference between the true rover speed and the sensed wheel speed; the linear displacement of the rover does not correspond to the rotational displacement of the wheel.

Slippage is indirectly measured from encoders and the true rover speed. The motor controller converts the number of encoder counts over time to rotational speed. A rigid wheel has a fixed radius from the motor axis to wheel rim; the wheel speed at the rim is compared to the true rover speed. For this thesis, it is assumed that the true rover speed is provided by speckle velocimetry [32]. Wheel slip occurs when the wheel spins in terrain faster than forward motion; the wheel encoders sense greater revolutions than actual linear displacement. Wheel skid occurs when the wheel moves 
forward faster than it spins; the wheel encoders sense fewer revolutions than actual linear displacement. Wong [16] developed a method to determine the slippage $j$ based on the slip velocity along the wheel-terrain interface, shown in Figure 9.

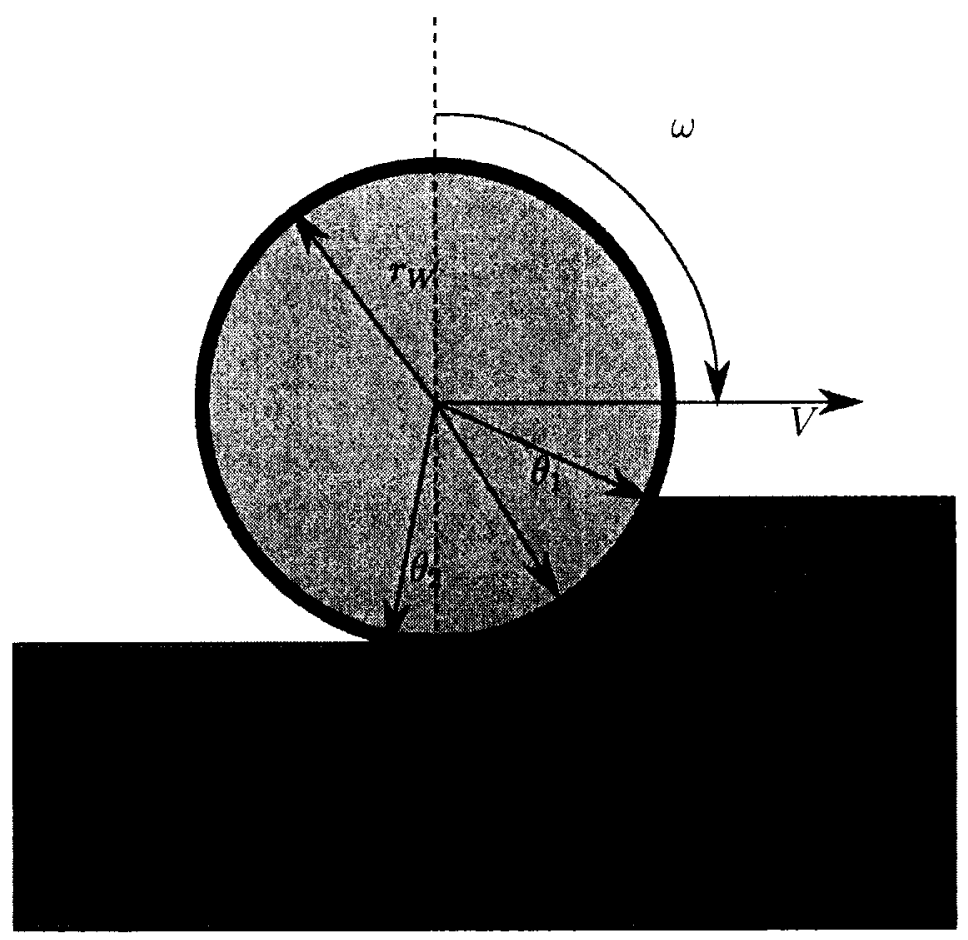

Figure 9: The slip velocity occurs along the wheel-terrain interface

The slip velocity, $V_{j}$, for a rigid wheel is tangent to the wheel-terrain interface. It is a function of the contact angle $\theta_{C}$, the radius $r_{W}$, wheel slip ratio $i$, and motor shaft rotational speed $\omega$ as shown in Equation 10:

$$
\begin{aligned}
V_{j} & =r_{W} \omega-V \cos \theta \\
V & =r_{W} \omega(1-i) \\
i & =1-\frac{V}{r_{W} \omega} \\
V_{j} & =r_{W} \omega(1-(1-i) \cos \theta)
\end{aligned}
$$


where $V$ is the translational velocity of the wheel parallel to level surface, and $\theta$ is the contact angle on the surface as shown in Figure 9. The amount of slippage $j$ between the wheel and the terrain is found by integrating the slip velocity over an arbitrary length of time:

$$
j=r_{W} \int_{0}^{t} \omega(1-(1-i) \cos \theta) \mathrm{d} t
$$

where the angular velocity $\omega=\mathrm{d} \theta / \mathrm{d} t$. The amount of slippage can be found by integrating over the wheel-terrain contact angle:

$$
\begin{aligned}
& j=r_{W} \int_{\theta_{2}}^{\theta_{1}}(1-(1-i) \cos \theta) \mathrm{d} \theta \\
& j=r_{W}\left(\left(\theta_{1}-\theta_{2}\right)-(1-i)\left(\sin \theta_{1}-\sin \theta_{2}\right)\right) \\
& j=r_{W}\left(\theta_{1}-(1-i)\left(\sin \theta_{1}\right)\right)
\end{aligned}
$$

where $\theta_{1}$ is the entry contact angle (where the wheel makes contact with the terrain) and $\theta_{2}$ is the exit contact angle (where the wheel looses contact with the terrain); both angles are relative to vertical as shown in Figure 9. The total slippage $j$ is positive over the wheel-terrain contact surface and increases as the contact angle increases. The exit angle $\theta_{2}$ is negative relative to the vertical; therefore the total contact angle $\theta_{C}=\theta_{1}-\theta_{2}$ is the sum of the two values. The exit angle $\theta_{2}$ is assumed to be negligible and is set to zero. The shear stress distribution formula becomes:

$$
\tau=(c+\sigma \tan \phi)\left(1-e^{\frac{-r_{W}}{K}\left(\theta_{C}-(1-i)\left(\sin \theta_{C}\right)\right)}\right)
$$

and allows for the shear stress $\tau=f\left(\sigma, i, \theta_{C}\right)$ to be determined from the measurable slip ratio $i$ and contact angle $\theta_{C}$. 
Reina [33] proposed combining three indicators to detect linear slip or skid: comparing encoder readings with each other; comparing encoder readings with z-axis gyro readings; and monitoring the motor currents. The encoder indicator uses fuzzy logic to compare the differences in longitudinal velocity between wheel pairs. The gyro indicator determines if there is any z-axis rotation compared to the wheel commands. The current indicator uses measured motor current and classical terramechanics theory. The torque applied to the wheel is a function of the current drawn by the motor. An estimation of the current required to overcome rolling resistance can be made for known terrain conditions. Slip is detected when the actual current drawn differs from the required current by a predefined percentage. They tested their slip detection indicators in a laboratory setting. Their rover was driven over both a sandy slope and two sand mounds. When logically OR-ed the indicators correctly detected slippage $94 \%$ of the time on the sandy slope and $61 \%$ of the time on the two sand mounds. The slip indicators are useful to indicate if the wheels are slipping beyond a specific threshold. However, these indicators are not able to quantify slip, which is required for the traction model. It is assumed that on Mars the wheels will always encounter some degree of slip $[34,35]$. The current indicator, which correctly detected slip $91 \%$ of the time on the sandy slope, does present a simple metric to flag loose soil or drift material. This flag can be added as a penalty to mapping and path planning algorithms to indicate difficult terrain.

The shear stress distribution equation now relates the terrain parameters to three measurable values: wheel slip ratio, wheel load, and current. The following two sections discuss the remaining unknowns: the terrain contact angle and wheel sinkage.

\subsubsection{Terrain Contact Angle and Wheel Sinkage}

Figure 10 shows the geometric relationship between the depth to which the wheel sinks, $z$, and the wheel contact angle, $\theta_{C}$. The wheel contact angle was previously 
shown to be $\theta_{C}=\theta_{1}-\theta_{2}$ with the exit angle $\theta_{2}$ assumed to be zero. The contact angle can then be approximated from the wheel sinkage:

$$
\begin{gathered}
z=r_{W}-r_{W} \cos \theta_{C} \\
\theta_{C}=\cos ^{-1}\left(1-\frac{z}{r_{W}}\right)
\end{gathered}
$$

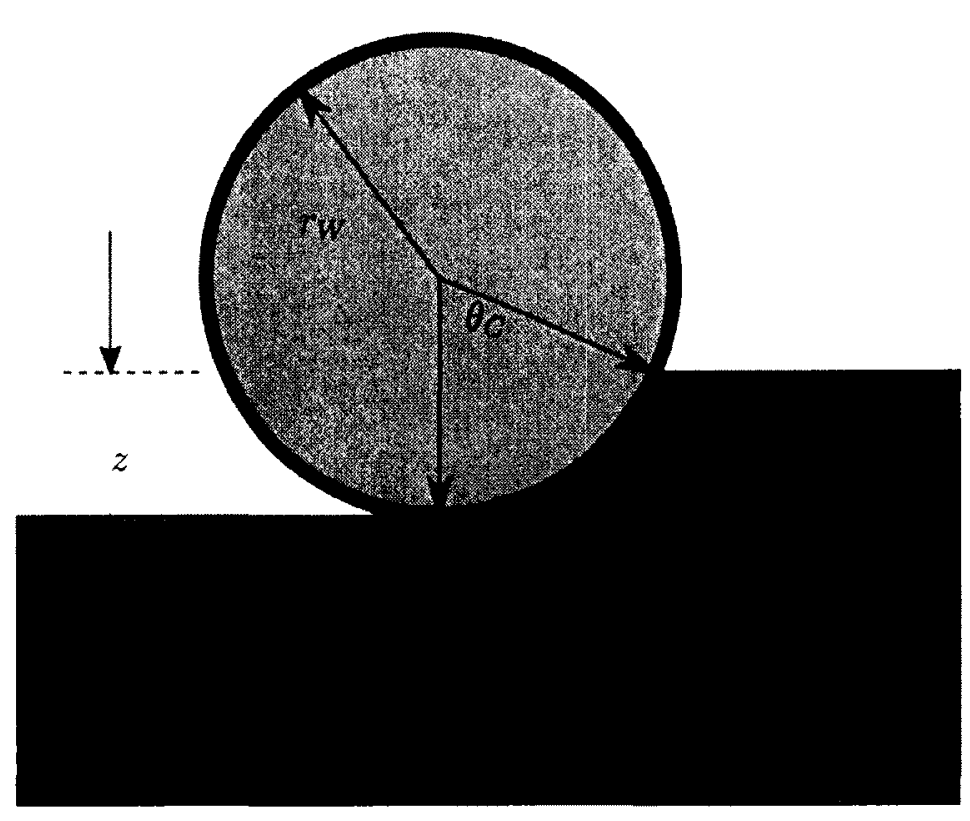

Figure 10: Relationship between the wheel sinkage $z$ and the contact angle $\theta_{C}$

\subsubsection{Wheel Sinkage and Wheel Loading}

The wheel sinkage is more readily measurable than the contact angle. A rigid wheel compresses and sinks into terrain due to the wheel load and terrain characteristics. The free body diagram in Figure 11 shows the amount of sinkage, $z$, resulting from wheel load. Bekker [15] proposed a relationship between normal pressure of the load 
on the terrain $p$ and the sinkage of the load into the terrain $z$ shown in Equation 21 with the terrain parameters $n, k_{c}$, and $k_{\phi}$. By setting $\frac{k_{c}}{b}+k_{\phi}=k_{e q}$, the relationship is reduced to Equation 22. The values $n, k_{c}$, and $k_{\phi}$ are estimated from plotting a best-fit line through experimentally collected pressure-sinkage data. Accurate measurements of both sinkage and pressure are required in order to get the best estimate of these parameters.

$$
\begin{aligned}
& p=\left(\frac{k_{c}}{b}+k_{\phi}\right) z^{n} \\
& p=k_{e q} z^{n}
\end{aligned}
$$

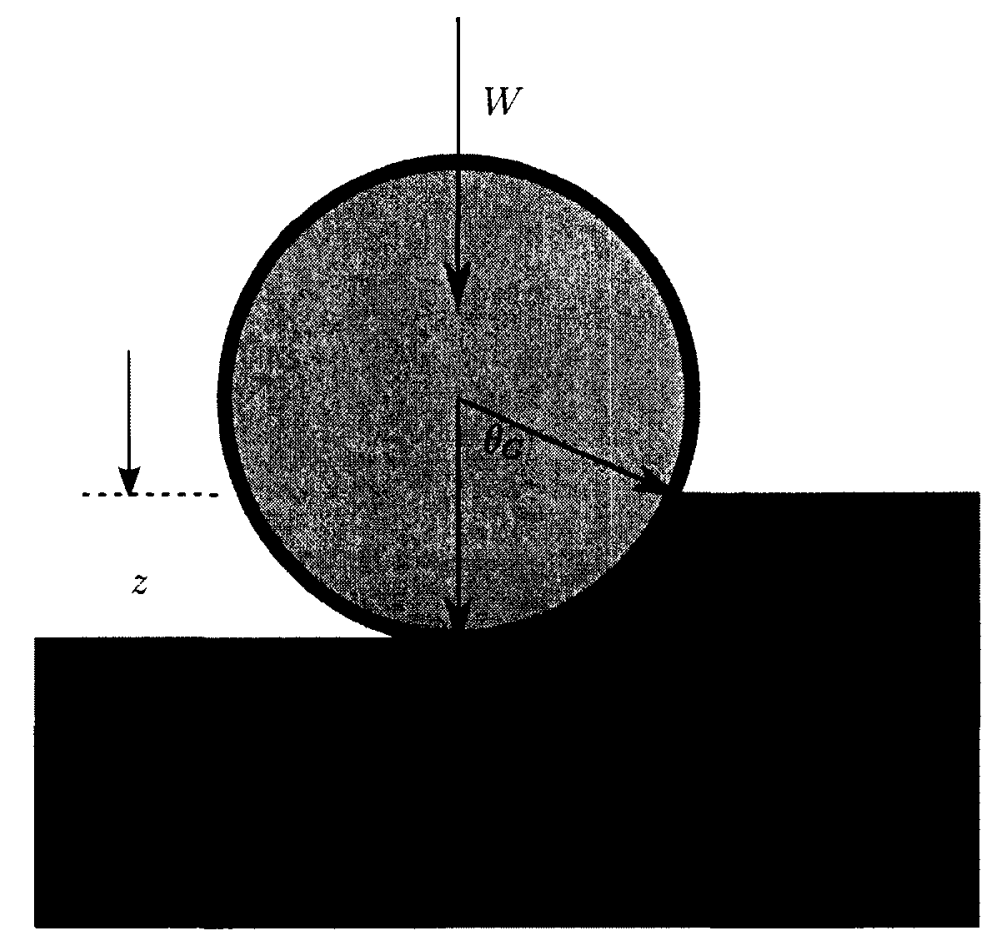

Figure 11: Relationship between the wheel sinkage $z$ and the wheel load $W$

For terrestrial soils, pressure and sinkage are measured using a bevameter. Penetration plates of known sizes are forced into terrain with hydraulic cylinders to a known depth. The bevameters are vehicle mounted and taken off-road to get 
estimates of the pressure-sinkage parameters in-situ. This technique is not suitable for planetary applications due to the mass and power needed to drive hydraulic cylinders into terrain. In addition, the sinkage depth, $z$, would require visual sinkage estimation. The sinkage can be related to the load on the wheel by combining Equations 23 and 24:

$$
\begin{aligned}
& W=w_{W} \int_{0}^{\theta_{C}} \sigma r_{W} \cos (\theta) \mathrm{d} \theta \\
& \sigma r_{W} \cos (\theta) \mathrm{d} \theta=p \mathrm{~d} x \\
& W=r_{W} w_{W}\left[\int_{0}^{\theta_{C}} p(\theta) \cos \theta \mathrm{d} \theta+\int_{0}^{\theta_{C}} \tau(\theta) \sin \theta \mathrm{d} \theta\right]
\end{aligned}
$$

Bekker's model [15] assumes the radial pressure, $\sigma$, on the terrain is equal to the normal pressure, $p$, in the model described in Equations 21 and 22. The vertical load of the wheel, $W$, applies over a uniform contact patch that is a function of the wheel's radius, $r_{W}$, width, $w_{W}$, and contact angle with the terrain, $\theta_{C}$, as shown in Equation 23. The pressure-sinkage relation can then be combined with the radial pressure term to form Equation 24, which represents the normal stress distribution on the wheel-terrain interface:

$$
W=-w_{W} \int_{0}^{z_{r}} p \mathrm{~d} x=-w_{W} \int_{0}^{z_{r}} k_{e q} z^{n} \mathrm{~d} x
$$

From the geometry of the wheel-terrain interaction model, $x$ is related to wheel 
diameter $D_{W}$ and depth $z$ :

$$
\begin{aligned}
x^{2} & =\left[D_{W}-\left(z_{r}-z\right)\right]\left(z_{r}-z\right) \\
x^{2} & =D_{W}\left(z_{r}-z\right) \\
2 x d x & =-D_{W} \mathrm{~d} z \\
W & =w_{W} k_{e q} \int_{0}^{z_{r}} \frac{z^{n} \sqrt{D_{W}}}{2 \sqrt{z_{r}-z}} \mathrm{~d} z
\end{aligned}
$$

Following a series expansion, Equation 30 is simplified to a function that relates the sinkage depth to the vertical wheel load as shown in Equation 31:

$$
W=-\frac{w_{W} \sqrt{D_{W}}(n-3) k_{e q} z_{r}^{\left(\frac{2}{2 n+1}\right)}}{3}
$$

However, Bekker's pressure-sinkage parameters must be known a priori in order to solve for the wheel sinkage. Therefore the wheel sinkage cannot be estimated from the wheel load alone; it must be measured directly in order to solve the shear stress distribution using the simplified wheel-terrain interaction model.

Wheel sinkage is difficult to measure autonomously on a wheeled rover. Reina [33] proposed a visual sinkage estimation (VSE) algorithm to estimate the wheel-terrain contact angle and the wheel sinkage. Their proposal required a pattern of concentric black circles on a white background be attached to the inside of the wheel. This proposal also assumes a camera will be in visual contact with the wheel-terrain interface. They tested their VSE algorithm on a $16 \mathrm{~cm}$ diameter wheel in a variety of lighting and terrain conditions. Images were captured and processed at $5 \mathrm{~Hz}$. The average estimation error was $8 \%$ and did not exceed $15 \%$. The estimation error could be reduced with better cameras and finer wheel patterns. The advantage to VSE is its simple implementation: a patterned wheel cover, a camera, and an image processor. Its 
disadvantage is the mass, power and computation required to implement. Estimating sinkage on more than one wheel would require more cameras, more wheel covers and more image processing.

Wilcox [36] describes a method to detect sinkage on a six-wheeled articulated rover. The rover with which this was tested was functionally equivalent to the Mars Pathfinder rover Sojourner. The rover's rocker-bogie linkages allowed all six wheels to remain in contact with the terrain. These linkages were passive but instrumented to sense the pitch and articulation. Wilcox presents a simple model of a rover driving over undisturbed terrain. The elevation differences between the front and rear wheels are calculated based on the pitch and articulation values. Forward looking lasers sense the elevation of terrain ahead of the rover. The elevation difference from the rear wheel to the points ahead of the rover are also computed. He assumes that the front wheels will sink into the undisturbed terrain. He further assumes that the rear wheels will not sink further into the soil when driven over the same terrain. Wilcox notes that if this assumption is not approximately correct it will lead to a general failure of the entire method. The elevation difference between the front wheel and rear wheel, as estimated with the rocker-bogie pitch and articulation angles, is the basis of the sinkage estimate; the forward elevation difference is the basis for the future sinkage prediction. Wilcox's results with the rover showed that his method worked well to indicate sinkage; however due to large sensor noise it was not able to provide a good estimate of the sinkage. He also noted that the computer resources were already burdened with navigation and mobility calculations and this sinkage estimate could only be performed once per wheel radius of traverse.

Wilcox's sinkage estimate method could be applied to a micro-rover such as Kapvik. It has the same instrumented rocker-bogie to sense the pitch and articulation. Even one estimate per wheel radius of traverse would be adequate enough to avoid obstacles. However, as Wilcox noted, the sensor noise was too large to provide a good estimate 
of sinkage. The sinkage parameter in classical terramechanics theory is required for estimating cohesion and friction angle. A noisy estimate could be used as a flag for mobility mapping; however, it would not be useful for estimating regolith parameters.

\subsection{Traction Analysis of the Rigid Wheel}

The purpose of estimating the terrain parameters is to determine if the rover can develop sufficient traction to overcome terrain resistance and avoid becoming immobilized. This section presents the analysis to determine the required tractive force, otherwise known as thrust.

\subsubsection{Tractive Force}

The rover's whed motors must provide sufficient tractive force to overcome motion resistance so that the rover can move. Figure 12 shows the free body diagram of the forces acting on a six-wheeled rover. The tractive force, $F$, must overcome aerodynamic resistance $R_{a}$, wheel-terrain motion resistance $R_{t}$, inertia $m a$ (if the rover is accelerating), gravity (if the rover is at an incline), and drawbar pull $D P$.

The primary resisting force on the rover is wheel-terrain motion resistance. This resistance is a combination of geometric obstacle resistance, internal running gear resistance, and vehicle-terrain resistance. The internal running gear resistance is assumed to be zero for a rigid wheel. Geometric obstacles are left out of this analysis as the effort required to overcome them is dependent upon the characteristics of the obstacle. The interaction between the vehicle and the terrain is usually the most

significant source of resistance [16]. This resistance is caused by wheel sinkage. It is assumed that the wheels will not sink further than the height of the wheel and cause the belly of the rover to come in contact with the terrain. Belly drag is another source of vehicle-terrain resistance; however, for this thesis it is assumed that the rover will 


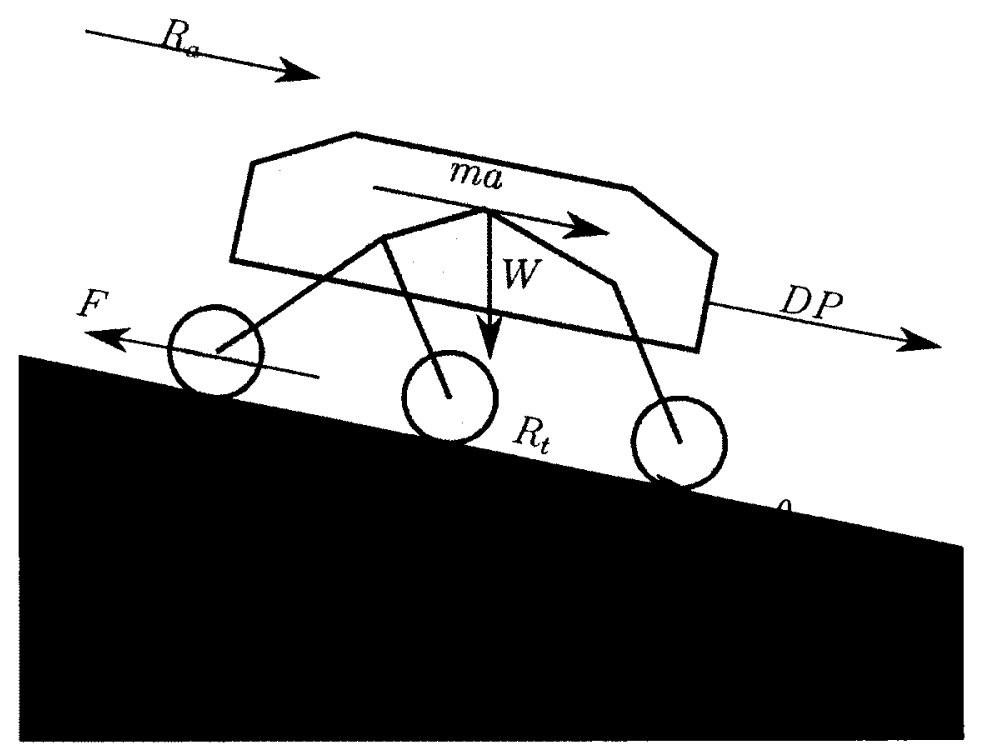

Figure 12: Diagram of the forces acting on a micro-rover accelerating up an incline

not be able to overcome motion resistance should the wheels be completely submerged so as to allow the rover belly to touch the terrain.

The remaining resisting forces are neglected from analysis; aerodynamic, inertia, and gravity. Schoficld [37] presents Mars atmospheric data collected from the Mars Pathfinder (Sojourner) mission. The surface atmospheric density was found to be $0.0176 \mathrm{~kg} / \mathrm{m}^{3}$. The wind speed was found to be nominally less than $10 \mathrm{~m} / \mathrm{s}$ and down to $1 \mathrm{~m} / \mathrm{s}$ in the morning. The aerodynamic resistance for a small rover on Mars is assumed to be negligible compared to motion resistance. The inertia force is considered to be negligible compared to the terrain resistance as Kapvik's design speed is $2.2 \mathrm{~cm} / \mathrm{s}$. In addition, the rover is assumed to be traversing over level terrain and not on an incline. However, including the effect of gravity and inertia in the traction analysis is straightforward, as long as the incline angle and acceleration are measurable. 
Drawbar pull $D P$ represents the potential for acceleration, slope climbing, or towing or pushing a load. It is the net force available after resistances are subtracted from the thrust as shown in Equation 32. Kapvik's design configuration includes an externally mounted tether to allow the rover to negotiate down a steep incline and winch itself up. However, the tether is not intended to tow a load behind Kapvik during its traverse:

$$
D P=F-\Sigma R
$$

The remaining force acting on the rover is the tractive force, or thrust, developed by the wheels. The tractive force must be greater than the terrain resisting force (or terrain resistance). The amount of tractive force developed by the motors is determined by the torque of the motors and efficiency of delivering that torque to the wheels. The maximum traction available is determined by the shear stress distribution at the wheel-terrain interface:

$$
\begin{aligned}
& F=r_{W} w_{W} \theta_{C} \tau \\
& F=r_{W} w_{W} \theta_{C}(c+\sigma \tan \phi)\left(1-e^{\frac{-r_{W}}{K}\left(\theta_{C}-(1-i)\left(\sin \theta_{C}\right)\right)}\right)
\end{aligned}
$$

where $r_{W} w_{W} \theta_{C}$ is the contact area. This tractive force must be greater than the terrain resistance in order for the rover to move. A decrease in terrain cohesion or shearing resistance angle will result in a decrease in available traction. If the available traction is less than the terrain resistance, the rover will be immobilized.

\subsubsection{Land Locomotion Resistance}

Land locomotion resistance is the most significant source of resistance on the rigid wheel system. The two components of land locomotion resistance are compaction 
resistance due to static loading and sinking into terrain, and slip sinkage due to the burrowing action of slipping wheels.

Slip sinkage is referred to the sinkage due to shear loading. The amount of sinkage due to slip is added to the sinkage due to static load to give the total sinkage of the wheel. Bekker [15] presents sinkage as a the vertical deformation in the presence of a vertical pressure. He also presents thrust as the horizontal force related to slip deformation and shear load. Bekker states the vehicle sinkage can be assumed to be independent of shear stress for moderate loads and deformations. Bekker proposed that if the vehicle load was less than the soil bearing capacity, the soil deformation due to slip would be negligible. This proposal was found to be correct for cohesive soils but not for loose frictional soils. Slip sinkage is more prevalent in dry frictional soils compared to plastic cohesive soils. Static sinkage can be used for cohesive soils as an approximation however this approximation is poor for dry sand. Wong [23] empirically shows these effects; under constant pressure loads, the sinkage increases more rapidly for dry sand than for clay in the presence of increasing shear displacement.

Lyasko [38] presents an analytic formula for estimating the slip sinkage for a wheeled vehicle as a function of the wheel slip and static sinkage:

$$
\begin{aligned}
& z_{S S}=k_{S S} z \\
& k_{S S}=\frac{1+i}{1-0.5 i}
\end{aligned}
$$

His study showed that this relation is valid for various soil bins.

\subsection{Mars Regolith Parameters}

The research focus for this thesis was estimating Mars regolith parameters with a micro-rover on-line during its traverse phase. Wong [39] showed that the tractive 
performance of a rigid wheeled rover on extraterrestrial terrain could be predicted from analysis of the same rover on terrestrial terrain. Past Mars exploration missions have conducted experiments to estimate the cohesion and shearing resistance angle. However, those experiments were conducted while the rover was stationary. Results from the Mars Pathfinder Sojourner in-situ regolith tests characterized Martian regolith to be similar to clayey silt with embedded sands, granules, and pebbles $[2,40]$. Sojourner was used as a test platform to conduct in-situ experiments to determine the cohesion and friction angle of the regolith. The tractive force for a single wheel was determined from the wheel torque that was taken as a function of drawn motor current and no-load current. The rover team took the currents to be a function of temperature. The shearing resistance angle $\phi$ was assumed to be the same as the angle of repose $\Psi$ that was estimated from camera images. They estimated the cohesion $c$ from the Mohr-Coulomb criteria using the least squares method; wheel slip was not taken into account. Table 1 gives the Mars regolith parameters estimated by the Mars Pathfinder rover team $[2,40]$.

Table 1: Mars regolith parameters estimated by the Sojourner rover team

\begin{tabular}{|c|c|c|}
\hline Cohesion $c(\mathrm{kPa})$ & Shearing Angle $\phi$ & Notes \\
\hline 0.238 & $36.6^{\circ}$ & moderately dense deposit \\
\hline 0.53 & $26^{\circ}$ & weak, porous deposit \\
\hline
\end{tabular}

The MER team conducted in-situ experiments to estimate the local cohesion and shearing angle with both Spirit, at Gusev Crater, and Opportunity at Meridiani Plains. The engineering data used for the estimation included temperature, motor voltages, motor currents, vehicle orientation, and the rocker-bogie positions. Data was recorded at $8 \mathrm{~Hz}$ during the wheel's commanded rotation of $0.3 \mathrm{rad} / \mathrm{s}$. The collected data was used to solve the Mohr-Coulomb criteria $\tau=c+\sigma \tan \phi$.

The friction angle was estimated from wheel-digs into the tailings; the tailings 
are loose terrain that has its cohesiveness destroyed from prior wheel action. The Mohr-Coulomb criteria simplifies to:

$$
\begin{aligned}
\tau & =\sigma \tan \phi, \\
\frac{F_{S}}{r_{W} \Omega} & =\frac{F_{N}}{r_{W} \Omega} \tan \phi
\end{aligned}
$$

where the $F_{S}$ is the shear force and $F_{N}$ is the normal force acting at the wheelterrain interface. $\Omega$ is the rotational sweep of the wheel commanded for the wheel-dig experiment. The normal force is determined from static analysis from the vehicle orientation and known mass. The shear force $F_{S}$ is a function of the motor torque and wheel radius. The torque is determined from the net motor work; the net motor work is calculated by subtracting the no-load motor work from the measured motor work [41]:

$$
\begin{aligned}
W_{E M} & =I V_{M O T} t \\
W_{N E T} & =W_{E M}-W_{N L} \\
F_{S} & =\frac{W_{N E T}}{r_{W} \Omega}=\frac{T}{r_{W}}
\end{aligned}
$$

The MER team estimated the local cohesion by modelling the shear stress along the wheel-terrain interface. The wheel-terrain interface contact area $A$ was calculated by estimating the wheel sinkage $z$ by comparing Hazcam images of the wheel to engineering models. With these two estimates, the wheel contact angle $\theta_{C}$ was also estimated. A number $N$ of incremental stresses were integrated over the contact area of the wheel-terrain interface to get an estimate for cohesion as shown in the following 
equations:

$$
\begin{aligned}
F_{S_{q}} & =\left(\frac{F_{N}}{N} \cos \theta_{q}\right) \tan \phi+c A_{q} \\
F_{S} & =\sum_{q=1}^{N} \frac{F_{N}}{N} \cos \theta_{q} \tan \phi+\sum_{q=1}^{N} c A_{q} \\
F_{S} & =F_{N} \tan \phi \sum_{q=1}^{N} \frac{\cos \theta_{q}}{N}+c A \\
F_{S} & =\frac{F_{N} \tan \phi \sin \theta_{C}}{\theta_{C}}+c A=\frac{W_{N E T}}{r_{W} \Omega} \\
c & =\frac{W_{N E T} \theta-F_{N} \tan \phi \sin \theta r_{W} \Omega}{r_{W} A \theta \Omega}
\end{aligned}
$$

and the corresponding test results are shown in Table 2 [41].

Table 2: Mars regolith parameters estimated in-situ by the Spirit and Opportunity. The test labels correspond to which rover conducted the test (labelled as 'A' for Spirit and 'B' for Opportunity) and on which sol

\begin{tabular}{|c|c|c|l|}
\hline Test & Cohesion $c(\mathrm{kPa})$ & Shearing Angle $\phi$ & Notes \\
\hline Asol047 & 0.7 & $30^{\circ}$ & $\begin{array}{l}\text { Fine-grained terrain, } 6.5 \mathrm{~cm} \\
\text { depth }\end{array}$ \\
\hline Asol113 & 0.5 & $30^{\circ}$ & Rocky terrain, $8 \mathrm{~cm}$ depth \\
\hline Asol135 & 1.1 & $37^{\circ}$ & Rocky terrain, $11 \mathrm{~cm}$ depth \\
\hline Bsol023 & 0.8 & $37^{\circ}$ & Sandy terrain, 9 cm depth \\
\hline Bsol054 & 0.6 & $33^{\circ}$ & Aeolian ripples, $3 \mathrm{~cm}$ depth \\
\hline Bsol073 & 1.0 & $30^{\circ}$ & Plains, 11 cm depth \\
\hline Bsol366 & 1.2 & $34^{\circ}$ & Plains, 11 cm depth \\
\hline Bsol919 & 0.1 & $36^{\circ}$ & Smooth plains, $2.4 \mathrm{~cm}$ depth \\
\hline
\end{tabular}

In addition to rovers, Mars regolith parameters have been estimated in-situ by the Viking and Phoenix landers using narrow blades [42] and robotic scoops [43] for digging trenches. Those parameter estimates are shown in Table 3. For both landers, camera images and motor feedback were required for estimating the parameters $[42,43]$. 
Table 3: Mars regolith parameters estimated in-situ by the Viking and Phoenix landers

\begin{tabular}{|c|c|c|c|}
\hline Lander & Cohesion $c(\mathrm{kPa})$ & Shearing Angle $\phi$ & Notes \\
\hline Viking & 1.6 & $18.0^{\circ}$ & Drift material \\
\hline Viking & 1.1 & $34.5^{\circ}$ & Crusty to Cloddy Material \\
\hline Viking & 5.5 & $30.8^{\circ}$ & Blocky Material \\
\hline Phoenix & $0.2-1.2$ & $38^{\circ}$ & - \\
\hline
\end{tabular}

\subsubsection{Lunar Regolith Parameters}

The focus of this thesis is to present a method to estimate the Mars regolith parameters using a micro-rover scout. The same approach can be used for estimating Lunar regolith parameters; those Lumar parameters are presented in this section.

Lunar regolith is characterized as a mixture of rock fragments, mineral fragments, breccias, agglutinates, and glass. The proportion of each varies across the surface. Both NASA and Soviet Lunar programs, including Luna, Surveyor, and Apollo, studied the physical properties of Lunar regolith in-situ. Additional returned samples were studied on Earth however those samples had limitations due to the manner in which they were transported back to Earth. The geotechnical properties studied were particle size and shapes, density, porosity, compressibility, permeability and diffusivity, bearing capacity, shear strength slope stability and trafficability [44].

The Lunokhod 1 rover took approximately 327 cone penetrometer and vane shear measurements in-situ over a $5 \mathrm{~km}$ traverse. The Lunokhod 2 rover took similar measurements for a combined total of approximately 1000 measurements of depths to $10 \mathrm{~cm}$. Apollo 15 and 16 astronauts used a self-recording penetrometer to perform 17 tests to depths to $74 \mathrm{~cm}$. Earlier estimates were based on physical interactions between the Apollo Lunar Modules and the astronauts, and the soil. The Lunar Sourcebook [44] presents its recommended values for cohesion and friction angle in 
Table 4 . The values in the first row are applicable to micro-rovers as the wheel sinkage is not expected to be greater than $15 \mathrm{~cm}$.

Table 4: Recommended cohesion and friction angle for lunar regolith based on depth

\begin{tabular}{|c|c|c|c|c|}
\hline & \multicolumn{2}{|c|}{ Cohesion, c (kPa) } & \multicolumn{2}{c|}{ Friction Angle, $\phi$} \\
\hline Depth Range $(\mathrm{cm})$ & Average & Range & Average & Range \\
\hline $0-15$ & 0.52 & $0.44-0.62$ & $42^{\circ}$ & $41-43^{\circ}$ \\
\hline $0-30$ & 0.90 & $0.74-1.1$ & $46^{\circ}$ & $44-47^{\circ}$ \\
\hline $30-60$ & 3.0 & $2.4-3.8$ & $54^{\circ}$ & $52-55^{\circ}$ \\
\hline $0-60$ & 1.6 & $1.3-1.9$ & $49^{\circ}$ & $48-51^{\circ}$ \\
\hline
\end{tabular}

Trafficability over lunar regolith was studied from the eight-wheeled Lunakhod rover and the four-wheeled Apollo Lunar Roving Vehicle (LRV). The LRV cruised at an average speed of $6-7 \mathrm{~km} / \mathrm{hr}$ with a total load of over $700 \mathrm{~kg}$. Wheel-slip was estimated to be $2-3 \%$. The soil compaction resistance was estimated by comparing the actual and estimated energy consumption of the LRV [44].

Costes [24] studied lunar regolith simulants to estimate pressure-sinkage and shear parameters. Soil compaction and drawbar pull were calculated using these parameters and compared with the LRV performance observations. The original estimated parameters were calculated in Imperial units and are presented in SI units in Table 5. The parameters are in the same range as terrestrial sand.

Table 5: Soil parameters derived from tests on lunar soil simulants

\begin{tabular}{|c|c|c|}
\hline$k_{c}$ & Pressure-sinkage parameter & $1.4 \mathrm{kN} / \mathrm{m}^{2}$ \\
\hline$k_{\phi}$ & Pressure-sinkage parameter & $820 \mathrm{kN} / \mathrm{m}^{2}$ \\
\hline$n$ & Pressure-sinkage parameter & 1 \\
\hline$c$ & Cohesion & $0.170 \mathrm{kPa}$ \\
\hline$\phi$ & Soil friction angle & $35^{\circ}$ \\
\hline$K$ & Shear deformation parameter & $0.018 \mathrm{~m}$ \\
\hline
\end{tabular}


The surface the LRV and Lunakhod traversed was classified as medium - dense a few centimetres below the surface. The Lunakhod wheels were observed to sink only a few centimetres in these conditions. However, both the LRV and Lunakhod encountered patches of loose, soft regolith. Lunakhod was observed to sink $20 \mathrm{~cm}$ in this regolith [44].

\section{$2.6 \quad$ Non-Geometric Obstacles}

Planetary exploration rovers must detect obstacles to autonomously navigate the surface. This thesis defines obstacles as either geometric or non-geometric. Geometric obstacles are hazards which can be characterized by their geometry. Such obstacles include rocks, crevices and steep slopes. These geometric obstacles can be identified using vision- or laser-based sensors.

Non-geometric obstacles are characterized by their mechanical properties. These obstacles include weak terrain characterized by its strength and friction. Weak terrain causes greater slip and wheel sinkage which degrades mobility. Non-geometric obstacles are a direct function of the interaction between the terrain and the rover contact points. Both Viking 1 and the Mars Exploration Rover (MER) Spirit sank in drift material; Viking 1 was designed as stationary probe whereas Spirit become one.

Brooks [14] and Halatci [45] present vision- and vibration-based methods for classifying non-geometric obstacles. Their results showed that the classifiers could detect large changes in features, such as the differences between rock, sand and beach class. Kleiner [46] furthered this classification method by incorporating laser data; his results showed the classification between five different terrain types. However, these methods were not shown to be robust enough to detect changes in terrain properties and "no research has addressed the detection of non-geometric obstacles where their appearance has not been known a priori" [14]. 


\section{Chapter 3}

\section{Multilayer Perceptron with Backpropogation}

The previous chapter presented other methods for estimating terrain parameters on-line. This thesis presents a unique method for estimating terrain parameters using trained neural networks. This method has not been used, or otherwise proposed to be used, for estimating terrain parameters or detecting non-geometric obstacles with planetary rovers.

This chapter provides a review of artificial neural networks (ANN) and how they are used for estimating Mars regolith parameters. Artificial neural networks are the computing equivalent to biological learning processes. Layers of neurons are connected together with synapses that trigger upon activation of inputs. An artificial neural network is a computing tool that adaptively responds to inputs to meet a desired output. The inputs can come in the form of known or unknown patterns. The desired output may be the emulation of a known pattern, or the identification of an unknown system. The adaptive learning process may be either a fixed training scheme or an unsupervised process. Once an ANN has been trained, it can be used to perform tasks based on their intended applications. Such applications include pattern recognition, optimization, and system identification $[47,48]$. 


\subsection{Artificial Neural Networks}

Artificial neural networks are built and trained based on the tasks they are required to perform. Simple tasks may only require a single layer of a few neurons. More complex tasks require multiple layers of several neurons. Networks that produce results by learning examples are supervised; networks that organize inputs to discover collective properties are unsupervised.

\subsubsection{Simple Neuron}

A simple neuron, shown in Figure 13, is connected by synapses to one or more inputs. Artificial neurons are expressed in mathematical form and have four components. First, the synapses connect incoming signals to a summation junction. These synapses are the free parameters of the neuron. Second, the summation junction adds together each of the input signals that gets multiplied by the synaptic weight. Third, a bias or threshold is further applied to the summation junction and acts to raise or lower activity level of the neuron. Finally, the combination then gets passed through an activation function to form the output of the neuron. The mathematical terms for neuron $q$ are given in Equations 47 to 49:

$$
\begin{aligned}
& v_{q}=\sum_{j=0}^{n} w_{q j} x_{j} \\
& u_{q}=g\left(v_{q}\right) \\
& y_{q}=g\left(\sum_{j=0}^{n} w_{q j} x_{j}\right)
\end{aligned}
$$

where

- The vector input signal, $\mathbf{x} \in \Re^{n \times 1}$ is multiplied by the synaptic weights, $\mathbf{w}_{\mathbf{q}} \in$ $\Re^{n \times 1}$; 
- $x_{0}$ is the bias or threshold signal to the neuron and it is multiplied by its respective synaptic weight $w_{q 0}$;

- The output of the summation junction, $v_{q}$, is then passed through an activation function, $g(\cdot)$; and

- The output of the activation function, $u_{q}$ is the axon. When the axon, $u_{q}$, is the output of the neural network it is denoted as $y_{q}$.

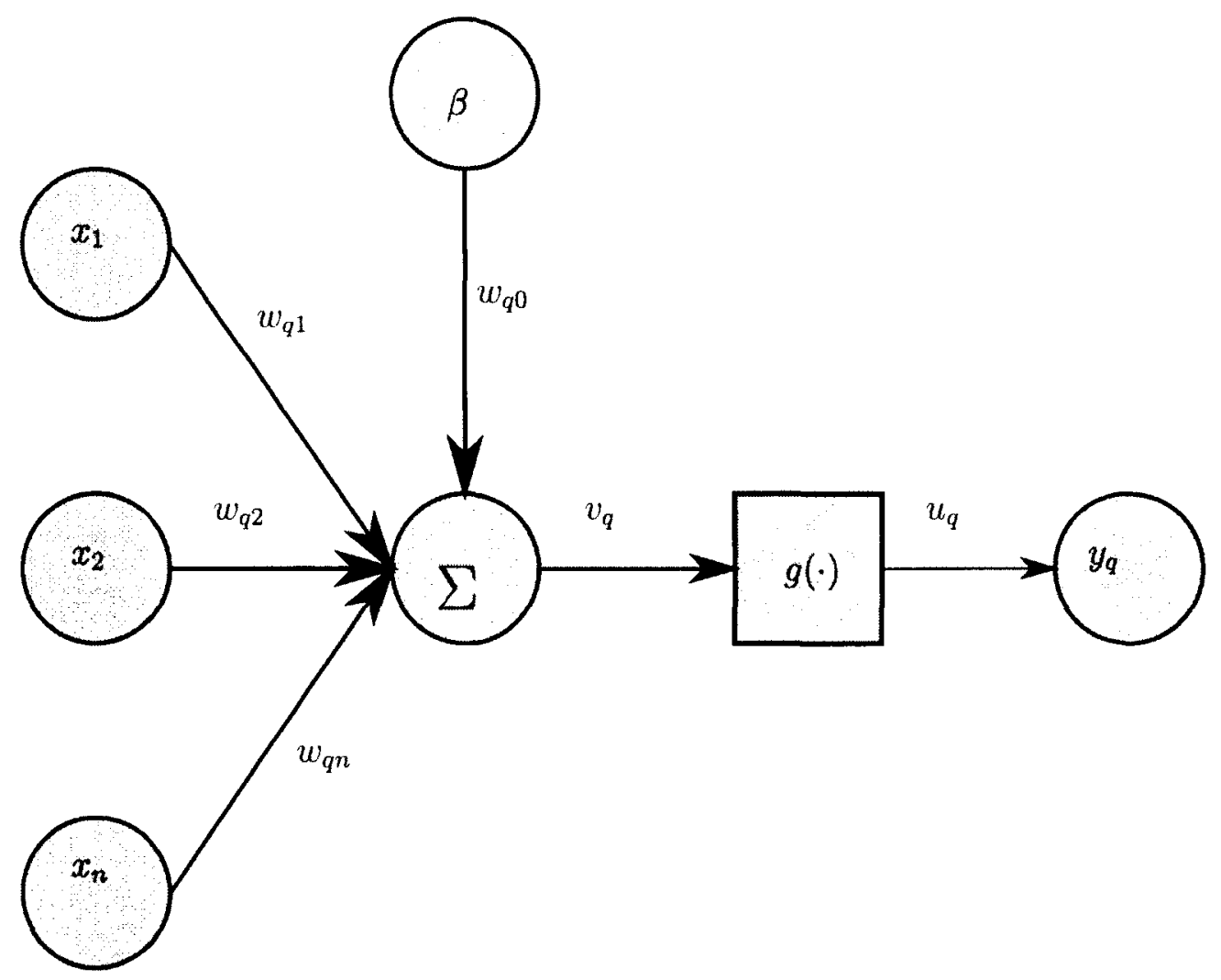

Figure 13: A simple artificial neuron, $q . n$ inputs are each connected by synaptic weight to a summing junction. The output of the summing junction is sent through an activation function 


\subsubsection{Activation Functions}

The activation function $g(\cdot)$ limits the strength of the axon in response to the summation of inputs. There are several different types of activation functions that are based on the requirements of the neural network. Non-linear sigmoid functions are commonly used in feedforward networks because they are continuously differentiable which is a requirement for updating synaptic weights with the backpropagation learning. The binary sigmoid function has saturation levels at 0 and 1 and an adjustable slope parameter, $\alpha$; it is used when the expected outputs of the network are all positive.

$$
\begin{aligned}
g_{b s}\left(v_{q}\right) & =\frac{1}{1+e^{-\left(x v_{q}\right.}} \\
g_{b s}^{\prime}\left(v_{q}\right) & =\alpha g_{b s}\left(v_{q}\right)\left[1-g_{b s}\left(v_{q}\right)\right]
\end{aligned}
$$

\subsubsection{The Simple Perceptron}

The simple perceptron, as shown in Figure 14, is a single neuron $q$ with supervised learning according to a weight updating algorithm. The vector input signal, $\mathbf{x} \in \Re^{n \times 1}$, is connected to the summing junction by the synaptic weights. The response of the simple perceptron is $y_{q}$; this output is compared to the desired response $d_{q}$. The error signal, $e=d_{q}-y_{q}$, is the basis for the synaptic weight update algorithm. 


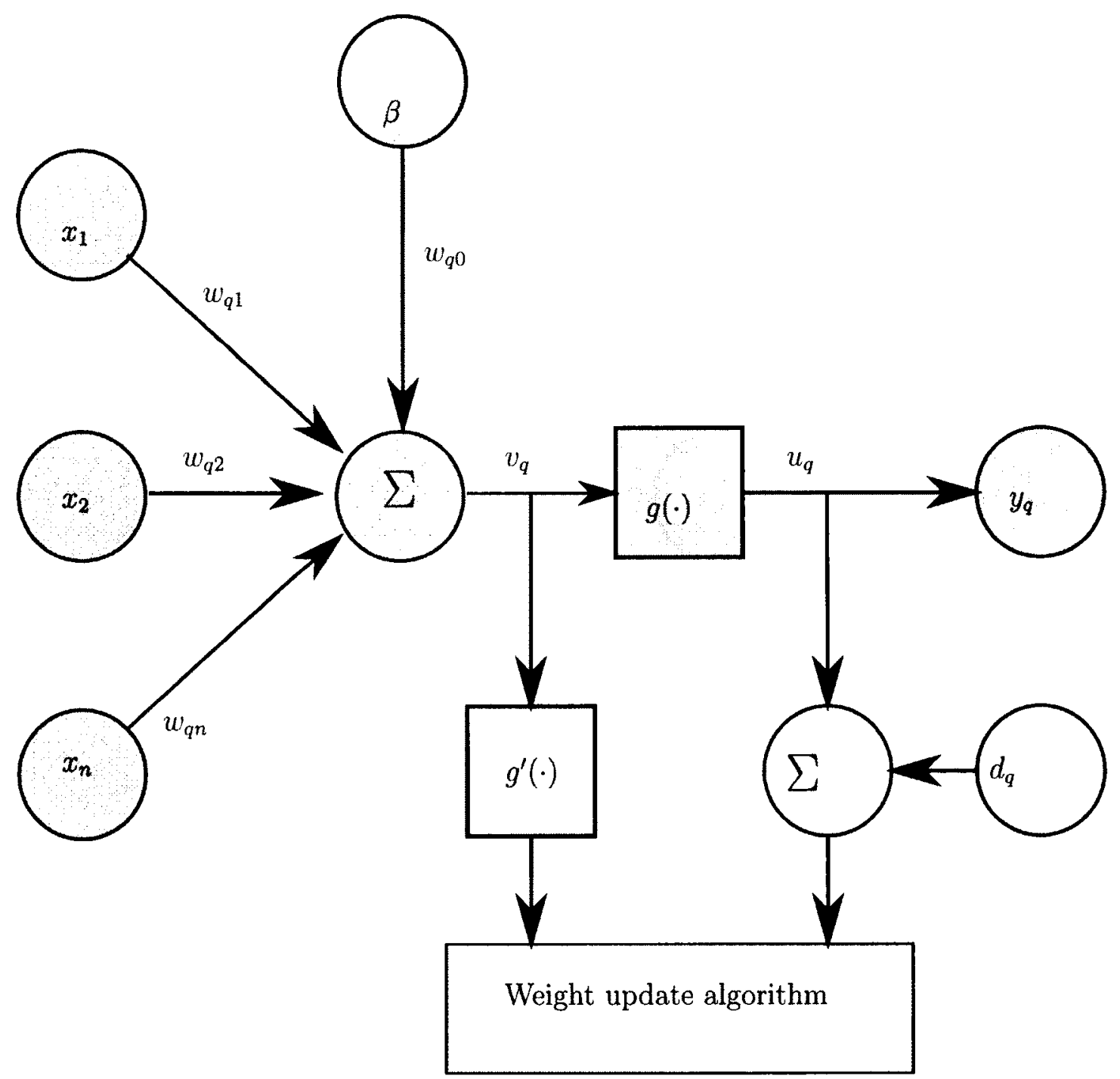

Figure 14: A simple perceptron with neuron $q$. The weights are updated until the output $y_{q}$ approximates the desired output $d_{q}$ 


\subsubsection{Multilayer Perceptron}

A feedforward multilayer perceptron (MLP), shown in Figure 15 contains more than one layer of many neurons:

- The "zero" layer is the vector input signal, $\mathrm{x} \in \Re^{n \times 1}$;

- $\mathbf{x} \in \Re^{n \times 1}$ feeds into the first "hidden" layer of neurons. There may be more than one hidden layers depending on the network architecture; and

- The last hidden layer fires synapses into the output layer which provides the vector response signal, $\mathbf{y} \in \Re^{m \times 1}$.

The neural network of this architecture performs a mapping $\Re^{n \times 1} \rightarrow \Re^{m \times 1}$. For most learning tasks, one or two layers are sufficient. The MLP is trained to emulate a desired signal or pattern. The error signal, $\mathbf{e} \in \Re^{m \times 1}$, is the difference between the network output, $\mathbf{y} \in \Re^{m \times 1}$, and the desired output, $\mathbf{d} \in \Re^{m \times 1}$. The error signal becomes the basis for updating the synaptic weights. 


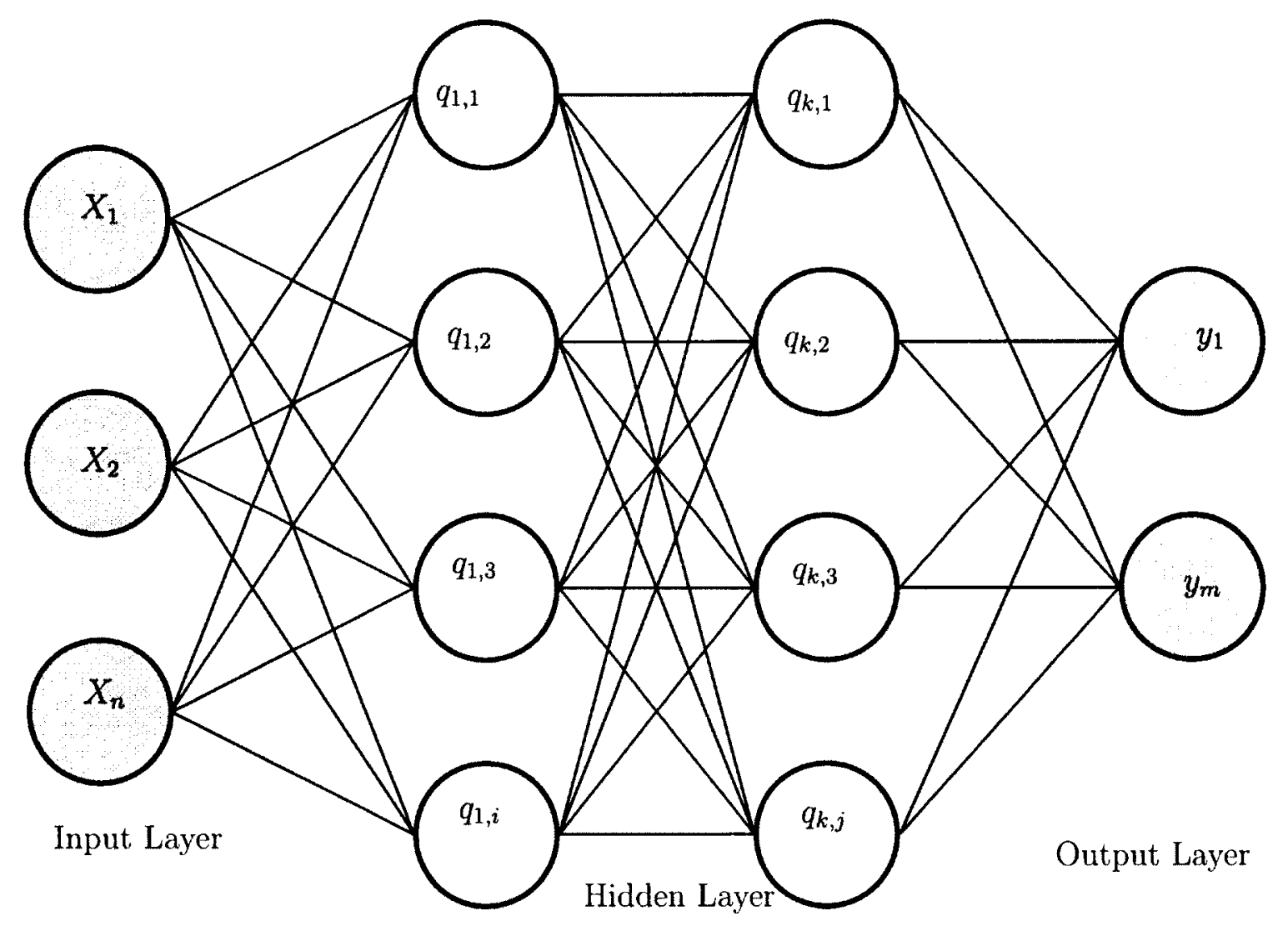

Figure 15: A multilayer perceptron with input $\mathrm{x} \in \Re^{n \times 1}$; the first hidden layer contains $i$ neurons; the $k$ th hidden layer contains $j$ neurons; and the output layer contains $m$ neurons. The weights are updated until the output $\mathbf{y} \in \Re^{m \times 1}$ approximates the desired output vector $\mathbf{d} \in \Re^{m \times 1}$ 


\subsubsection{Network Architecture and Construction}

This section describes the process to construct a neural network. The architecture of the neural network is the number of layers and neurons that make up the network; with more layers and neurons there are more synapses that can be adjusted. The architecture determines the time required for training the network, and the accuracy of the results provided by the network. Too few synapses will result in poor accuracy; too many synapses may over-fit the training data by introducing random noise and will take longer to train. The result of over-fitting is poor generalization to previously unseen data. A single hidden layer with enough neurons can approximate any function [47]. Determining an optimal network architecture remains an active research topic [49-51].

Lappas [51] presents an equation (Equation 52) to estimate the optimal number of neurons on a single hidden layer for a feed forward MLP based on the number of training sets $m_{L}$. The optimal number is stated to be between $1.25 S^{R}$ and $0.07 S^{L}$ :

$$
\begin{aligned}
& S^{R}=2 \sqrt{2^{s_{L}}} \\
& S^{L}=34.8 \sqrt{2^{n_{L}}}+14 n_{L}-11 \log _{2} n_{L}+2
\end{aligned}
$$

where $n_{L}=\log _{2} m_{L}$. This contrasts with Bartlett [50] who states that the number of synapses should linearly increase with the number of training sets.

When the structure of the network is set, the weights of the synapses must be initialized before backprogation training begins. Nguyen and Widrow [52] demonstrated an initialization algorithm that was shown to improve the training speed. Their algorithm uniformly distributes weights across the synapses as a function of the number of neurons in the layer [47]. They demonstrated the improvement in training speed with their 'truck backer upper' problem; the time for training with a set of 'thousands' reduced from 2 days to 4 hours [53]. They initialize the weights in four steps: 
Step 1 Compute a scaling factor, $\gamma=0.7 \sqrt[n]{n_{1}}$ that is a function of the number of components in the input layer $n_{0}$ and neurons in the hidden layer $n_{1}$

Step 2 Initialize the weights $w_{i j}$ with random numbers between -0.5 and 0.5

Step 3 Reinitialize the weights with the scaling factor

$$
w_{i j}=\gamma \frac{w_{i j}}{\left.\sqrt{(} \sum_{i=1}^{n_{1}} w_{i j}^{2}\right)}
$$

Step 4 The bias on the $i$ th neuron is randomly set to be between $-w_{i j}$ and $w_{i j}$

\subsection{Backpropagation Learning}

The MLP is trained with backpropagation $[47,48,54]$ to emulate a desired signal or pattern. The backpropagation algorithm, otherwise known as the generalized delta rule, updates the synaptic weights after the training patterns are presented until the error signal reduces to a predefined value. An epoch refers to the cycle of presenting a set of training patterns and updating the weights. The number of training patterns will influence the architecture of the network. A network is trained to respond to one or more training patterns after several epochs until the energy function, $E$, is minimized:

$$
E=\frac{1}{2}(\mathbf{d}-\mathbf{y})^{T}(\mathbf{d}-\mathbf{y})
$$

The synapses connect the $i^{\text {th }}$ input to the $j^{\text {th }}$ neuron in the layer. The synaptic weights, $w_{j i}$ of each layer, $s=1,2, \ldots, S$, are updated for the next epoch, $k+1$, according to the steepest-descent gradient approach. The update begins with the output layer, $S$, as the error signal is produced from its response. For this report, the derivation of 
the learning rule equation is not presented for the sake of brevity and only the final equation is provided:

$$
\Delta w_{j i}^{S}=\mu^{S} \delta_{j}^{S} u^{S-1}
$$

or

$$
w_{j i}^{S}(k+1)=w_{j i}^{S}(k)+\mu^{S} \delta_{j}^{S} u^{S-1}
$$

where the local error, or delta $\delta$, is given by:

$$
\delta_{j}^{S}=e^{\prime}\left(v_{j}^{S}\right)
$$

The learning rate, $\mu$, determines the magnitude of the update step and is chosen to be $\mu>0$. A small learning rate will slowly change the weights and will require a large number of epochs to complete the training. A large learning rate parameter will increase the speed of the training but can cause the algorithm to become unstable. The steepest descent gradient is applied to hidden layers in a similar fashion:

$$
w_{j i}^{s}(k+1)=w_{j i}^{s}(k)+\mu^{s} \delta_{j}^{s} u^{s}
$$

with $\delta$ is given by:

$$
\delta_{j}^{s}=\left(\sum_{h=1}^{n_{s+1}} \delta_{h}^{s+1} w_{h i}^{s+1}\right) g^{\prime}\left(v_{j}^{s}\right)
$$

where $h$ is the axon from the $j^{\text {th }}$ neuron in layer $s$. 


\section{Chapter 4}

\section{Method}

The preceding chapters presented the background information needed to develop a neural network for estimating the regolith parameters. This chapter presents the process how the neural network was developed and tested. The first section describes the motor controllers and software interface for Kapvik's instrumented chassis; the software interface provides the sensor inputs required by the neural network. The second section describes how the training set was developed for training the neural network; the training set is derived from terramechanics theory. The third section describes how the neural network is constructed and trained in Matlab.

\subsection{Kapvik's Motor Controller Interface}

This section presents the motor controller software interface for Kapvik. The motor controllers are connected together by a Controller Area Network (CAN) bus and to a Linux-based host by RS-232. A software interface implements the commands to control the wheels and sensor mechanisms. The development of the motor controller software interface forms the basis for solving the research topic of this thesis. This chapter describes the motor controllers, the motor assemblies that are controlled, the CAN bus, and the software interface. 


\subsubsection{Motor and Wheel Assembly}

The motor and wheel assembly, as shown in Figure 16, is the "flight" version to be used on Kapvik's analog mission. The motors were selected by Setterficld [6].

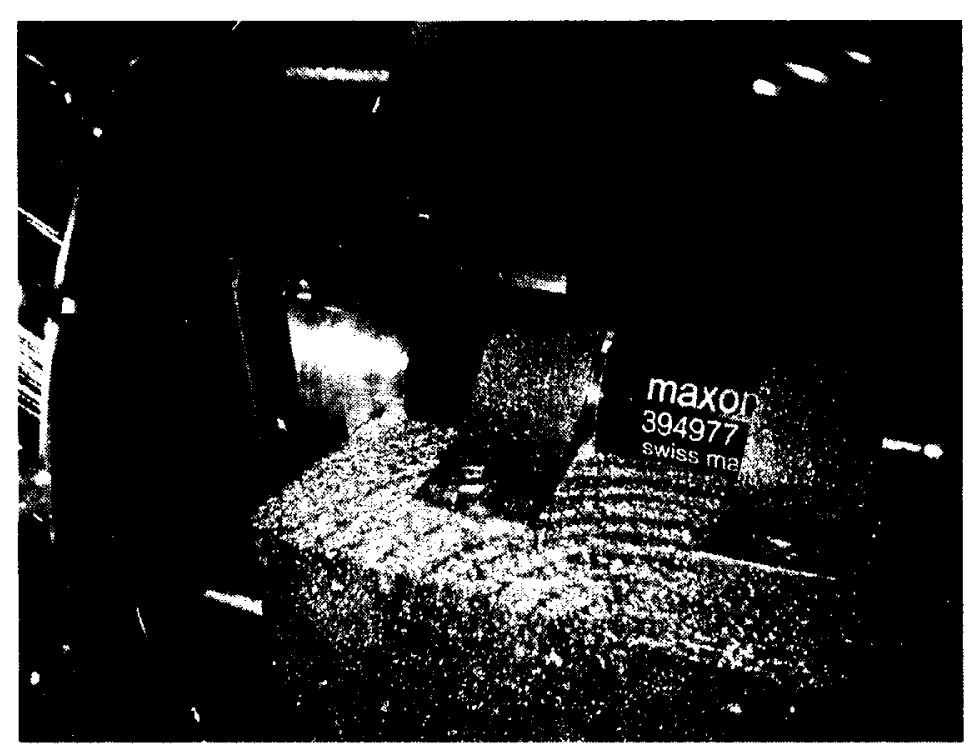

Figure 16: A Maxon Motor brushed DC motor drives a $15 \mathrm{~cm}$ diameter wheel

An encoder and gear set are attached to the motor. The encoder has a resolution of 500 counts per turn for a quadrature count (qc) of 2000 per revolution. A planetary gear head has 14:1 gear ratio; a harmonic drive has a 100:1 gear ration. The motor drives a wheel that is $15 \mathrm{~cm}$ in diameter. These values result in the following parameters used for the motor command:

- A total of 2,800,000 qc per revolution; 445634 qc per radian;

- Wheel circumference is $47.124 \mathrm{~cm}$; 1 wheel revolution is $47.124 \mathrm{~cm}$ translation;

- $59,420 \mathrm{qc} / \mathrm{cm}$; and

- A speed command of 1400 RPM translates to an output of 1 RPM, or $47.124 \mathrm{~cm} / \mathrm{min}$. 


\subsubsection{Maxon Motors EPOS 24/1 Motor Controller}

The Maxon EPOS 24/1 controllers were selected for their low mass, small form factor, and compatibility with the motors. The use of the EPOS controllers with Maxon motors is fully developed and documented, eliminating any interface development between the motors and controllers. All motors are controlled using the same type of controller which further reduced the software development time. Since each controller is a self contained unit they satisfied another requirement, design modularity. Additional motor controllers could be added as additional nodes on a CAN Bus.

CSA required Kapvik to be stored in temperatures from $-40^{\circ} \mathrm{C}$ to $+50^{\circ} \mathrm{C}$ and operate at $-20^{\circ} \mathrm{C}$ to $+40^{\circ} \mathrm{C}$. The lower bound of temperatures corresponds to expected conditions in Northern Canada and equatorial Mars. In addition, the entire rover had to be designed in a way that provided a "path to flight", i.e. it had to use components that have a suitable space qualified counterpart, or demonstrate suitability for space application. The chosen motor controllers have a rated operating temperature between $-10^{\circ} \mathrm{C}$ and $45^{\circ} \mathrm{C}$. This is a narrow window when compared to the overall required temperature range for the rover. Kapvik has a limited power budget of $30 \mathrm{~W}$ due to the constraints of being a micro-rover. This is the motivation behind a passive thermal control system. The Maxon motors are rated down to $-30^{\circ} \mathrm{C}$; however, the EPOS $24 / 1$ controllers are rated to only $-10^{\circ} \mathrm{C}$. The motor and controller pair's performance was characterized in an effort to determine how tolerant the motor control would be at sub-rated temperatures. The results of this testing show that the motor controllers can operate at sub-rated temperatures. The results of thermal testing are provided in Appendix B.

The EPOS 24/1, as shown in Figure 17, provides adjustable current, speed, and position control for a single DC motor. The motor controller accepts reference commands and activates the motor with closed-loop PI or PID control. The controller 
gains are programmable and can be adjusted during operation. The motor and controller performance characteristics and constraints are stored internally, and are also programmable and adjustable during operation. This allows for motor performance to be tuned for specific environmental or operational conditions. The controllers are capable of three primary control modes: constant current, constant velocity, and fine position control. The constant velocity mode is used to keep each of the Kapvik wheels driven at the same rotational velocity. This PI control mode samples the encoder and drawn current data at $1 \mathrm{kHz}$ to maintain a fixed rotational wheel velocity. The fine position control mode is similar in that the controller maintains the motor at a constant whed velocity. The difference is the control scheme takes into account initial position and final position. This PID control mode samples the encoder and drawn current data at $1 \mathrm{kHz}$ and is used for fine position control of the vision system and laser scanner position mechanisms. The fixed current mode is not presently used for any control mode for Kapvik.

\subsubsection{Communication Network}

A CAN bus links the six controllers to facilitate the dissemination of commands from the Linux-based master to the network of controller slaves via an RS232-CAN gateway. The commands are sent, via RS232, to the first node in the CAN network. This node performs the role of a CAN gateway and interprets all of the commands and translates them to CAN communication frames. CAN frames are sent throughout the CAN network. Each node on the network reads all of the frames but only accepts those that are designated for its specific node identification number. 


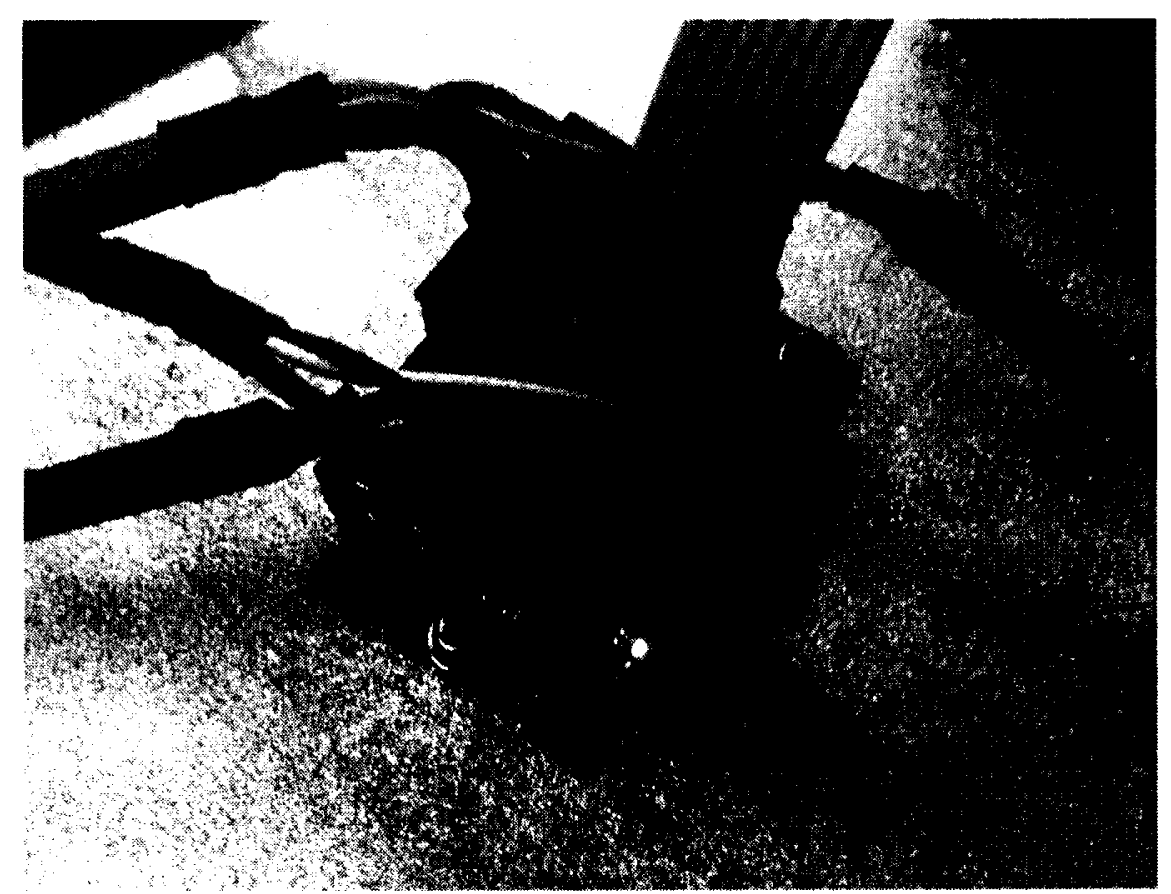

Figure 17: The Maxon Motor EPOS 24/1 motor controller. Each controller has power, data and communications connections. An LED indicates the function state of the controller

\subsubsection{Implementation}

The motor controller software interface was written in $\mathrm{C} / \mathrm{C}++$ for a Linux-based host. The host connects to one motor controller via RS232. This first controller, known as the gateway, interprets the commands and sends them along the CAN bus as CAN communication frames. Each additional motor controller on the CAN bus is assigned a specific node number. In the software, each motor can be individually controlled by addressing commands to a specific node. For Kapvik, there are nine motors: six for the wheels, two for the camera pan tilt unit, and one for the laser tilt unit.

The software was written to be interfaced with either the Linux development host or Kapvik's Player drivers. Player is an open-source robotic device server to interface with sensors and actuators [55]. The Player drivers were written by MPB Communications; the lower-level code had to be written to meet MPB's interface 
requirements. A simple command line interface accessed the lower-level code for internal development, testing, and data acquisition purposes.

The soltware interface sends commands that are interpreted by the firmware on the motor controller. The firmware allows the motor controller to operate in different states and operational modes. The software first initializes the motor controllers on the CAN bus. This initialization sets operating mode and the motor actuation speed. After initialization, either the wheels, camera pan tilt unit, or laser tilt unit can be operated. The software interface allows several wheel settings and operations: setting the default wheel speed; "joystick" operation for variable left-side and right-side wheel speeds; fixed-duration traversing; and data acquisition. Each low-level script can be accessed from either the Player or command line interfaces.

\subsection{Parameter Estimation with a Neural Network}

This section outlines the method of using a neural network to estimate terrain parameters in the following steps:

Step 1 Define the number of neurons in the hidden layer

Step 2 Initialize the synaptic weights with the Nguyen-Widrow algorithm

Step 3 Define the training goal

Step 4 Present input pattern from training set and compare response to desired response

- The vector input signal, $\mathbf{x} \in \Re^{n \times 1}=[W, i, I]$ feeds into the hidden layer

- For each hidden neuron:

- $\mathbf{x} \in \Re^{n \times 1}=[W, i, I]$ is multiplied by the synaptic weights, $\mathbf{w}_{\mathbf{q}} \in \Re^{n \times 1}$

- The $x_{0}=1$ bias is multiplied by its respective synaptic weight $w_{q 0}$ 
- The output of the summation junction, $v_{q}$, is then passed through an activation function, $g_{b s}\left(v_{q}\right)=\frac{1}{1+e^{-\alpha v_{q}}}$

- The output of the activation function, $u_{q}$ is the axon

- The hidden layer fires synapses into the output layer which provides the vector response signal, $\mathbf{y} \in \Re^{m \times 1}=[c, \tan \phi]$

- The network output $\mathbf{y} \in \Re^{m \times 1}=[c, \tan \phi]$ is compared to the desired output $\mathbf{d} \in \Re^{m \times 1}=[c, \tan \phi]$

- The error between the desired output and the network output $\mathbf{e}=\mathbf{d}-\mathbf{y}$ becomes the basis for weight adjustments

Step 5 Adjust weights with backpropagation until the defined training goal is met

It should be noted that the network output is $[c, \tan \phi]$ and is post-processed to give an angular value of $\phi$.

\subsubsection{Hidden Layer Sizing}

The number of neurons in the hidden layer is based upon the size of the training set. The range of optimal hidden neurons is determined from Equations 52 and 53, and Bartlett's linear relation (each neuron has six connections: 3 input, 2 output and 1 bias) [50]. The neural network was trained 100 times for each number of hidden neurons in the range. The neuron number that resulted in the best mean network performance (lowest mean mean-square-error (MSE)) was set as the optimal hidden layer size. Matlab Neural Network Toolbox is used for the neural network performance testing.

The training goal was set to be an MSE of 0.005 , or 10,000 epochs, whichever came first. Several runs showed the network would converge after approximately 5000 epochs, and runs for 100,000 epochs showed no further improvement. The steps to get the optimal number of hidden neurons are as follows: 
Step 1: Get size of training set $S_{\text {train }}$

Step 2: Get range of hidden neurons for statistical network training

Step 3: Run the neural network 100 times to determine the mean MSE

Step 4: Repeat Step 3 for range of neurons

Step 5: The hidden neuron number that results in the lowest MSE is selected as the optimal size

\subsubsection{Neural Network Training Set}

The neural network must first be trained in order to be used for parameter estimation. A training set is created in Matlab using the rover wheel dimensions, a set of terrain parameters $[c, \phi, K]$, and wheel-terrain interface variables $[z, i, I]$. A set of equations solves for the resultant weight on wheels that equates to those conditions. The procedure is given as follows:

Step 1: Define wheel dimensions $r_{W}$ and $w_{W}$

Step 2: Get $[c, \phi, K]$ from set of terrain classes

Step 3: Calculate $z_{S S}$ from $z$ and $i$ training set value

$$
z_{S S}=\left(\frac{1+i}{1-0.5 i}\right) z
$$

Step 4: Calculate $\theta_{C}$ from $z_{S S}, r_{W}$, and $w_{W}$

$$
\theta_{C}=\cos ^{-1}\left(1-\frac{z_{S S}}{r_{W}}\right)
$$


Step 5: Calculate $j$ from $i$ training set value

$$
j=r_{W}\left(\theta_{1}-\sin \left(\theta_{C}\right)+\mathbf{i}\left(\sin \left(\theta_{C}\right)\right)\right)
$$

Step 6: Calculate $T$ from $I$ training set value

$$
T=\kappa \zeta_{P G} \zeta_{H D} \eta_{P G} \eta_{H D} I
$$

Step 7: Calculate $\tau_{m}$

$$
\tau_{m}=\frac{2 T}{w_{W} r_{W}^{2} \theta_{C}}-\frac{c}{2}
$$

Step 8: Calculate $\sigma_{m}$

$$
\sigma_{m}=\frac{\frac{\tau_{m}}{1-e^{-j / K}}-c}{\tan \phi}
$$

Step 9: Calculate $W$

$$
\begin{gathered}
W=\frac{w_{W} r_{W}}{\theta_{C}}\left(\theta_{C} c-2 \sigma_{m}-2 \sigma_{m} \cos \left(\theta_{C}\right)-2 \tau_{m} \sin \left(\theta_{C}\right)+\right. \\
\left.4 \sigma_{m} \cos \left(\theta_{C} / 2\right)-2 c \sin \left(\theta_{C} / 2\right)+4 \tau_{m} \sin \left(\theta_{C} / 2\right)\right)
\end{gathered}
$$

Step 10: Create Input $[W, T, i]$ and Output $[c, \tan \phi]$ pair

Step 11: Repeat Steps 6 - 10 for each $I$ in the motor current training set

Step 12: Repeat Steps $5-11$ for each $i$ in the wheel slip training set

Step 13: Repeat Steps $3-12$ for each $z$ in the wheel sinkage training set

Step 14: Repeat Steps 2 - 13 for each terrain class 
Step 15: Randomize order of training pairs

The variables to generate the training set included the terrestrial soils given in Table 6 and representative values for Kapvik as observed during testing: motor current training values $(\mathrm{I}=45,60,75,90 \mathrm{~mA})$, wheel slip training values $(\mathrm{i}=0.01,0.02,0.03)$, and wheel sinkage training values $(\mathrm{z}=0.005,0.01,0.015,0.02 \mathrm{~m})$. These variations resulted in 192 training pairs. Several training runs showed that randomizing the order of the training pairs improved the network's ability to converge. The neuron range for statistical analysis was from 32 to 39 neurons; 35 neurons were found to have the lowest mean MSE. The 3:35:2 neural network was trained by backpropagation with momentum and learning updating for 10,000 epochs and an MSE of 0.0241 was reached.

Table 6: Terrestrial soil parameters used in initial neural network training

\begin{tabular}{|c|c|c|c|}
\hline Soil & Cohesion $c(\mathrm{kPa})$ & Shearing Angle $\phi$ & $K(\mathrm{~m})$ \\
\hline LETE Sand & 1.22 & $30.3^{\circ}$ & 0.0116 \\
\hline Sandy Loam & 3.15 & $30.0^{\circ}$ & 0.0420 \\
\hline Clayey Soil & 4.12 & $11.8^{\circ}$ & 0.0254 \\
\hline Medium Soil & 6.41 & $25.7^{\circ}$ & 0.0238 \\
\hline
\end{tabular}

The network was trained again with a greater number of variables to increase the size of the training set: motor current $(I=50,60,70,80,90,100 \mathrm{~mA})$, wheel slip ( $\mathrm{i}$ $=0.01,0.02,0.03)$, and wheel sinkage values $(\mathrm{z}=0.005,0.0075,0.01,0.0125,0.015$, $0.0175,0.02 \mathrm{~m}$ ). These variations resulted in 504 training pairs. The neuron range for statistical analysis was from 59 to 84 neurons; 64 neurons were found to have the lowest mean MSE. The 3:64:2 neural network was trained by backpropagation with momentum and learning updating for 10,000 epochs and a MSE of 0.0251 was reached. An increase of $178 \%$ more neurons increased the MSE by $4 \%$. It was found that further increasing the size of the training set led to a degradation in performance. 
The network size was set to 3:64:2 for terrain parameter estimation.

\subsection{Field Tests at Petrie Island}

The SEEG team tested Kapvik's mobility system, as shown in Figure 18, over two days in September 2011. Testing was conducted at Petrie Island, a municipal park located in the east end of Ottawa along the Ottawa River. The park has a flat sandy section (approximately $100 \mathrm{~m}$ in length) which was found to be suitable for testing. The field testing was conducted according to the verification test plan to verify the mechanical performance of Kapvik's instrumented mobility system. The test plan required Kapvik to be loaded to its design mass of $30 \mathrm{~kg}$ and traverse a variety of obstacles, distances, and terrain conditions. For each test condition, Kapvik's desired speed was set to $2.2 \mathrm{~cm} / \mathrm{s}$. The motor controller interface software collected the wheel load, current draw, motor speed, and rocker-bogie angle data at, $2 \mathrm{~Hz}$.

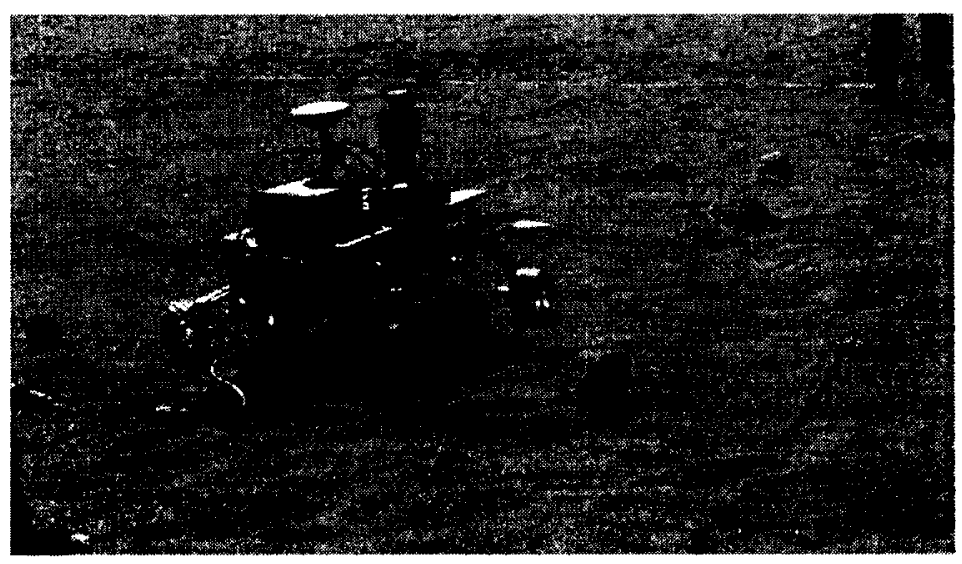

Figure 18: Testing Kapvik's mobility system at Petrie Island

Kapvik ran two additional tests at Petrie Island: one $10 \mathrm{~m}$ traverse over prepared terrain and one $10 \mathrm{~m}$ traverse over unprepared terrain. The prepared terrain consisted of sand that had been raked level. The unprepared terrain was as it was found: uneven with windswept footprints. The data from these additional tests was used for post-test 
analysis but not for on-line operation nor navigation purposes. 


\section{Chapter 5}

\section{Results}

This chapter presents the results from field testing at Petrie Island. The data collected from the Petrie Island tests were used in the trained neural network for estimating the terrain parameters. The network maps three sensed rover inputs to two terrain parameters.

\subsection{Estimating Petrie Island Terrain Parameters with Kapvik}

This section describes the results from estimating the terrain parameters with the trained neural network using data collected during Kapvik's mobility tests. The mobility testing was performed before Kapvik was fully integrated, and before on-line terrain parameter estimation was considered. A speckle velocimeter [32] was not available to provide the rover velocity to compare against the motor speed to calculate the slip ratio. The slip ratio was derived as follows: Kapvik was commanded to traverse $10 \mathrm{~m}$ as determined by the rotation speed of the wheels; the motor control interface software calculated how long to leave the motors running at a constant speed $(2.2 \mathrm{~cm} / \mathrm{s})$ for the wheels to have rotated the equivalent of $10 \mathrm{~m}(454.54 \mathrm{~s})$; the final distance travelled was $9.75 \mathrm{~m}$ for an average slip ratio of 0.025 . The constant slip 
ratio of 0.025 was appended to the motor current and wheel load data sets consisting of 909 data points were recorded during the traverse.

The 500 th data set was selected from the 909 ; from that set, the current ( $\mathrm{I}=$ $80 \mathrm{~mA}$ ) and wheel load $(\mathrm{W}=31.6 \mathrm{~N}$ ) from the 5 th wheel (wheel orientation shown in Figure 19) were selected as a first test point for the 3:64:2 neural network. These two values, along with the averaged slip ratio of 0.025 , were entered into the trained 3:64:2 neural network. The output gives the estimate of cohesion to be $3352 \mathrm{~N}$ and the shearing angle to be $28.6^{\circ}$. Both of these results are consistent with sandy loam shown in Table 7.

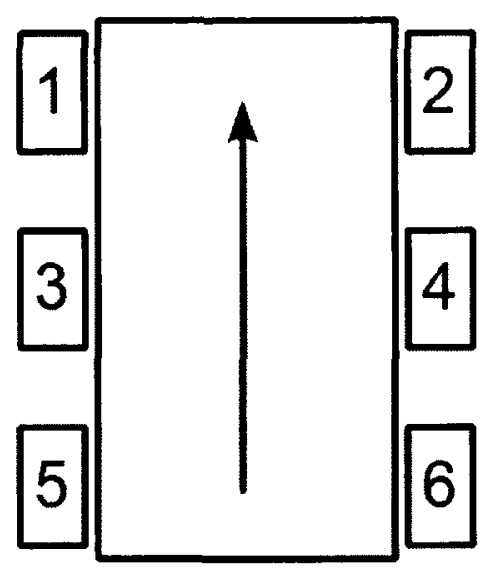

Figure 19: Wheel numbering for rover showing forward direction of motion

It should be noted that the terrain parameters were not measured at the time of the mobility testing and that the estimated parameters were compared only to the reported values in Table 7 . In his review of soil strength measurement techniques, Okello [56] highlights the variability of terrain parameter estimation by different techniques. The bevameter technique most closely simulates wheel-terrain interaction; however, measurements are static and do not account for slippage or slip-sinkage that dynamically occur in wheel-terrain interaction. Furthermore, Okello states that "there seems to be no standard, proven and above all, reliable technique currently available that can be universally applied to measure soil strength parameters appropriate to 
Table 7: Reported parameters of various terrains

\begin{tabular}{|l|c|c|}
\hline & Cohesion $c(\mathrm{kPa})$ & Shearing Angle $\phi$ \\
\hline LETE Sand & 1.15 & $31.5^{\circ}$ \\
\hline LETE Sand & 1.39 & $30.6^{\circ}$ \\
\hline Sand & 1.3 & $31.1^{\circ}$ \\
\hline Sandy Loam & 3.3 & $33.7^{\circ}$ \\
\hline Sandy Loam & 3.4 & $24.1^{\circ}$ \\
\hline Sandy Loam & 4.3 & $22.7^{\circ}$ \\
\hline Sandy Loam & 3.7 & $29.8^{\circ}$ \\
\hline Sandy Loam & 3.2 & $30.5^{\circ}$ \\
\hline Loam & 3.45 & $30.1^{\circ}$ \\
\hline Clayey Soil & 3.45 & $11.0^{\circ}$ \\
\hline Clayey Soil & 7.58 & $14.0^{\circ}$ \\
\hline Soft Soil & 3.71 & $25.6^{\circ}$ \\
\hline Medium Soil & 6.89 & $29.0^{\circ}$ \\
\hline Medium Soil & 8.62 & $22.5^{\circ}$ \\
\hline
\end{tabular}

prediction of vehicle performance" [56]. For this reason, the exact terrain parameters need not be measured and reasonable comparisons to reported values are sufficient.

The entire data set for all six wheels on prepared terrain was processed. The results for Wheel 3 are shown in Figures 20 and 21. The results for additional wheels are shown in Appendix A. Figure 20 shows the cohesion to be mostly between 3200 and $4000 \mathrm{~Pa}$ with a mean of $3726 \mathrm{~Pa}$ and relative standard deviation (RSD) of $6.4 \%$, which is to be expected from the terrain at Petrie Island. Figure 21 shows the shearing resistance angle to be between $26^{\circ}$ and $30^{\circ}$ with a mean of $27.8^{\circ}$ and $\mathrm{RSD}$ of $6.5 \%$, which is consistent with sandy loam. Table 8 lists the estimates from all six wheels. The RSD for the estimates can be compared to the RSD of sensor data in Table 9.

The three largest deviations in shearing resistance angle correlate to the three 


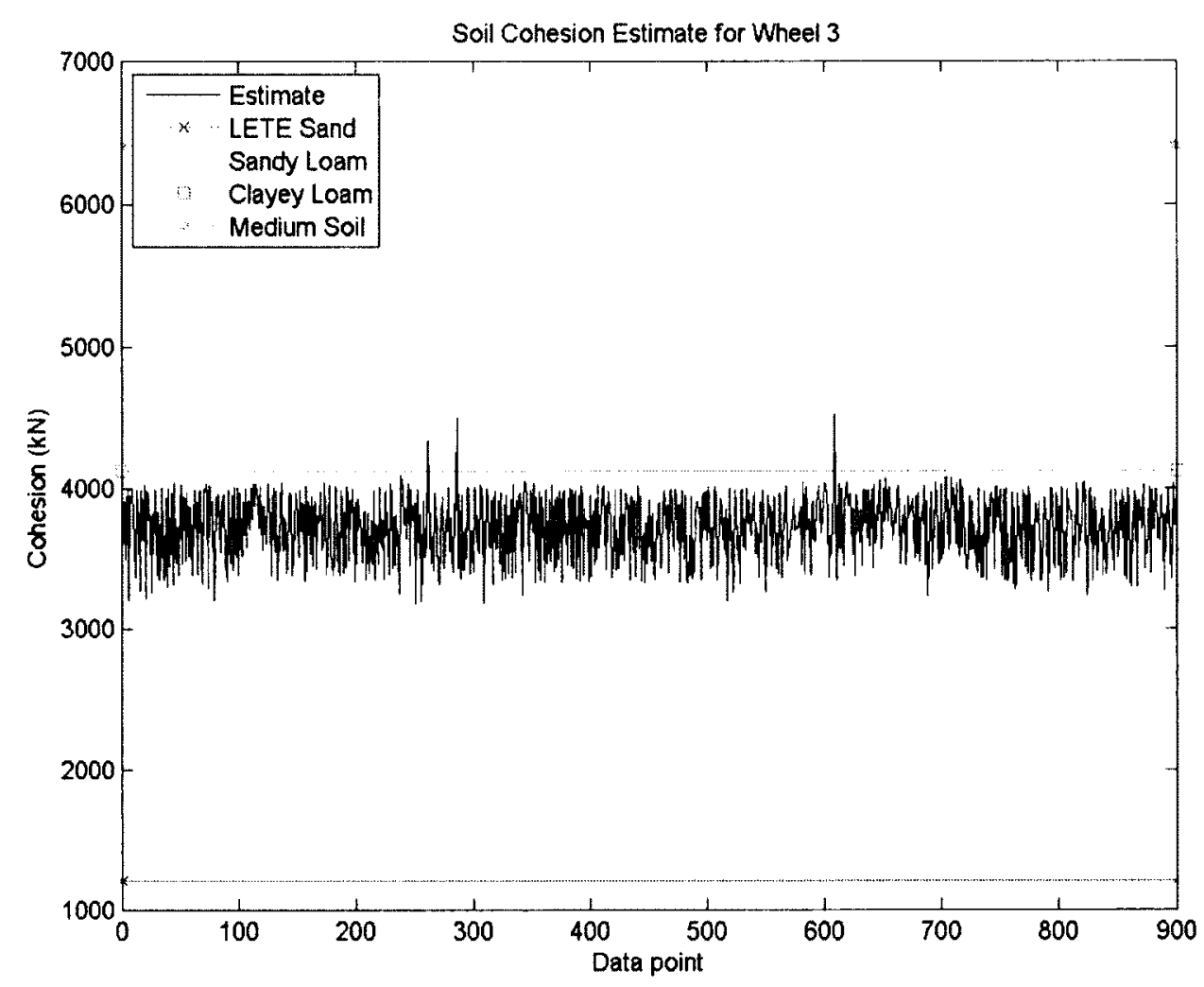

Figure 20: Terrain cohesion estimate for Wheel 3 on prepared terrain

spikes in cohesion. This is attributed to current data noise in which the reported current dropped momentarily. The drop in current translates to a drop in required torque to move the wheel which would be observed if the terrain had a higher cohesion. The neural network would report that to be more clayey loam-like based on the training set. 


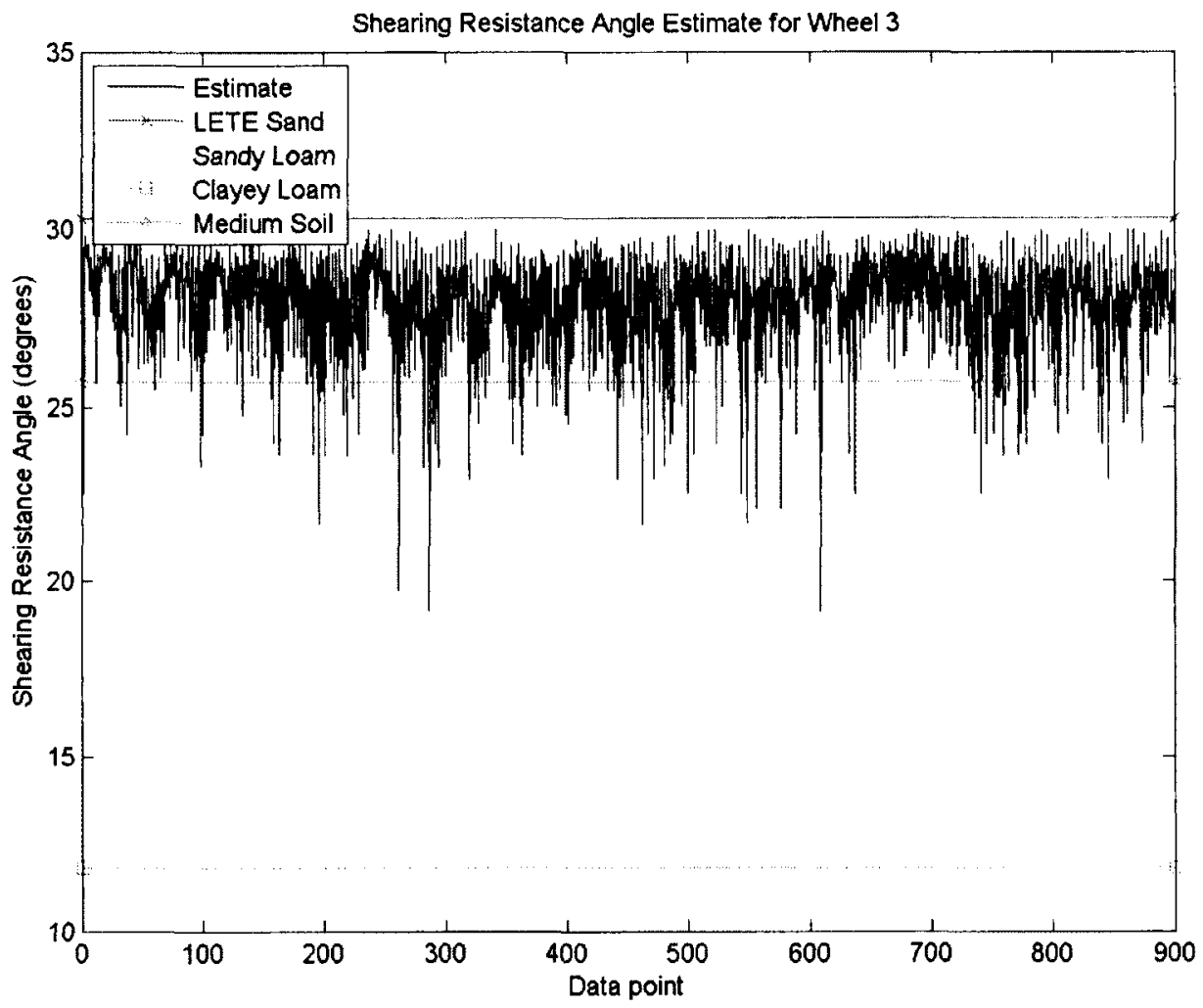

Figure 21: Terrain shearing resistance angle estimate for Wheel 3 on prepared terrain

Table 8: Terrain parameter estimates for prepared terrain

\begin{tabular}{|c|c|c|c|c|}
\hline Wheel & Mean Cohesion $c(\mathrm{kPa})$ & $\% \mathrm{RSD}$ & Mean Shearing Angle $\phi$ & $\% \mathrm{RSD}$ \\
\hline 1 & 3832 & $7.6 \%$ & $27.5^{\circ}$ & $8.4 \%$ \\
\hline 2 & 3849 & $13.1 \%$ & $26.6^{\circ}$ & $13.2 \%$ \\
\hline 3 & 3726 & $6.4 \%$ & $27.8^{\circ}$ & $6.5 \%$ \\
\hline 4 & 3644 & $7.8 \%$ & $26.5^{\circ}$ & $9.4 \%$ \\
\hline 5 & 3641 & $6.7 \%$ & $27.7^{\circ}$ & $6.9 \%$ \\
\hline 6 & 3737 & $11.5 \%$ & $26.2^{\circ}$ & $11.4 \%$ \\
\hline
\end{tabular}


Table 9: Relative standard deviation (RSD) for sensor data collected on prepared terrain

\begin{tabular}{|l|c|c|}
\hline Wheel & \%RSD of Current & \%RSD of Weight on Wheels \\
\hline 1 & $31.2 \%$ & $14.2 \%$ \\
\hline 2 & $38.8 \%$ & $11.9 \%$ \\
\hline 3 & $31.3 \%$ & $9.6 \%$ \\
\hline 4 & $36.5 \%$ & $7.0 \%$ \\
\hline 5 & $31.2 \%$ & $6.7 \%$ \\
\hline 6 & $35.1 \%$ & $7.2 \%$ \\
\hline
\end{tabular}


The data collected from the traverse over unprepared terrain was then inputted to the neural network. The results for Wheel 3 are shown in Figures 22 and 23. The results for additional wheels are shown in Appendix A. Figure 22 shows the cohesion to be mostly between 3200 and $4000 \mathrm{~Pa}$ with a mean of $3722 \mathrm{~Pa}$ and RSD of $6.7 \%$, which is to be expected from the sand at Petrie Island. Figure 23 shows the shearing resistance angle to be between $26^{\circ}$ and $30^{\circ}$ with a mean of $27.8^{\circ}$ and $\mathrm{RSD}$ of $6.5 \%$, which is consistent with sandy loam. Table 10 lists the estimates from all six wheels. The RSD for the estimates can be compared to the RSD of sensor data in Table 11.

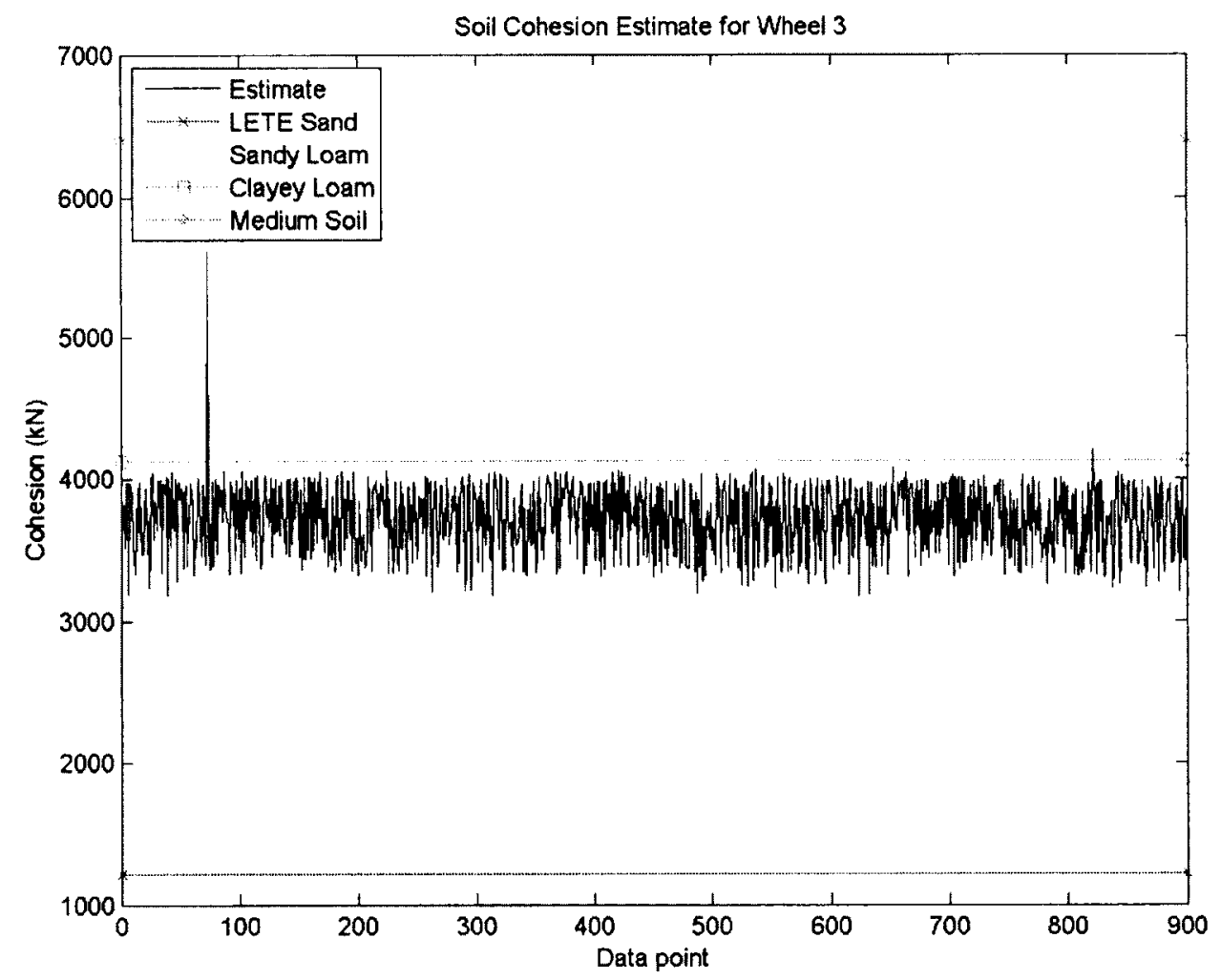

Figure 22: Terrain cohesion estimate from Wheel 3 on unprepared terrain

These results show that there is little difference in the estimates between prepared and unprepared terrain. In both cases, all six wheels given similar results, as expected. The RSD is similar between the cohesion and shearing resistance angle estimates for 




Figure 23: Terrain shearing resistance angle estimate from Wheel 3 on unprepared terrain

each wheel. Comparing the results to the sensor noise, shown in Tables 9 and 11, indicates that the sensor noise influences the estimates; higher sensor noise results in greater variance in the estimates.

In both cases, wheel 2 had the noisiest results as shown by its high RSD. In fact, the wheels on the right side of the rover had noisier values compared to the left side. The current drawn noise appears to have a greater influence than the wheel weight noise. This sensor noise could be attributed to noisier sensors or due to mechanically induced vibrations on the right side of the rover during its traverse.

The shearing resistance angle estimates have a downward bias. The output of the neural network will converge towards one of the training set values. In this case, the 
Table 10: Terrain parameter estimates for unprepared terrain

\begin{tabular}{|c|c|c|c|c|}
\hline Wheel & Mean Cohesion $c(\mathrm{kPa})$ & \%RSD & Mean Shearing Angle $\phi$ & $\% \mathrm{RSD}$ \\
\hline 1 & 3861 & $10.0 \%$ & $27.0^{\circ}$ & $10.4 \%$ \\
\hline 2 & 3931 & $17.5 \%$ & $25.8^{\circ}$ & $16.3 \%$ \\
\hline 3 & 3722 & $6.7 \%$ & $27.8^{\circ}$ & $6.5 \%$ \\
\hline 4 & 3693 & $9.4 \%$ & $26.3^{\circ}$ & $10.3 \%$ \\
\hline 5 & 3632 & $6.1 \%$ & $27.7^{\circ}$ & $6.2 \%$ \\
\hline 6 & 3711 & $7.6 \%$ & $27.2^{\circ}$ & $7.7 \%$ \\
\hline
\end{tabular}

Table 11: Relative standard deviation (RSD) for sensor data collected on unprepared terrain

\begin{tabular}{|c|c|c|}
\hline Wheel & \%RSD of Current & \%RSD of Weight on Wheels \\
\hline 1 & $33.4 \%$ & $16.1 \%$ \\
\hline 2 & $42.4 \%$ & $14.7 \%$ \\
\hline 3 & $31.6 \%$ & $9.3 \%$ \\
\hline 4 & $36.1 \%$ & $9.4 \%$ \\
\hline 5 & $30.7 \%$ & $6.6 \%$ \\
\hline 6 & $29.2 \%$ & $7.2 \%$ \\
\hline
\end{tabular}

training set values for shearing angle are $30.3^{\circ}, 30^{\circ}, 25.7^{\circ}$, and $11.8^{\circ}$. Most of the estimate points are between $25.7^{\circ}$ and $30.3^{\circ}$. The remaining points converge towards the fourth value at $11.8^{\circ}$. Therefore, the results that don't converge towards $25.7^{\circ}$ or $30.3^{\circ}$ will converge towards $11.8^{\circ}$ as shown by the figures. This downward bias can be explained by the noisy current data when the current values are low. Lower current values translate into less torque required, which can be interpreted as the more cohesive training value (clayey loam) that has the shearing resistance angle of $11.8^{\circ}$.

Next, the effect of changing slip was examined. When a rover encounters loose terrain, such as Opportunity did at Purgatory Ripple, it experiences high slip [34,35]. The trained 3:64:2 neural network was fed the sensor data from the prepared terrain 
test. However, instead of a constant slip ratio, the slip increases from $2.5 \%$ to $25 \%$ at time step 450 , and then from $25 \%$ to $95 \%$ at time step 600 . As shown in Figure 24, the output of the neural network shows the cohesion estimate to decrease when the slip increases, which is to be expected. When the slip increases to $95 \%$, the cohesion is estimated to be a mean value of $1164 \mathrm{~N}$. This drop in cohesion may result in insufficient traction and an immobilized rover. The estimated drop in cohesion occurs when the data is processed by the neural network.

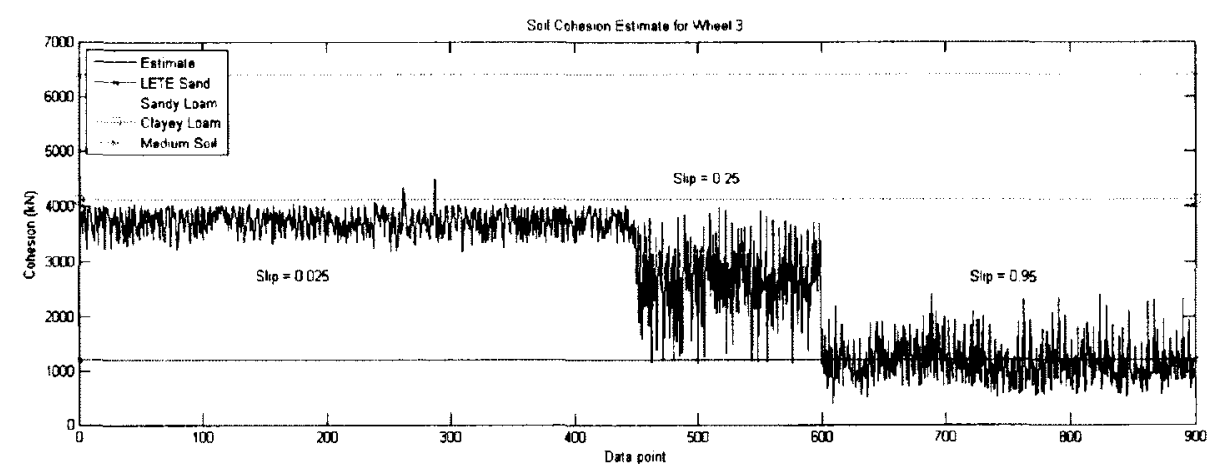

Figure 24: Terrain cohesion estimate with changing slip ratio for Wheel 3

The objective of estimating the terrain parameters is to detect when the cohesion or shearing angle decrease. A decrease in either one of these terrain parameters will result in a decrease in shear stress developed at the wheel-terrain interface. The consequence of decreased shear stress is the decrease in the maximum thrust developed by the rover wheels. When the developed thrust is insufficient to overcome terrain resistance, as was the case with Spirit, the rover will become immobilized.

Kapvik has a traverse speed similar to Mars rovers of similar size: $2 \mathrm{~cm} / \mathrm{s}$. This is slow enough to allow the traction controller to react to sensed drift material. The front wheels may come into contact with the drift material; the wheel sensors on those wheels would show an increase in tractive effort. The traction controller would interpret the sensor data of the front wheels with the neural network. It would determine that the terrain was drift material and prevent the rover from driving further into 
where it could be trapped. Another scenario would have the traction controller sense variations in terrain and operate the wheel motors accordingly to improve efficiency. The estimated regolith parameters would be converted into mobility metrics that are fed into the mapping utility. Weak terrain such as drift material would be highly penalized whereas compact terrain would be favourable. 


\section{Chapter 6}

\section{Conclusions and Recommendations}

The goal of this thesis is to provide evidence to support the research question given in Chapter 1.1:

Can a planetary micro-rover estimate terrain parameters online during its traverse phase without measuring the wheel contact angle $\theta_{C}$ or wheel sinkage $z$ ?

This supportive evidence was provided using terramechanics theory, multilayer perceptrons and Kapvik's instrumented micro-rover chassis. The terramechnics theory for a rigid wheel, similar to Kapvik, was presented in Chapter 2. Similar research has shown that visual measurements of the wheel contact angle and wheel sinkage are required to estimate the regolith parameters. Neural networks are capable of mapping inputs to outputs through a hidden layer of neurons by adjusting the weights of the connecting synapses. Chapter 3 presents the multilayer perceptron, and backpropagation algorithm used to train the neural network. The inputs to the trained neural network are sensor data taken from Kapvik's motor controllers via the motor controller software interface. Chapter 4 presented the motor controller and software created to control Kapvik's mobility system and acquire sensor feedback from each wheel: analogue load cells, motor current draw, and motor shaft rotation speed. 
This sensor data, when applied to the trained neural network, resulted in terrain parameters expected to be found at the Petrie Island test site. These results were presented in Chapter 5 .

The collected sensor data for the Kapvik test did not include wheel contact area or wheel sinkage; the three sensor data points were collected online during Kapvik's traverse phase. These three inputs were fed into a trained neural network that outputted two terrain parameter estimates. These two parameters determine the maximum tractive effort that can be developed between the wheel and the terrain interface. Online knowledge of these parameters can be used for traction control and for detecting non-geometric obstacles.

The method for estimating the terrain parameters was not demonstrated online due to the contractual time constraints associated with the Kapvik project. However, there is minimal computational effort in running the neural network. The computational effort is greatest during neural network training. However, this training would be performed prior to installation on a micro-rover. Once installed on the micro-rover, results are processed as they are collected as the neural network remains fixed in its current implementation.

\subsection{Contributions}

1. The creation of a proof-of-concept to estimate terrain cohesion and shearing resistance angle on-line using a trained neural network. This method allows terrain parameters to be estimated without the need for measuring the wheel sinkage or wheel contact angle. Using a neural network is novel to terrain parameter estimation.

2. The development of the motor controller network and software interface for the Kapvik micro-rover. This software was also used in the environmental testing of 
the motor and controller pair for validating the use of these COTS components for sub-rated conditions.

\subsection{Future Work}

Following discussions with engineers at JPL, there is a possibility of obtaining data from the presently operational MER Opportunity. A neural network will need to be trained using MER parameters and the previously estimated Mars regolith parameters. The other possibility discussed was writing a script that could be uploaded to Opportunity to test in-situ. In-situ testing would require far more software development, but the results would be valuable validation.

\subsection{Recommendations}

It is hoped that continuing to apply neural computing techniques to terramechanics theory will allow for more robust parameter estimation. The current neural network uses three sensors as inputs. Additional sensor data available on Kapvik, such as vibrations from an IMU, could also serve as inputs so long as there is a model on how different terrain produces those data. Similarly, the effect of elevation could be incorporated. The tests presented in this thesis occurred on level terrain and the neural network does not take elevation into account.

The parameter estimation method described in this thesis needs to be tested with known data of a known terrain. Bevameter measurements of the terrain will give a more precise baseline to compare the estimated terrain parameters. The error between the measured and the estimated parameters would give a better indication as to the validity of using MLPs for estimating the terrain parameters or at least estimating the variation in terrain parameters. The terrain would need to be measured at the same 
time as the wheel data is collected. One possibility is to test this research on Kapvik now that it is integrated with all of its components. The test could be performed at a location with similar terrain to that of Petrie Island. The wheel load and motor current would be collected as usual; the wheel slip would be calculated based on the measured motor shaft angular speed and the measured rover velocity. These three parameters would then be fed into the previously trained neural network during the traverse to estimate the local terrain parameters. The terrain parameters would be measured and compared to the estimates provided by the MLP.

One of the primary limitations to using a multilayer perceptron for estimating terrain parameters is the requirement for a training set. Prior knowledge of the terrain is required in order to generate a training set. A more diverse knowledge of terrain will allow for a more robust training set; however, the MLP is intended to be used for planetary exploration where there is little to no prior knowledge. For the Moon and Mars, there is sufficient knowledge to generate a basic training set that will allow for, at the very least, variations in the terrain to be detected. One recommendation to get around this limitation is to use unsupervised neural networks, such as self-organizing maps.

At present, the motor controller commands are written to communicate to the first CAN node via RS232 communication; all commands are written in RS232 frame lengths. This is an acceptable interim solution; however, it remains the communications bottleneck for the controller network. As observed in data collection functions, there is a limit on the sample rate for collecting useful data points such as current, speed and position. Faster communication between the Linux-based host and the CAN bus will allow for higher sampling rates. As such, all of the motor commands will need to be rewritten in the CAN frame structure; however, this can only be realized when a proper CAN-COM cable is acquired. Higher sampling rates may allow for random data noise to be filtered out. 


\section{List of References}

[1] T. Muro and J. O'Brien. Terramechanics - Land Locomation Vehicles. A.A. Balkema Publishers. ISBN 905809572X (2004).

[2] R. Team. "Characterization of the Martian Surface Deposits by the Mars Pathfinder Rover, Sojourner." Science 278(5344), 1765 1768. ISSN 00368075 (1997).

[3] L. L. Karafiath and E. A. Nowatzki. Soil Mechanics for Off-Road Vehicle Engineering. Trans Tech Publications. ISBN 0878490205 (1978).

[4] R. E. Arvidson, J. F. Bell, P. Bellutta, N. A. Cabrol, J. G. Catalano, J. Cohen, L. S. Crumpler, D. J. Des Marais, T. A. Estlin, W. H. Farrand, R. Gellert, J. A. Grant, R. N. Greenberger, E. A. Guinness, K. E. Herkenhoff, J. A. Herman, K. D. Iagnemma, J. R. Johnson, G. Klingelhöfer, R. Li, K. A. Lichtenberg, S. A. Maxwell, D. W. Ming, R. V. Morris, M. S. Rice, S. W. Ruff, A. Shaw, K. L. Siebach, P. A. de Souza, A. W. Stroupe, S. W. Squyres, R. J. Sullivan, K. P. Talley, J. A. Townsend, A. Wang, J. R. Wright, and A. S. Yen. "Spirit Mars Rover Mission: Overview and selected results from the northern Home Plate Winter Haven to the side of Scamander crater." Journal of Geophysical Research 115. ISSN 0148-0227 (2010).

[5] S. W. Squyres, R. E. Arvidson, D. Bollen, J. F. Bell, J. Brückner, N. A. Cabrol, W. M. Calvin, M. H. Carr, P. R. Christensen, B. C. Clark, L. Crumpler, D. J. Des Marais, C. D'Uston, T. Economou, J. Farmer, W. H. Farrand, W. Folkner, R. Gellert, T. D. Glotch, M. Golombek, S. Gorevan, J. A. Grant, R. Greeley, J. Grotzinger, K. E. Herkenhoff, S. Hviid, J. R. Johnson, G. Klingelhöfer, A. H. Knoll, G. Landis, M. Lemmon, R. Li, M. B. Madsen, M. C. Malin, S. M. McLennan, H. Y. McSween, D. W. Ming, J. Moersch, R. V. Morris, T. Parker, J. W. Rice, L. Richter, R. Rieder, C. Schröder, M. Sims, M. Smith, P. Smith, L. A. Soderblom, R. Sullivan, N. J. Tosca, H. Wänke, T. Wdowiak, M. Wolff, and A. Yen. "Overview of the Opportunity Mars Exploration Rover Mission to Meridiani Planum: Eagle 
Crater to Purgatory Ripple." Journal of Geophysical Research 111(E12). ISSN 0148-0227 (2006).

[6] T. P. Setterfield. "Instrumented Rocker-Bogie Chassis Design and Net Traction Estimation." MASc Thesis September, Carleton University (2011).

[7] M. Cross, C. Nicol, A. Qadi, and A. A. Ellery. "Application of COTS Components For Martian Surface Exploration." (2012).

[8] D. Shirley and J. Matijevic. "Mars Pathfinder Microrover." Autonomous Robots 2(4), 283-289. ISSN 0929-5593 (1995).

[9] B. Muirhead. "Mars rovers, past and future." In "2004 IEEE Aerospace Conference Proceedings (IEEE Cat. No.04TH8720)," pages 128 134. IEEE. ISBN 0-78038155-6.

[10] T. P. Rivellini. "Mars rover mechanisms designed for Rocky 4." In "The 27th Aerospace Mechanisms Symposium," (1993).

[11] J. Chottiner. "Simulation of a Six Wheel Martian Rover Called the Rocker Bogie." Msc thesis, The Ohio State University (1992).

[12] A. Kleiner. "Online learning terrain classification for adaptive velocity control." In "2010 IEEE Safety Security and Rescue Robotics," pages 1 7. IEEE. ISBN 978-1-4244-8898-8 (2010).

[13] C. Brooks and K. Iagnemma. "Vibration-based terrain classification for planctary exploration rovers." IEEE Transactions on Robotics 21(6), 1185 1191. ISSN 1552-3098 (2005).

[14] C. A. Brooks and K. D. Iagnemma. "Self-Supcrvised Classification for Planctary Rover Terrain Sensing." In "2007 IEEE Aerospace Conference," pages 1-9. IEEE. ISBN 1-4244-0524-6 (2007).

[15] M. Bekker. Introduction to Terrain-Vehicle Systems. University of Michigan Press (1969).

[16] J. Y. Wong. Terramechanics and Off-Road Vehicle Engineering. Elsevier, 2nd edition. ISBN 9780750685610 (2010).

[17] K. Yoshida, T. Watanabe, N. Mizuno, and G. Ishigami. "Slip, Traction Control , and Navigation of a Lunar Rover." In "Proceedings of the 7th International Symposium on Artificial Intelligence, Robotics and Automation in Space," (2003). 
[18] G. Ishigami, A. Miwa, K. Nagatani, and K. Yoshida. "Terramechanics-based model for steering maneuver of planetary exploration rovers on loose soil." Journal of Field Robotics 24(3), 233-250. ISSN 15564959 (2007).

[19] H. Shibly, K. Iagnemma, and S. Dubowsky. "An equivalent soil mechanics formulation for rigid wheels in deformable terrain, with application to planetary exploration rovers." Journal of Terramechanics 42(1), 1 13. ISSN 00224898 (2005).

[20] K. Iagnemma, H. Shibly, and S. Dubowsky. "On-line terrain parameter estimation for planetary rovers." In "Proceedings 2002 IEEE International Conference on Robotics and Automation (Cat. No.02CH37292)," volume 3, pages 31423147. IEEE. ISBN 0-7803-7272-7 (2002).

[21] K. Iagnemma and S. Dubowsky. Mobile Robots in Rough Terrain: Estimation, Motion Planning, and Control with Application to Planetary Rovers, volume 12. Spinger, star edition. ISBN 3-540-21968-4 (2004).

[22] K. Hornik, M. Stinchcombe, and H. White. "Multilayer feedforward networks are universal approximators." Neural Networks 2(5), 359 366. ISSN 08936080 (1989).

[23] J. Y. Wong. Theory of Ground Vehicles. John Wiley \& Sons, 4th edition. ISBN 0-470-17038-7 (2008).

[24] N. C. Costes, J. E. Farmer, G. C. Marshall, and S. Flight. "MOBILITY PERFORMANCE OF THE LUNAR ROVING VEHICLE : TERRESTRIAL STUDIES - APOLLO 15 RESULTS." Apollo The International Magazine Of Art And Antiques (December) (1972).

[25] V. Asnani, D. Delap, and C. Creager. "The development of wheels for the Lunar Roving Vehicle." Journal of Terramechanics 46(3), 89-103. ISSN 00224898 (2009).

[26] R. Bauer, W. Leung, and T. Barfoot. "Experimental and simulation results of wheel-soil interaction for planetary rovers." In "2005 IEEE/RSJ International Conference on Intelligent Robots and Systems," pages 586 591. IEEE. ISBN 0-7803-8912-3 (2005).

[27] R. Irani, R. Bauer, and a. Warkentin. "A dynamic terramechanic model for small lightweight vehicles with rigid wheels and grousers operating in sandy soil." Journal of Terramechanics 48(4), 307-318. ISSN 00224898 (2011). 
[28] N. Patel, R. Slade, and J. Clemmet. "The ExoMars rover locomotion subsystem." Journal of Terramechanics 47(4), 227-242. ISSN 00224898 (2010).

[29] O. Kromer. "Adaptive Flexible Wheels for Planetary Exploration." In "62nd International Astronautical Congress," Cape Town (2011).

[30] C. Tan, Y. Zweiri, K. Althoefer, and L. Seneviratne. "Online Soil Parameter Estimation Scheme Based on NewtonRaphson Method for Autonomous Excavation." IEEE/ASME Transactions on Mechatronics 10(2), 221 229. ISSN 1083-4435 (2005).

[31] R. Yousefi Moghaddam, A. Kotchon, and M. Lipsett. "Method and apparatus for on-line estimation of soil parameters during excavation." Journal of Terramechanics 49(3-4), 173-181. ISSN 00224898 (2012).

[32] T. O. H. Charrett, L. Waugh, and R. P. Tatam. "Speckle velocimetry for high accuracy odometry for a Mars exploration rover." Measurement Science and Technology 21(2), 025301. ISSN 0957-0233 (2010).

[33] G. Reina, L. Ojeda, A. Milella, and J. Borenstein. "Wheel slippage and sinkage detection for planetary rovers." IEEE/ASME Transactions on Mechatronics 11(2), 185-195. ISSN 1083-4435 (2006).

[34] J. Biesiadecki, E. Baumgartner, R. Bonitz, B. Cooper, F. Hartman, P. Leger, M. Maimone, S. Maxwell, A. Trebi-Ollennu, E. Tunstel, and J. Wright. "Mars exploration rover surface operations: driving opportunity at Meridiani Planum." IEEE Robotics \& Automation Magazine 13(2), 63-71. ISSN 1070-9932 (2006).

[35] R. Lindemann, D. Bickler, B. Harrington, G. Ortiz, and C. Voothees. "Mars exploration rover mobility development." IEEE Robotics 8 Automation Magazine 13(2), 19-26. ISSN 1070-9932 (2006).

[36] B. H. Wilcox. "Non-Geometric Hazard Detection for a Mars Microrover." Technical report, Jet Propulsion Laboratory, Houston, Texas, USA (1994).

[37] J. T. Schofield. "The Mars Pathfinder Atmospheric Structure Investigation/Meteorology (ASI/MET) Experiment." Science 278(5344), 1752-1758. ISSN 00368075 (1997).

[38] M. Lyasko. "Slip sinkage effect in soilvehicle mechanics." Journal of Terramechanics 47(1), 21-31. ISSN 00224898 (2010). 
[39] J. Wong. "Predicting the performances of rigid rover wheels on extraterrestrial surfaces based on test results obtained on earth." Journal of Terramechanics 49(1), 49-61. ISSN 00224898 (2011).

[40] H. J. Moore, D. B. Bickler, J. A. Crisp, H. J. Eisen, J. A. Gensler, A. F. C. Haldemann, J. R. Matijevic, L. K. Reid, and F. Pavlics. "Soil-like deposits observed by Sojourner, the Pathfinder rover." Journal of Geophysical Research 104(E4), 8729-8746. ISSN 0148-0227 (1999).

[41] R. Sullivan, R. Anderson, J. Biesiadecki, T. Bond, and H. Stewart. "Cohesions, friction angles, and other physical properties of Martian regolith from Mars Exploration Rover wheel trenches and wheel scuffs." Journal of Geophysical Research 116(E2). ISSN 0148-0227 (2011).

[42] R. E. Arvidson, J. L. Gooding, and H. J. Moore. "The Martian surface as imaged, sampled, and analyzed by the Viking landers." Reviews of Geophysics 27(1), 39 . ISSN 8755-1209 (1989).

[43] A. Shaw, R. E. Arvidson, R. Bonitz, J. Carsten, H. U. Keller, M. T. Lemmon, M. T. Mellon, M. Robinson, and A. Trebi-Ollennu. "Phoenix soil physical properties investigation." Journal of Geophysical Research 114. ISSN 0148-0227 (2009).

[44] G. H. Heiken, D. T. Vaniman, and B. M. French, editors. Lunar Sourcebook: A User's Guide to the Moon. Cambridge University Press. ISBN 0521334446 (1991).

[45] I. Halatci, C. A. Brooks, and K. Iagnemma. "Terrain Classification and Classifier Fusion for Planetary Exploration Rovers." In "2007 IEEE Aerospace Conference," pages 1-11. IEEE. ISBN 1-4244-0524-6 (2007).

[46] A. Kleiner. "Online learning terrain classification for adaptive velocity control." In "2010 IEEE Safety Security and Rescue Robotics," pages 1 7. IEEE. ISBN 978-1-4244-8898-8 (2010).

[47] F. M. Ham and I. Kostanic. Principles Of Neurocomputer for Science and Engineering. McGraw-Hill. ISBN 0070259666 (2001).

[48] S. Haykin. Neural Networks: A Comprehensive Foundation. Prentice-Hall, second edi edition. ISBN 0132733501 (1999).

[49] E. B. Baum. "On the capabilities of multilayer perceptrons." Journal of Complexity 4(3), 193-215. ISSN 0885064X (1988). 
[50] P. Bartlett. "The sample complexity of pattern classification with neural networks: the size of the weights is more important than the size of the network." IEEE Transactions on Information Theory 44(2), 525-536. ISSN 00189448 (1998).

[51] L. Georgios. "Neural networks and multimedia datasets: estimating the size of neural networks for achieving high classification accuracy." In "Proceedings of the 9th WSEAS international conference on Multimedia systems \& signal processing," pages $237-242(2009)$.

[52] D. Nguyen and B. Widrow. "Improving the learning speed of 2-layer neural networks by choosing initial values of the adaptive weights." International Joint Conference on Neural Networks 3, 21-26 (1990).

[53] D. Nguyen. "The truck backer-upper: an example of self-learning in neural networks." In "International Joint Conference on Neural Networks," pages 357-363 vol.2. IEEE (1989).

[54] D. Ruck, S. Rogers, M. Kabrisky, P. Maybeck, and M. Oxley. "Comparative analysis of backpropagation and the extended Kalman filter for training multilayer perceptrons." IEEE Transactions on Pattern Analysis and Machine Intelligence 14(6), 686-691. ISSN 01628828 (1992).

[55] B. Gerkey, R. Vaughan, K. Stoy, A. Howard, G. Sukhatme, and M. Mataric. "Most valuable player: a robot device server for distributed control." In "Proceedings 2001 IEEE/RSJ International Conference on Intelligent Robots and Systems. Expanding the Societal Role of Robotics in the the Next Millennium (Cat. No.01CH37180)," volume 3, pages 1226-1231. IEEE Ind Electr Soc; IEEE Robot \& Automat Soc; Robot Soc Japan; Soc Instrument \& Control Engineers, IEEE. ISBN 0-7803-6612-3 (2001).

[56] A. Okello. "A review of soil strength measurement techniques for prediction of terrain vehicle performance." Journal of Agricultural Engineering Research 50, 129-155. ISSN 00218634 (1991).

[57] K. Ueura and R. Slatter. "Development of the Harmonic Drive Gear For Space Applications."

[58] I. Schafer, P. Bourlier, F. Hantschack, E. Roberts, S. Lewis, D. Foster, and C. John. "Space Lubrication and Performance of Harmonic Drive Gears."

[59] Maxon Motor Ag. "Program 2010/2011." (2010).

[60] Maxon Motor Ag. "EPOS Communication Guide." (2006). 


\section{Appendix A}

\section{Terrain Estimation Results}

This appendix contains the results of terrain parameter estimation for all six wheels on both prepared and unprepared terrain.

\section{A.1 Prepared Terrain Results}

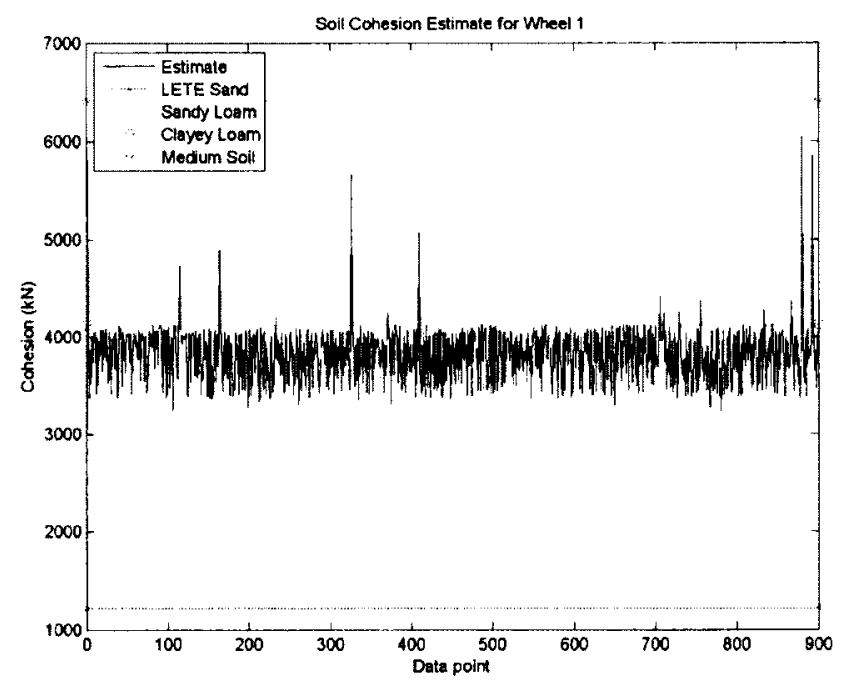

Figure 25: Terrain cohesion estimate for Wheel 1 on prepared terrain 


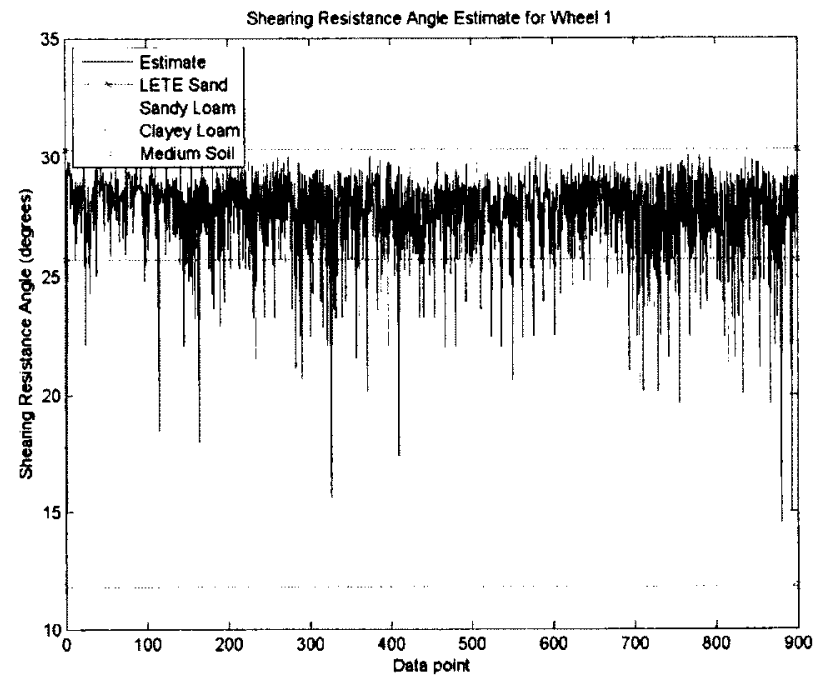

Figure 26: Terrain shearing resistance angle estimate for Wheel 1 on prepared terrain

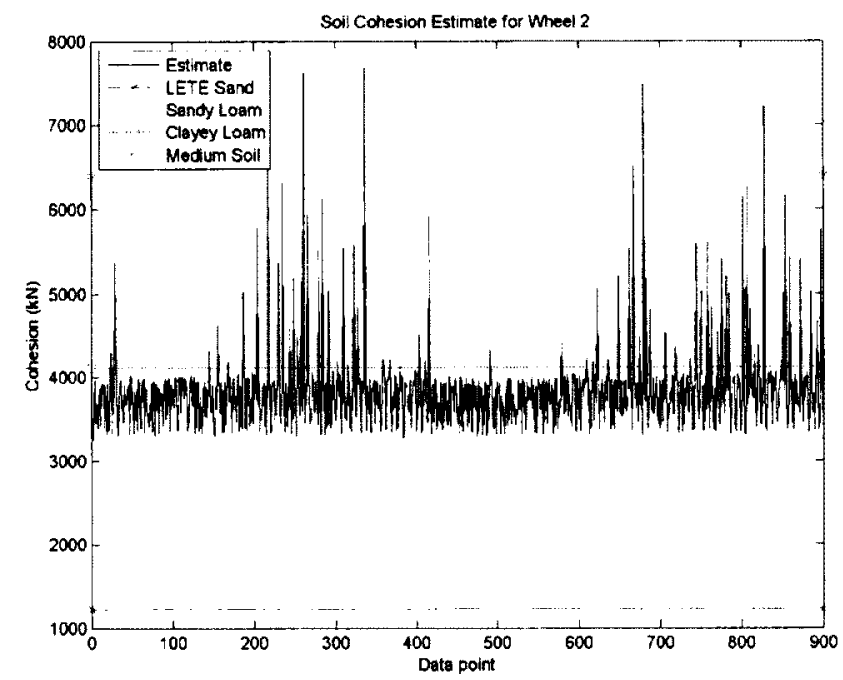

Figure 27: Terrain cohesion estimate for Wheel 3 on prepared terrain 


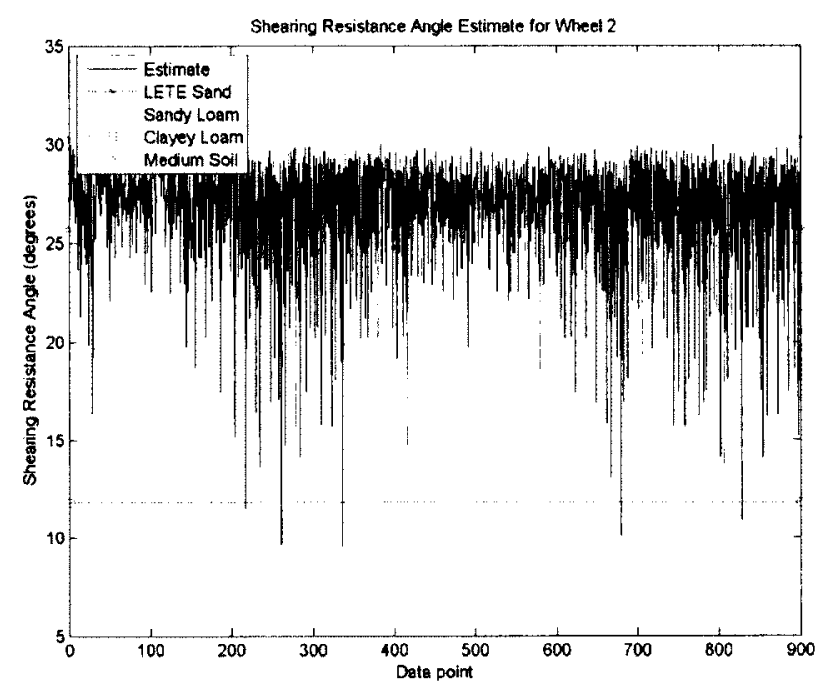

Figure 28: Terrain shearing resistance angle estimate for Wheel 2 on prepared terrain

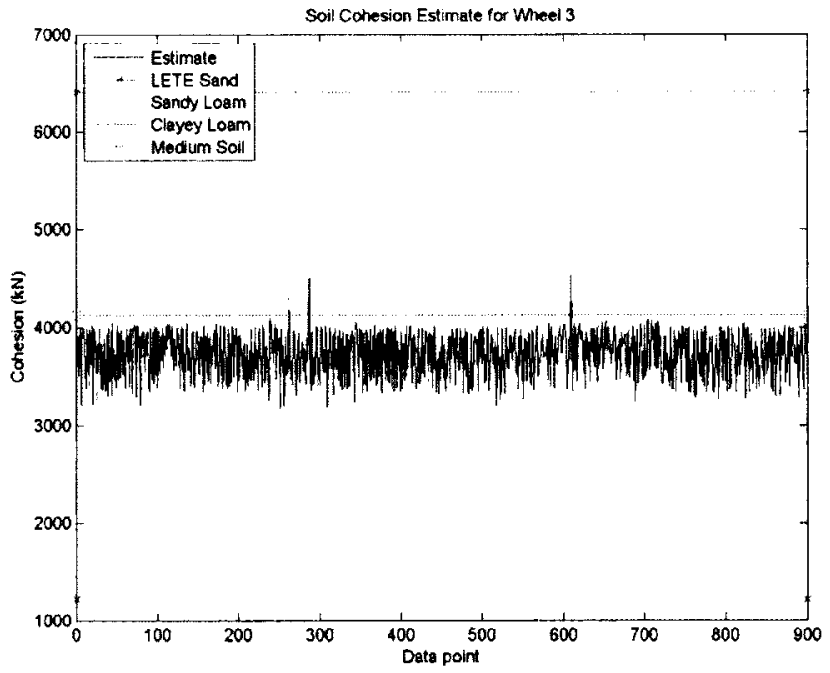

Figure 29: Terrain cohesion estimate for Wheel 3 on prepared terrain 


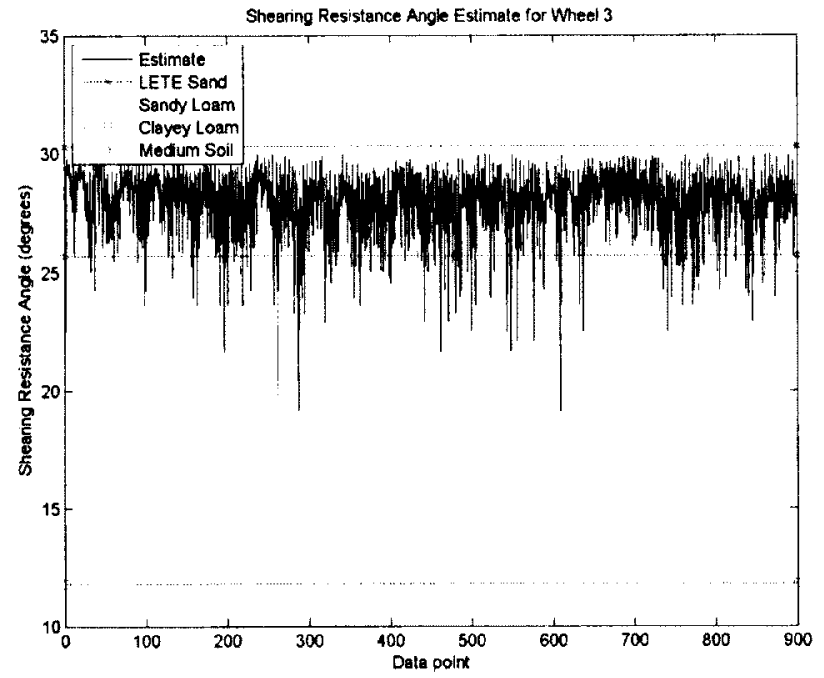

Figure 30: Terrain shearing resistance angle estimate for Wheel 3 on prepared terrain

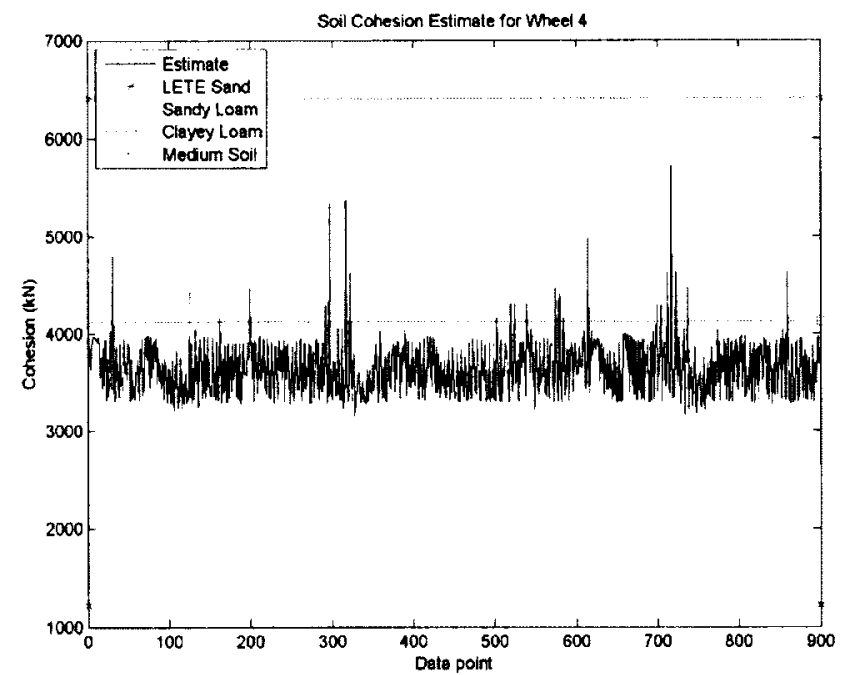

Figure 31: Terrain cohesion estimate for Wheel 4 on prepared terrain 


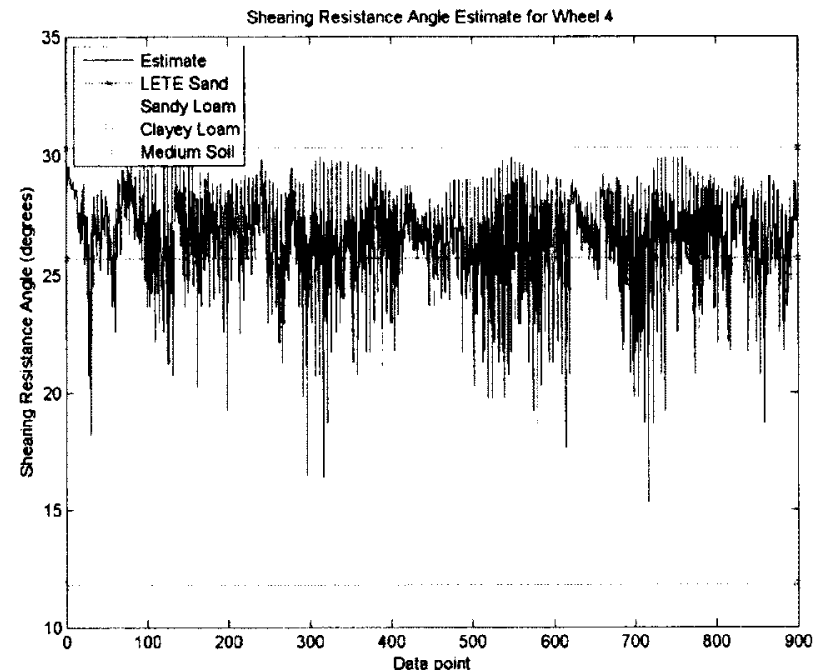

Figure 32: Terrain shearing resistance angle estimate for Wheel 4 on prepared terrain

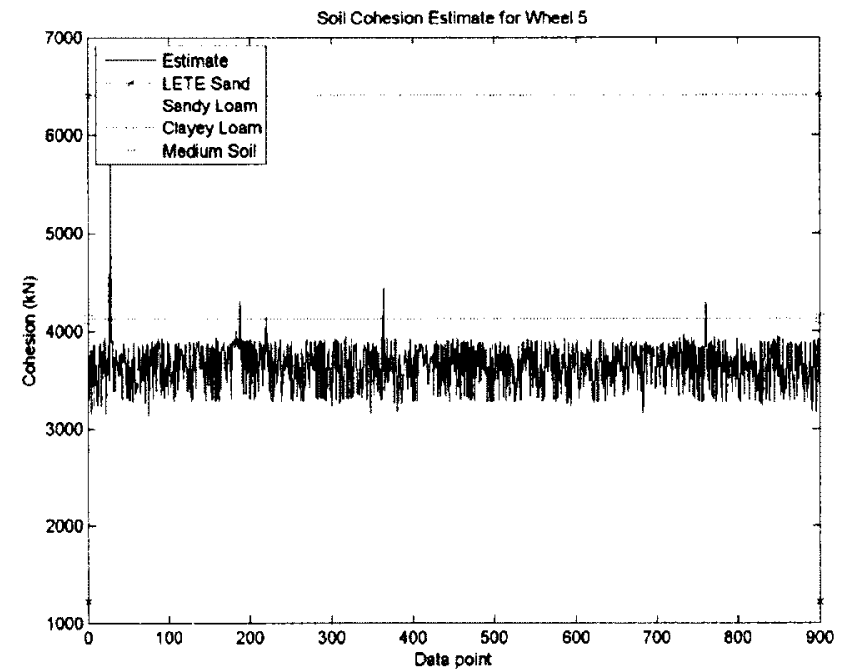

Figure 33: Terrain cohesion estimate for Wheel 5 on prepared terrain 


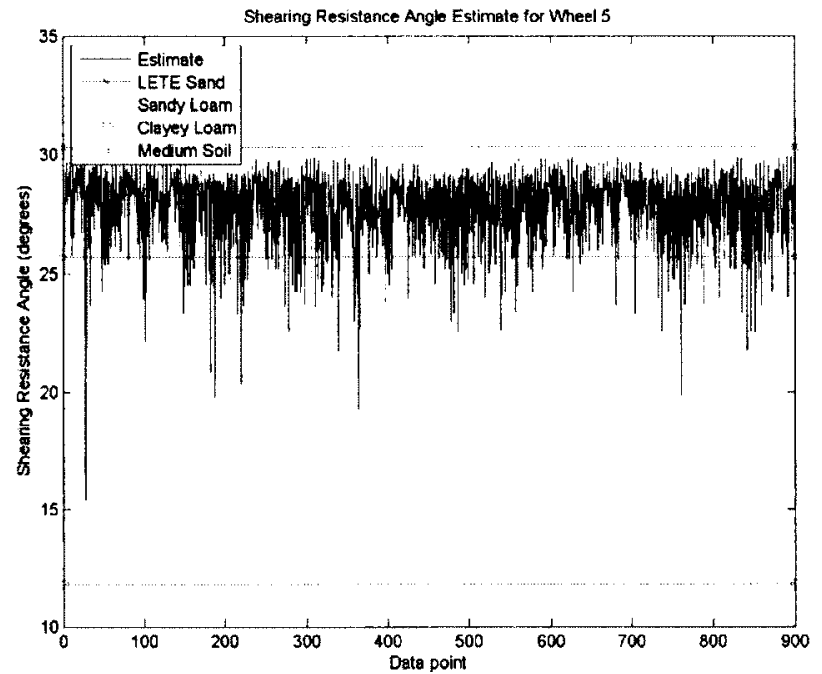

Figure 34: Terrain shearing resistance angle estimate for Wheel 5 on prepared terrain

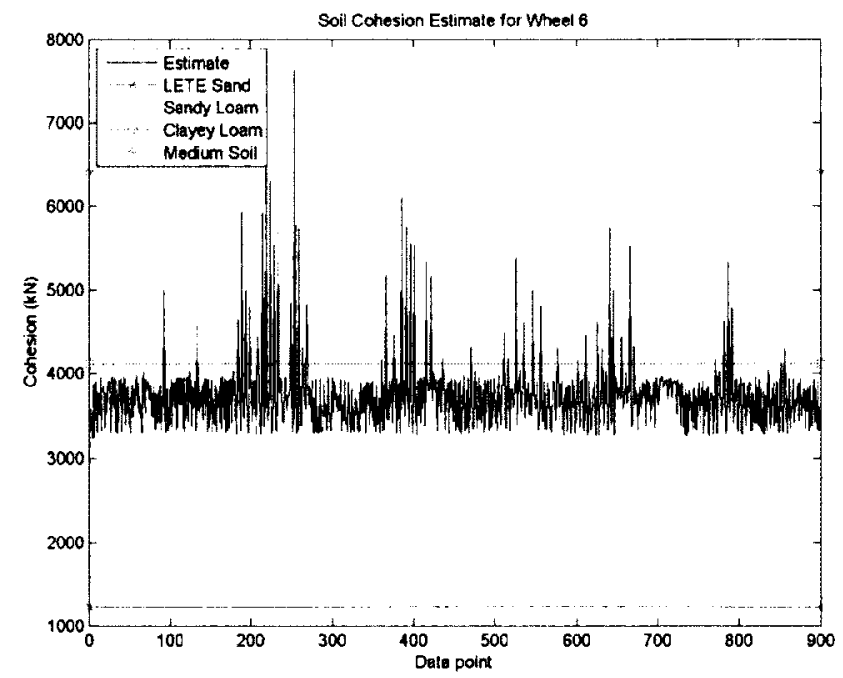

Figure 35: Terrain cohesion estimate for Wheel 6 on prepared terrain 


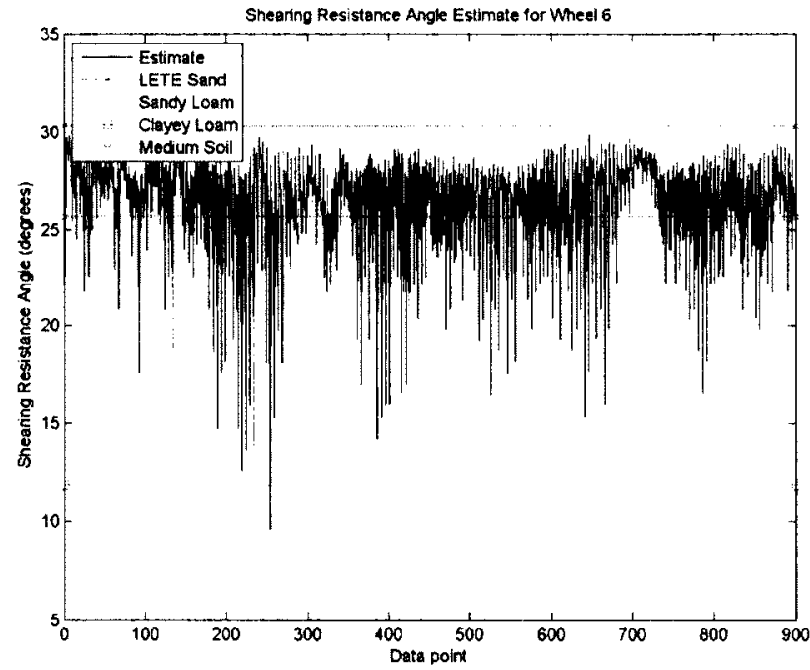

Figure 36: Terrain shearing resistance angle estimate for Wheel 6 on prepared terrain 


\section{A.2 Unprepared Terrain Results}

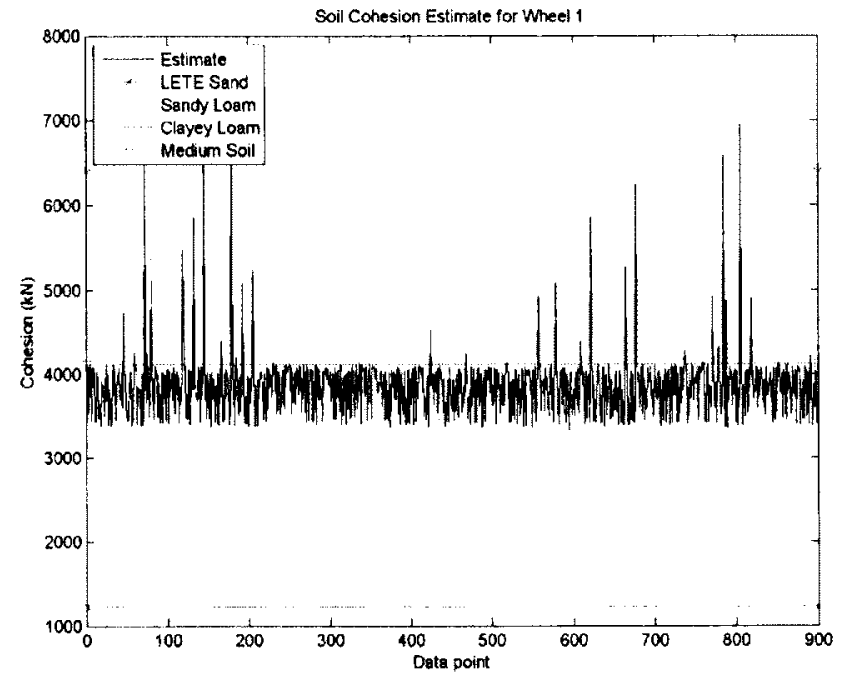

Figure 37: Terrain cohesion estimate for Wheel 1 on unprepared terrain 


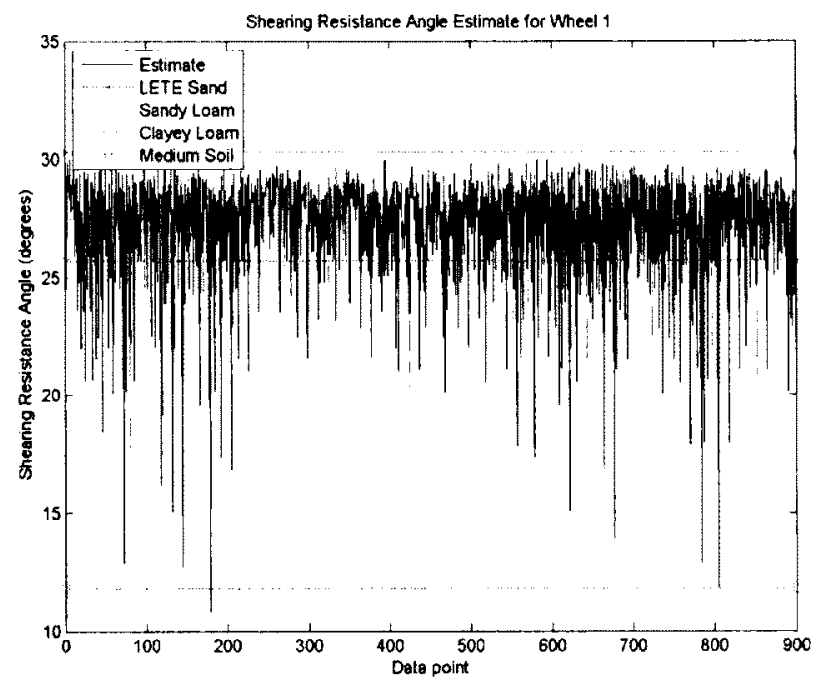

Figure 38: Terrain shearing resistance angle estimate for Wheel 1 on unprepared terrain

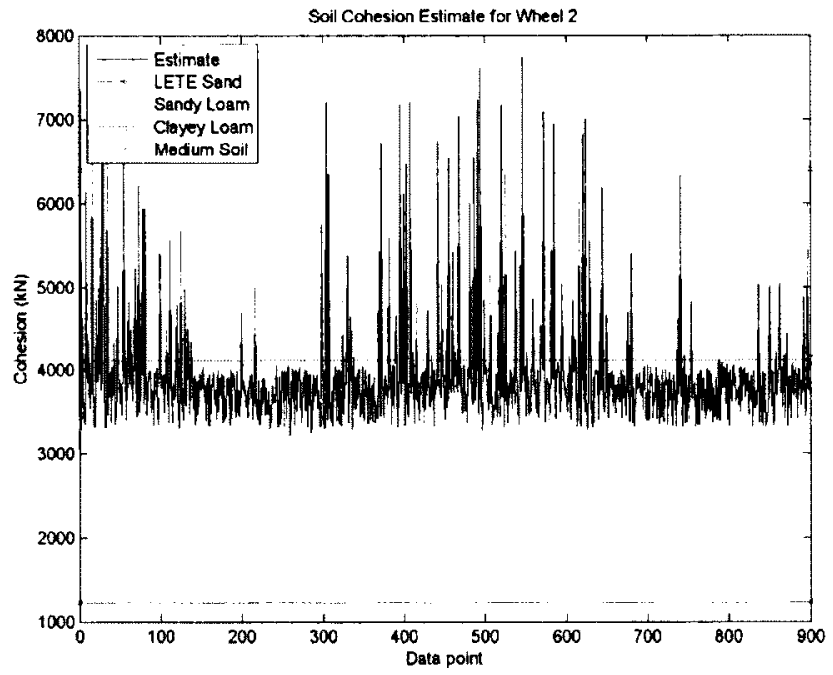

Figure 39: Terrain cohesion estimate for Wheel 3 on unprepared terrain 


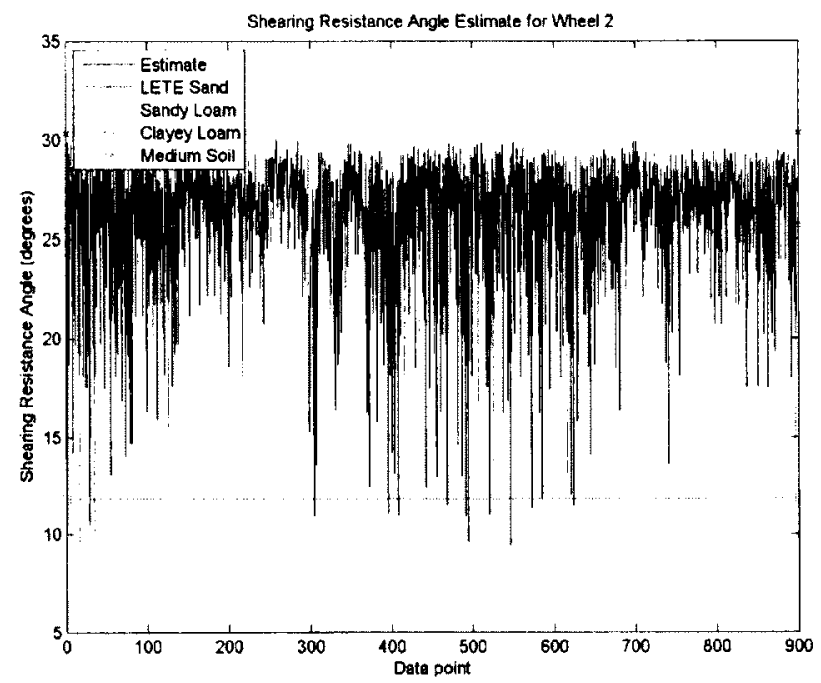

Figure 40: Terrain shearing resistance angle estimate for Wheel 2 on unprepared terrain

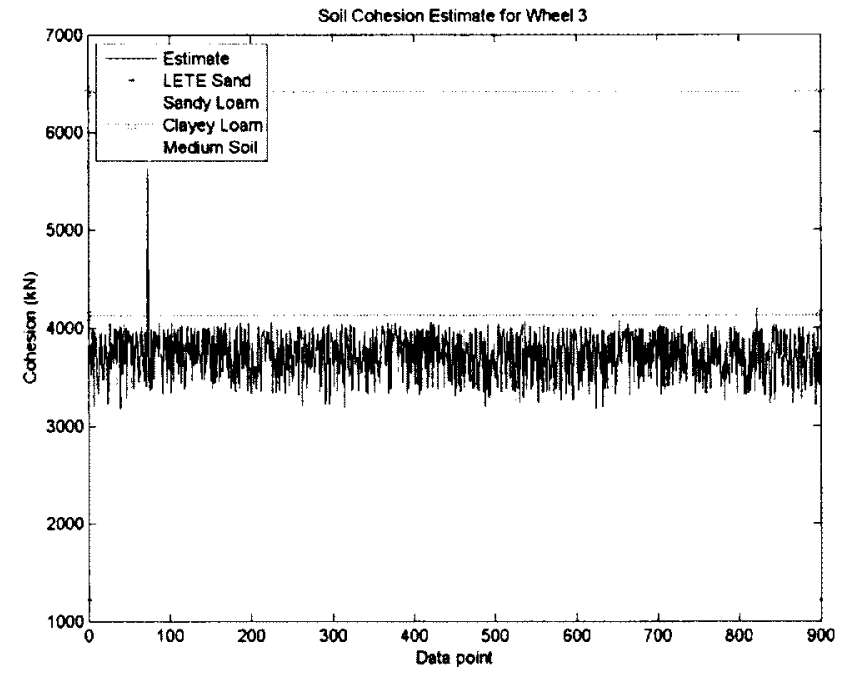

Figure 41: Terrain cohesion estimate for Wheel 3 on unprepared terrain 


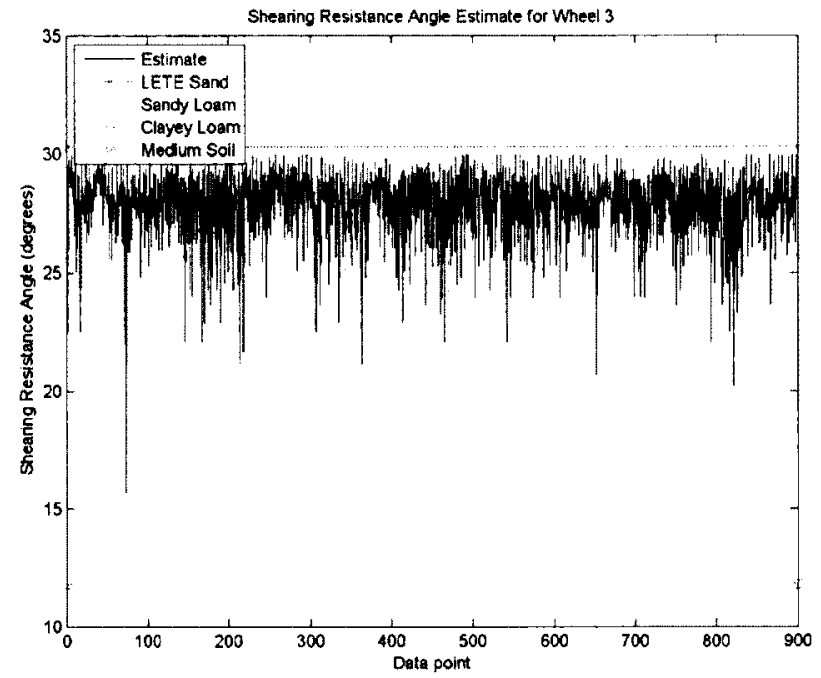

Figure 42: Terrain shearing resistance angle estimate for Wheel 3 on unprepared terrain

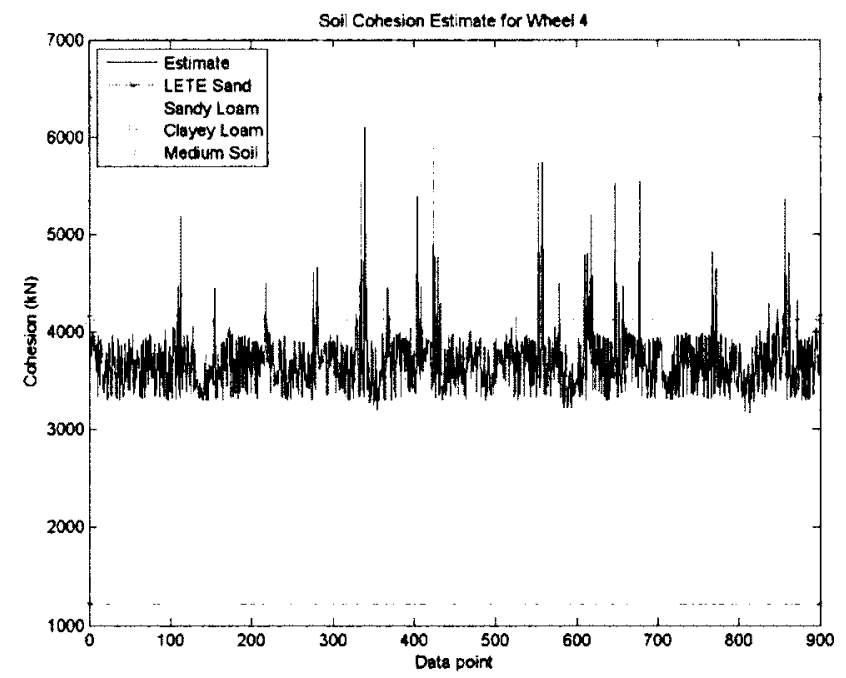

Figure 43: Terrain shearing resistance angle estimate for Wheel 4 on unprepared terrain 


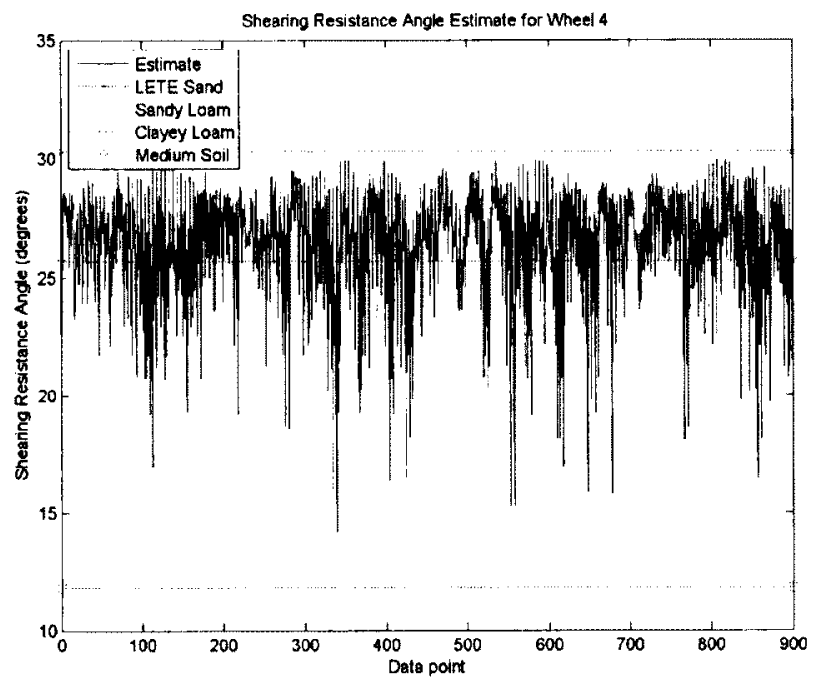

Figure 44: Terrain shearing resistance angle estimate for Wheel 4 on unprepared terrain

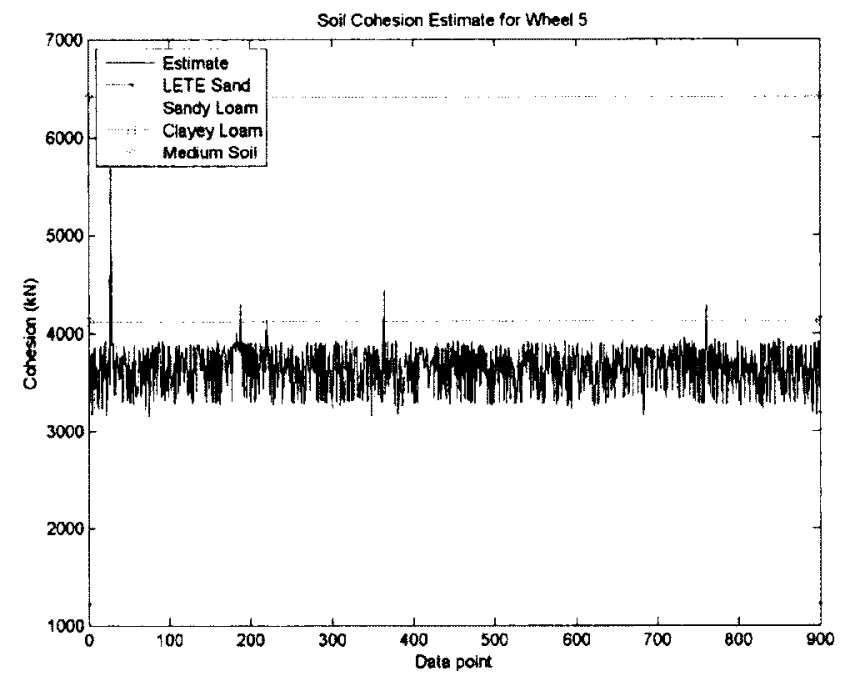

Figure 45: Terrain cohesion estimate for Wheel 5 on unprepared terrain 


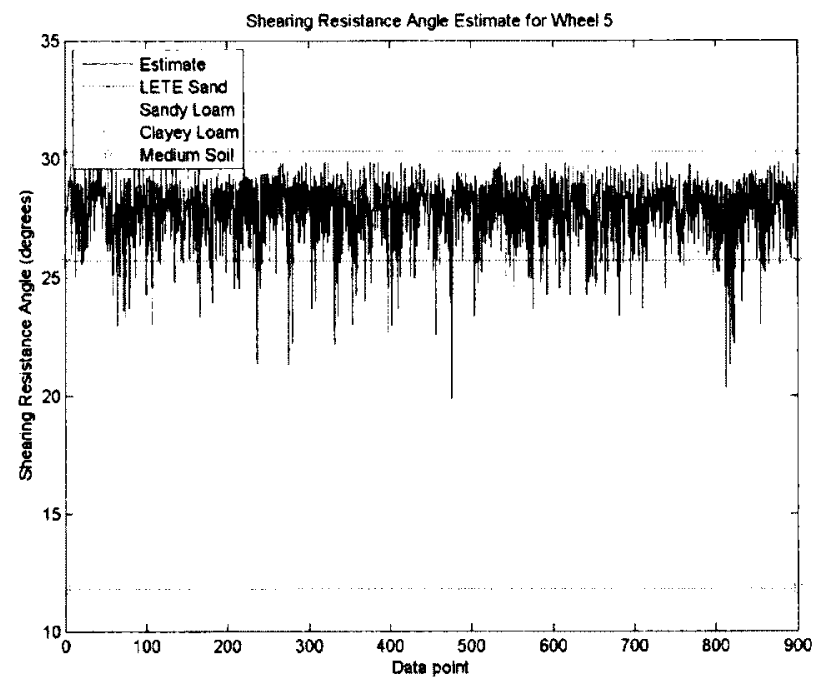

Figure 46: Terrain shearing resistance angle estimate for Wheel 5 on unprepared terrain

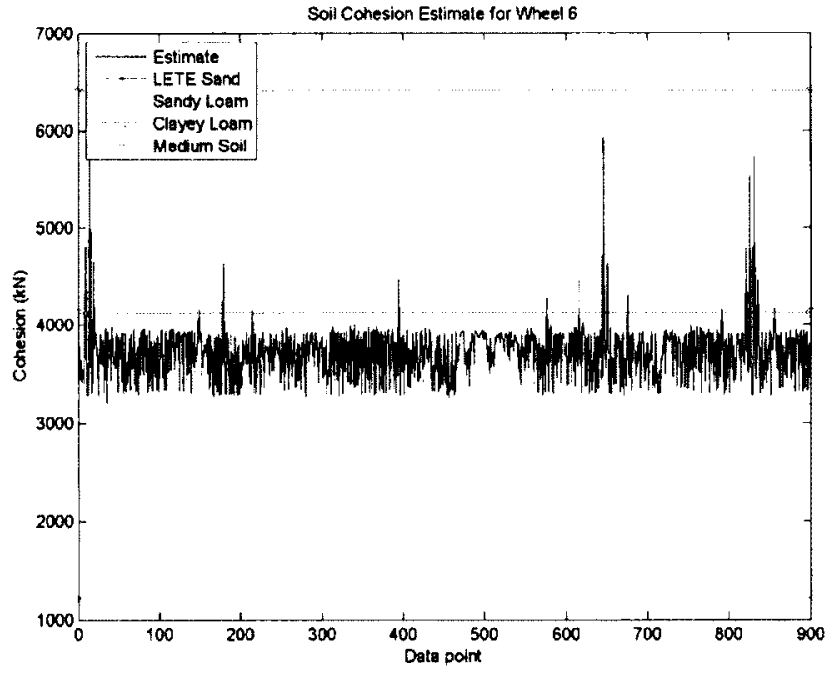

Figure 47: Terrain cohesion estimate for Wheel 6 on unprepared terrain 


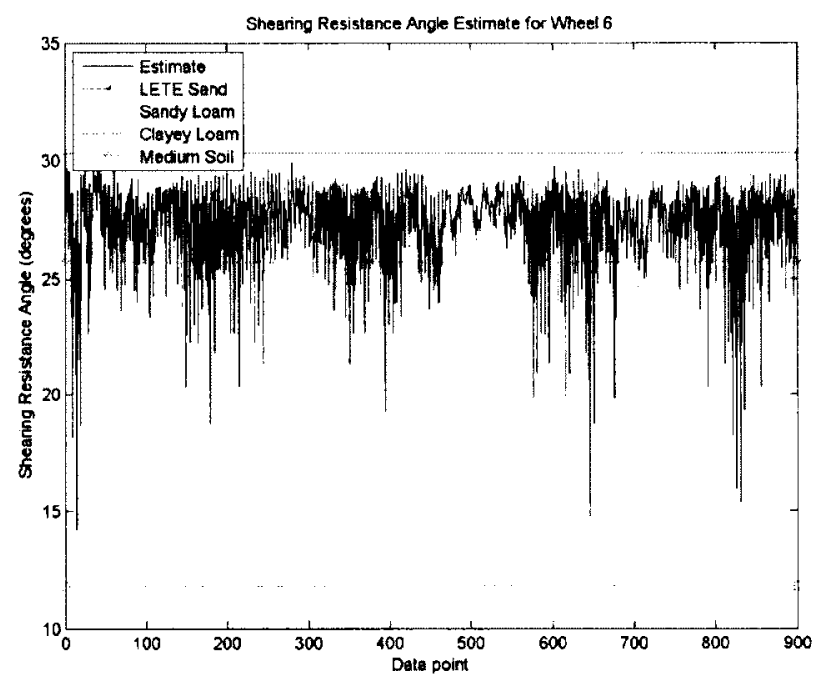

Figure 48: Terrain shearing resistance angle estimate for Wheel 6 on unprepared terrain 


\section{Appendix B}

\section{Motor and Controller Temperature}

\section{Testing}

This appendix contains excerpts from the submitted paper "Application of COTS Components For Martian Surface Exploration" that presents the results of the motor and controller temperature testing. The temperature testing was performed, and the results analyzed, by Cross and Nicol [7] to justify the motor controller selection for Kapvik.

The NASA Sojourner rover, previously known as the Pathfinder Microrover Flight Experiment (MFEX), faced similar challenges in its development. The MFEX team of engineers identified several components, including the motors and gears, as technological challenges to operating a low-cost micro-rover at Martian surface temperatures down to $-80^{\circ} \mathrm{C}$ and survival down to $-110^{\circ} \mathrm{C}$. Prior to MFEX, brushless motors were the preferred option for space applications. However, their integrated electronics were deemed unsuitable for the Martian temperatures and moving the electronics inside the avionics box was deemed unsuitable for the amount of wiring that would be crossing over moving parts. The MFEX engineers instead selected brushed Maxon motors for their torque-to-mass performance. While the motors and gears were selected off-the-shelf, MFEX engineers worked with Maxon to modify the 
Table 12: Operating and Storage Temperatures $\left({ }^{\circ} \mathrm{C}\right)$ for Selected Components

\begin{tabular}{l|cc|cc} 
& \multicolumn{2}{|c|}{ Operation } & \multicolumn{2}{c}{ Storage } \\
& $\min$ & $\max$ & $\min$ & $\max$ \\
\hline Mission Requirements & -20 & +40 & -40 & +50 \\
Maxon RE16 Motor & -20 & +65 & -20 & +65 \\
Maxon RE25 Motor & -30 & +100 & -30 & +100 \\
Maxon planetary gear & -40 & +100 & -40 & +100 \\
Maxon EPOS 24/1 Controller & -10 & +45 & -40 & +85 \\
Harmonic Drive & 0 & +50 & 0 & +50 \\
Encoders & -25 & +85 & -25 & +85 \\
\hline
\end{tabular}

units to optimize them for the low temperatures. The capacitors were encapsulated to improve power usage, and the gearing was suitably lubricated for the temperature. The resulting actuator was shown to operate without degradation over $8 \mathrm{~km}$ [57].

For Kapvik, it was not appropriate to have any custom modifications at its current development state as it is not a flight model. The entire mobility system was designed with off-the-shelf components and tested to meet its environmental criteria. Most offthe-shelf components, such as the motors, have space qualified versions or modifications available. Customized parts, such as the rocker-bogie, were designed to be space qualifiable.

CSA requires Kapvik to be stored in temperatures from $-40^{\circ} \mathrm{C}$ to $+50^{\circ} \mathrm{C}$ and operate at $-20^{\circ} \mathrm{C}$ to $+40^{\circ} \mathrm{C}$. The lower bound of temperatures corresponds to expected conditions in Northern Canada and equatorial Mars. Table 12 summarizes the thermal requirements for the Kapvik micro-rover as well as the rated performance of the selected mobility equipment.

The Maxon motors were selected for their heritage on previous Mars rovers. The Maxon RE25 motor is not space qualified; however, it best met the operational 
requirements for Kapvik. The Maxon EPOS 24/1 controllers were selected for their low mass, small form factor, and compatibility with the motors. The use of the EPOS controllers with Maxon motors is fully developed and documented, eliminating any interface development between the motors and controllers. All motors are controlled using the same type of controller which further reduced the software development time. Since each controller is a self contained unit they, satisfied another requirement: design modularity. Additional motor controllers could be added as additional nodes on a CAN Bus. The Maxon motors rated down to $-30^{\circ} \mathrm{C}$; however, the EPOS $24 / 1$ controllers are rated to only $-10^{\circ} \mathrm{C}$.

The motivation for subjecting the motor and controller assemblies to temperature tests was to increase the confidence in their performance at sub-rated temperatures. That way the off-the-shelf components could be used without modification and there would be no need to actively control their environment. An actively controlled temperature would increase the complexity of the motor assembly enclosure and increase the power demand on an already limited power budget. The motor controllers are located within an avionics enclosure that would be at a higher temperature than the motors during operation; however, the motor controllers were at this point deemed to be a critical component to test for compliance. It was found after the test data analysis that the rated temperature for the harmonic drive was only $0^{\circ} \mathrm{C}$.

The temperature experiments were conducted in an environmental test chamber and housed in the Department of Electronics at Carleton University. The component is rated to be stored in temperatures as low as $-40^{\circ} \mathrm{C}$ and testing was done as cold as $-30^{\circ} \mathrm{C}$. Three motor and controller pairs were connected by CAN Bus. One pair was kept in the environment chamber, and the other two pairs had one motor or controller inside and the other outside. The three pairs ran simultaneously for temperatures ranging from $+40^{\circ} \mathrm{C}$ down to $-30^{\circ} \mathrm{C}$ at 5 degree intervals. At each temperature, each of the three operating mode profiles was run three times. The chamber was set to a 
desired temperature and the components were allowed to sit for many hours to allow the entire set-up to reach a steady state.

The first test was to determine if the controller would pass a desired current to the motors in sub-rated temperatures. Since this is not a binary pass or fail, the metric chosen to judge the trend of the performance over temperature was the standard deviation between the input and the output current and velocity for different modes. In order to determine if the performance was adequate it must be compared to the rest of the range of temperatures the component will experience. The effects of temperature change of each motor and controller pair were separated and then the combined effect was viewed. Tests were done using constant velocity mode, constant current mode and position mode. Velocity mode was the nominal control mode for the wheel motors. If the results showed the performance of the velocity mode deteriorated much more rapidly in sub-rated temperatures than the current mode, it may be worthwhile to take advantage of this mode in some way. Early tests showed that without a start-up phase, a cold motor would produce very noisy results for the first number of runs. This was attributed to the fact that lubrication in the motor and gearing has more viscous effects when cold. Subsequent experimental runs had a warm-up phase with current applied to the motors to warm up the lubrication before the actual test was done.

At the time of testing, Kapvik's motor control software was developed enough to be incorporated into these temperature experiments. At colder temperatures, the motors were allowed to run for a warm-up period before running a series of constant speed, constant current, and positioning profiles. For the constant current mode, the demand current, measured current drawn and measured output shaft speed were sampled at $10 \mathrm{~Hz}$ and recorded for later analysis. The resolution of the current monitor is $1 \mathrm{~mA}$. Similarly for the constant speed mode, the mode at which the wheels are operated, the demand speed, measured output speed, and measured current drawn were sampled 
and recorded. The resolution of the encoders are 1 RPM. The position mode was similar to the velocity mode with the only difference being the demand speed was the pre-defined position profile speed. For each of the operating modes, the magnitudes and directions of the demand values were altered to show the step response. The duration varied from approximately 1 minute at each step down to only a few seconds.

The initial purpose of these tests was to determine whether or not the controllers could operate at $-20^{\circ} \mathrm{C}$. Results show the standard deviation of the error for the three nodes tested over the range of temperatures from $-30^{\circ} \mathrm{C}$ to $+40^{\circ} \mathrm{C}$ when controlled with the velocity mode. These curves show that there is similar performance in velocity mode regardless of the controller's temperature with the motor at a constant temperature. This means that the controller is able to maintain the desired output velocity to some accuracy across the temperature range. As the motor temperature decreases, the standard deviation remains consistent until $-20^{\circ} \mathrm{C}$ and begins to increase below that. This would once again indicate the controller is able maintain the desired output velocity across the required temperature range.

Looking at the current output of the controller, there is a bias in performance depending on the direction the motor spins. The results show that the current draw decreases at lower temperature in the positive current direction and increases in the negative current direction. This divergence is likely due to the warm up phase where the motor is spun in the positive current direction for a few minutes. The difference in current drawn between room temperature and $-20^{\circ} \mathrm{C}$ is $\pm 25 \mathrm{~mA}$ depending on the direction. This difference increases up to $\pm 40 \mathrm{~mA}$ at $-30^{\circ} \mathrm{C}$. The current draw is, as expected, greater at lower temperatures. To meet the same velocity profile the current requirement increases four-fold at $-20^{\circ} \mathrm{C}$. Despite no change in the motor controller's temperature, the decrease in the motor temperature causes the velocity output to be unable to match the desired profile. This shows that it is not the motor controller, but the gearing that is the critical component in the chassis design. 
Table 12 shows that while the motor is rated to $-30^{\circ} \mathrm{C}$, the harmonic drive attached to the motor is only rated down to $0^{\circ} \mathrm{C}$. Schafer [58] identified the critical interface to be between the wave generator and the flexspline within the harmonic drive. As the temperature decreases, the lubrication becomes more viscous. The motor has to work harder to overcome this greater friction. This additional force/loss of efficiency could be the cause of the problems seen at $-31^{\circ} \mathrm{C}$.

The constant current mode, while not used in Kapvik's operation, showed very little noise at any temperature. However, the output velocity greatly decreases. A simple calculated rate of current drawn per output speed shows the drastic difference in performance for the two modes. At room temperature, this ratio is similar for the two modes. However at $-20^{\circ} \mathrm{C}$ the ratio is 5 times greater in current mode than velocity mode. Furthermore, the ratio in velocity mode is 5 times greater at $-20^{\circ} \mathrm{C}$ than it is at room temperature. It is better to use a slightly noisy velocity control, than a more precise current control as it is more energy efficient. 


\section{Appendix C}

\section{Hardware Specifications}

\section{C.1 RE25 Motor and Gearing}

The Maxon Motors RE25 brushed DC motor was selected by Setterfield [6] and has the following motor characteristics [59]:

- Product number 339154

- Graphite brushes

- 36 VDC nominal operating voltage. Note that $24 \mathrm{VDC}$ is used for Kapvik and thus in this test assembly platform

- $30.3 \mathrm{mNm}$ maximum continuous torque

- $33.8 \mathrm{nNm} / \mathrm{A}$ torque constant

- $25 \mathrm{~mm}$ diameter

The Maxon Motors GP26B planetary gearhead was selected by Setterfield [6] and has the following characteristics [59]:

- Product number 144029 
- 14:1 gear ratio

- $56 \%$ transmission efficiency

The Harmonic Drive gearhead was selected by Setterfield [6] and has the following characteristics:

- Product number CSF-11-2XH-F

- 100:1 gear ratio

- $51 \%$ transmission efficiency

\section{C.2 EPOS 24/1 Motor Controller}

The EPOS 24/1 has the following characteristics [59]:

- 9 - 24 VDC operating voltage. The Kapvik power supply will nominally be at 24 VDC but will have mild variations during operation. The test platform has a power supply fixed at 24 VDC

- Maximum continuous output current of 1 A. This complies with the maximum current of the motor

- The sample rate for speed and position control is $1 \mathrm{kHz}$; the sample rate for current control is $10 \mathrm{kHz}$

- 6 digital inputs; 2 10-bit resolution analog inputs with range of $0-5 \mathrm{~V} ; 3$ channel encoder inputs

- Hardware CAN node identification switch; 16 nodes can be hard-configured on a single CAN bus 
- Encoder voltage output; 2 digital outputs

- RS232 interface with $115,200 \mathrm{bit} / \mathrm{s}$ communication rate; CAN interface with $1 \mathrm{Mbit} / \mathrm{s}$ communication rate

- CAN Gateway command translation

The RS232 protocol for serial communication has the following characteristics [60]:

- Physical Layer

- 1 wire each for transmitting and receiving, and 1 ground wire

- A negative voltage with respect to the ground, between -3 and $-25 \mathrm{~V}$, represents a logic value of ' 1 '

- A positive voltage with respect to the ground,

- between 3 and $25 \mathrm{~V}$, represents a logic value of ' 0 '

- Data Layer

- The serial data transfer is asynchronous. Each byte is transmitted individually with a 1 start bit, 8 data bits, 1 stop bit format

As such, the commands are generated for an RS232 compatible frame structure [60]:

- 1 Word /2 Byte /16 bit Header

- 8 bit 'OpCode'; Either 'Read Object' or 'Write Object'

-8 bit length 'Len-1'

* Indicates the number of 16 bit Data words that follow the header

* The Data field must be at 1 word in length to a maximum of 256

- Data array of $\mathrm{N}$ number of Word /2 Byte /16 bit entries 
- The first 8 bit entry represents the Index of the command

- The second 8 bit entry is split into two components

* 4 bit subindex of the command

* 4 bit CAN node-ID

- The response to a 'Read Object' command contains additional 8 bit entries that contain the value of the object that is read

- The final Word is a 16 bit long cyclic redundancy check checksum.

- A similar frame structure is used for 'Write Object' commands that are used to send instructions to controller

\section{C.3 Encoder}

The Maxon Motors magneto-resistant quadrature encoder was selected by Setterficld [6] and has the following characteristics:

- Product number 225778

- 500 counts per turn

- 3 channels with line driver

\section{C.4 Load Sensor}

The Sherborne Sensors SS4000M load sensor was selected by Setterfield [6] and has the following characteristics:

- $\pm 200 \mathrm{~N}$ 